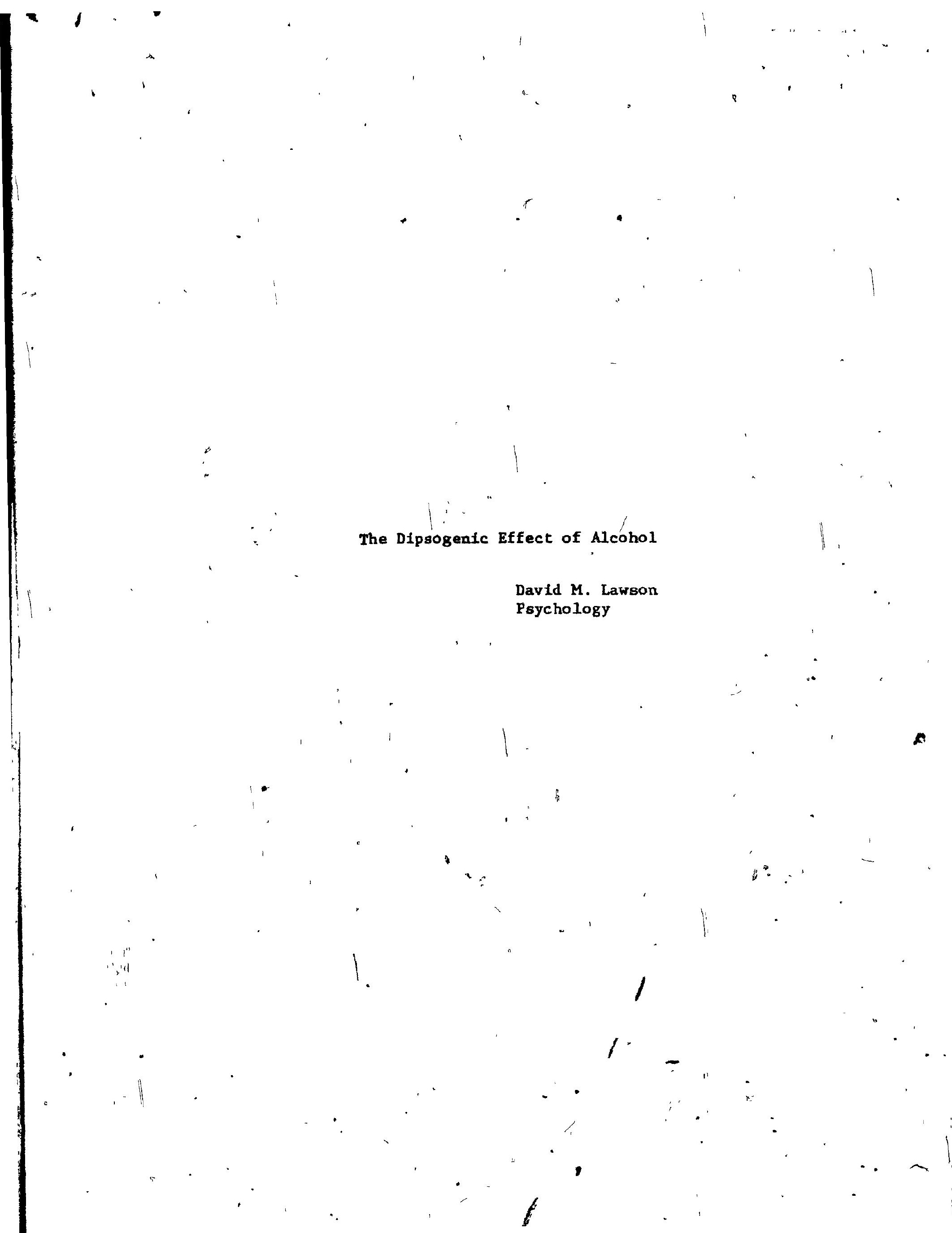


THE DIPSOGENIC EFFECT OF ALCOHOL AND THE LOSS OF CONTROL PHENOMENON

by

David M. Lawson

0

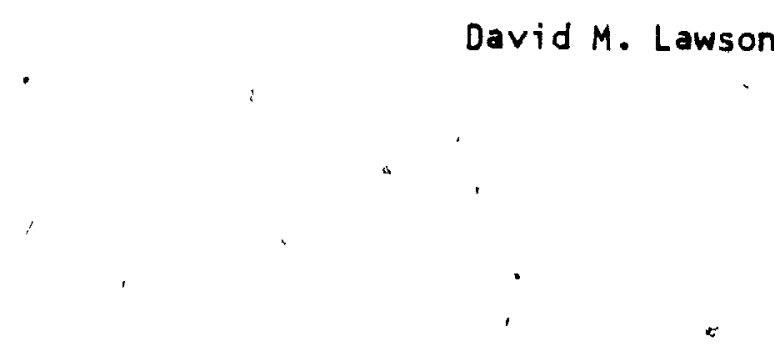

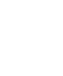

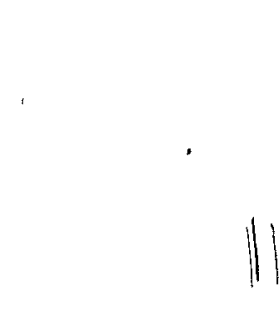

(4)

A thes is submitted to the Faculty of Graduate studids and Research in partial fulfillment of the requi rements for the degree of Doctor of Philosophy

Department of Psychology

McGill University

Montreal

May, 1977

1 


\section{THE DIPSOGENIC EFFECT OF ALCOHOL AND THE LOSS OF}

\section{CONTROL PHENOMENON}

David M. Lawson

Abstract

The acute effects of alcohol ingestion on thirst and fluid intake were assessed. The effects were related to the dehydration known to result from the acute ingestion of alcohol. In the fir'st study, 14 male social drinkers aged 18 to 30 years consumed $0.8 \mathrm{gm}$ of alcohol $/ \mathrm{kg}$ body weight during one session and a placebo $(0.05 \mathrm{gm} / \mathrm{kg}$ of alcohol) of equal volume during the other. Subjective thirst-ratings and urine specimens were obtained during each session followed by unobtrusive measures of ad lib' water intake. Analyses of variance indicated that alcohol ingestion significantly increased thirst, fluid intake and urine output, and decreased urine specific gravity. Moreover, intake after alcohol was significantly correlated with post-ingestion measures of fluid and electrolyte balance. In a replication of this study with 16 male alcoholics aged 29 to 48 years, alcohol had no effect on subjective thirst and its dipsogenic effect was delayed. These findings, and alcohol's failure to increase craving in the alcoholics, were viewed'as consistent with a theoretical model which emphasizes the contributions of both cognitive labelling processes and fluid and electrolyte metabolism to the loss of control phenomenon in alcoholism. 
Ph.D.

Psychologie

\section{L'EFFET DIPSOGENIQUE DE L'ALCOOL ET LE}

PHENOMENE DE: PERTE DU CONTROLE

David M. Lawson

\section{Résumé \\ Les effets aigus de l'ingestion d'alcool sur la soif et}

l'ingestion de liquide ont été évalués. Ces effets étaient alliés

à la déshydratation survenant à la suite de l'ingestion aigue d'alcool. Lors d'une premièrg étude, 14 hommes buvepurs d'occasion âgés de 18 à 30 ans, ont conșomé en une séance 0.8 grames d'alcool par kilogramme de poijds corporel; une autrefois un placebo d'égal volume contenant $0.05 \mathrm{gm}$ par $\mathrm{kg}$ d'alcool. Évaluation subjective de soif et spécimens d'uriné furent obtenus pendant la session, suivis par mesures discrètes de l'ingestion de l'eau au besoin. L'analyse de variations a montré que l'ingestion d'alcool augmentait de façon significative Aa soif, l'ingestion de l'eau et le débit urinaire, en diminuant la gravité spécifique de l'urine. De plus, la quantité d'eay ingérée après l'alcool avait une corrélation significative avec les mesures post-ingestion de la balance de l'eau et des électrolytes. Cette étude reprise sur 16 hommes alcooliques âgés de 29 à 48 ans a montre que l'alcool n'avait aucun effet sur la sensation subjective de soif tandis que són effect dipsogínique était retardé. Ces constatations et le défaut de l'alcool d'augmentpr l'appéténce pour l'alcool chez les alcooliques, sont interprétés comme étant compatibles avec le modèle théorique qui insiste sur la 


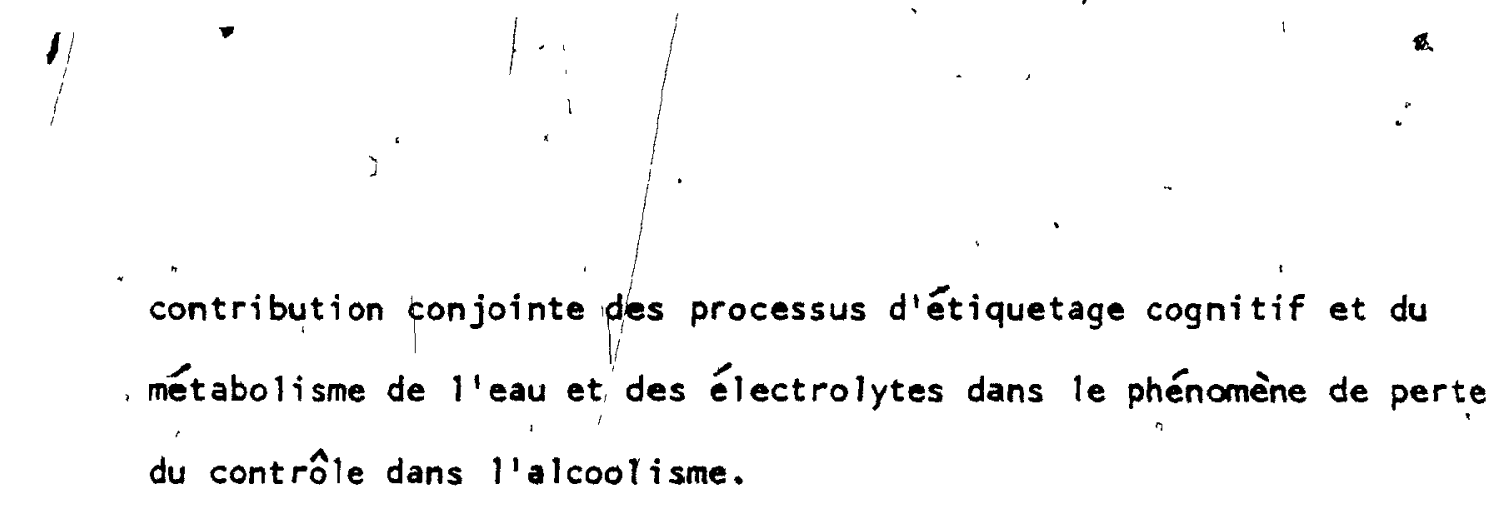

contribution conjointe des processus d'étiquetage cognitif et du métabolisme de l'eau et des électrolytes dans le phénomène de perte du contrôle dans l'alcoolisme.

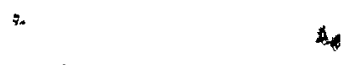

4

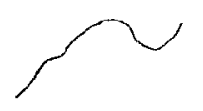

0 
Many people have contributed to this research during the extended period of its development and execution. In particular, I am deeply indebted to Drs. Peter E. Nathan and G. Terence Wilson who, by their words of encouragement and their invitation to use their laboratory facilities at Rutgers University, provided both the. impetus and the opportunity for the resumption of the research which began in Montreal. The major portion of this investigation, therefore, was supported by the U.S. Public Health Service through its grant (AA 00259-06) to Dr. Nathan.

I also wish to express my appreciation to Dr. Ernest Poser for stimulating my interest in the problems of alcohol abuse and for obtaining financial support for the preliminary studies from the Medical Research Council of Canada. In addition, I owe a special debt of gratitude to Drs. Ronald Melzack, Muriel Stern and Norman White for their support and encouragement and for suggesting numerous improvements in earlier drafts of the dissertation.

For their many hours of patient and accurate data collection, my sincere thanks go to Mr. Harry Heermans, Mrs. Elizabeth Anne Kirschling, Mr. Donald Morgan, Mrs. Lorraine O'Brien and Mrs. Beverly Wojciehowski, the staff of the Alcohol Behavior Research Laboratory. I am also very grateful to Dr. John Miller for his guidance and assistance with the data analysis. 
My thanks are also Zue "to Mr. M. J. McCormick, Senior VicePresident, The House of Seagram Ltd., and to Mr. J. H. Lerner, Director, Alcoholic Beverage Control of New Jersey for generously providing the liquor used in this researchi to Mrs. Barbara Honig and Mrs. Karen Peterson for their meticulous care in typing the manuscript; and to the National Research Council of Canada for its financial support during the initial development of this research. Acknowledgement is also due to the men who served as subjects, without whom the investigation could not have been undertaken.

Throughout the years of my involvement with this research and the many obstacles and frustrations I experienced, I have been deeply inspired by the confidence expressed by my parents and parents-in-law, and by the love and patience of my wife. It is to them I owe the greatest debt of all.

This work is dedicated to my wife, Lindsay, and my son, Andrew, without whose personal sacrifice it would never have been completed. 
TABLE OF CONTENTS

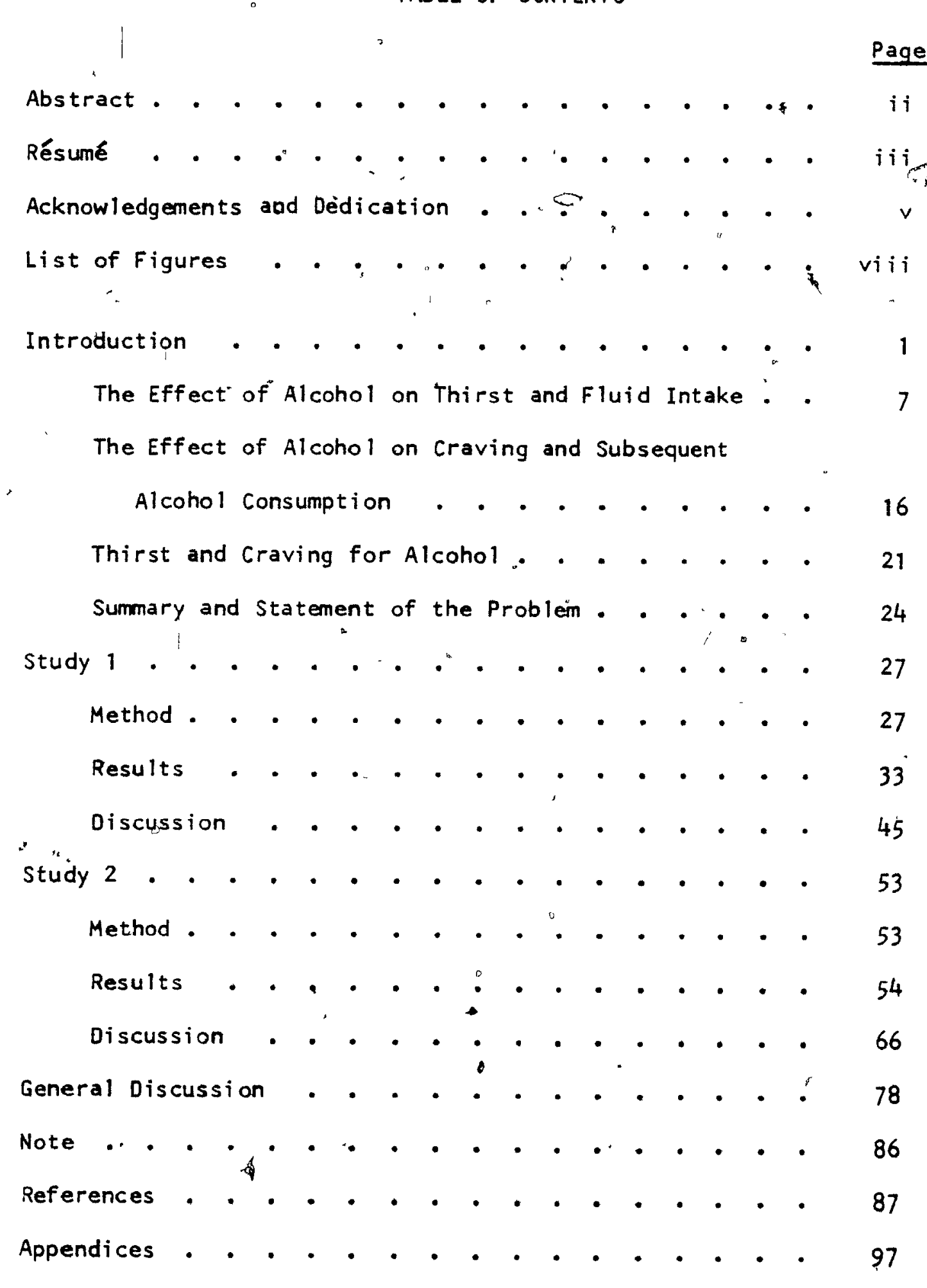




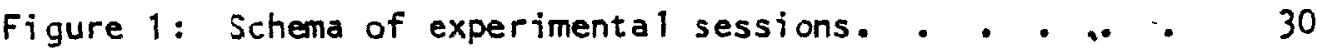

Figure 2: Mean urine volume at 30 minute intervals following the administration of alcohol and placebo in Sttdy 1 .

Figure 3: Mean urine specific gravity at 30 -minute intervals following the administration of a cohol and placebo in study 1... . .

Figure 4: Mean fluid intake at 30 -minute intervals

following the administration of alcohol and

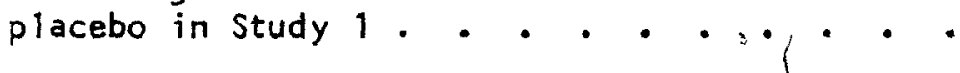

Figure 5: Cumulative fluid intake at 30 -minute intervals

following the administration of alcohol and placebo in Study $1 . . . .8 . . .$. .

Figure 6: Scatterdiagram of the relationship between mean urine specific gravity and 1.5 -hour fluid intake following the administration of alcohol in study 1

Figure 7: Mean urine volume at 30 -minute intervals following the administration of al cohol and placebo in Study 2

Figure 8: Mean urine specific gravity at 30 -minute intervals following the administration of alcohol and placebo in Study 2. . . . . . . .

Figure 9: Mean fluid intake at 30 minute intervals following the administration of alcohol and placebo in Study.2. . . . . . . . . . . .

Figure 10: Cumulative fluid intake of alcoholics at 30 minute intervals following the administration of alcohol and placebo in Study 2. 
$C^{\circ}$

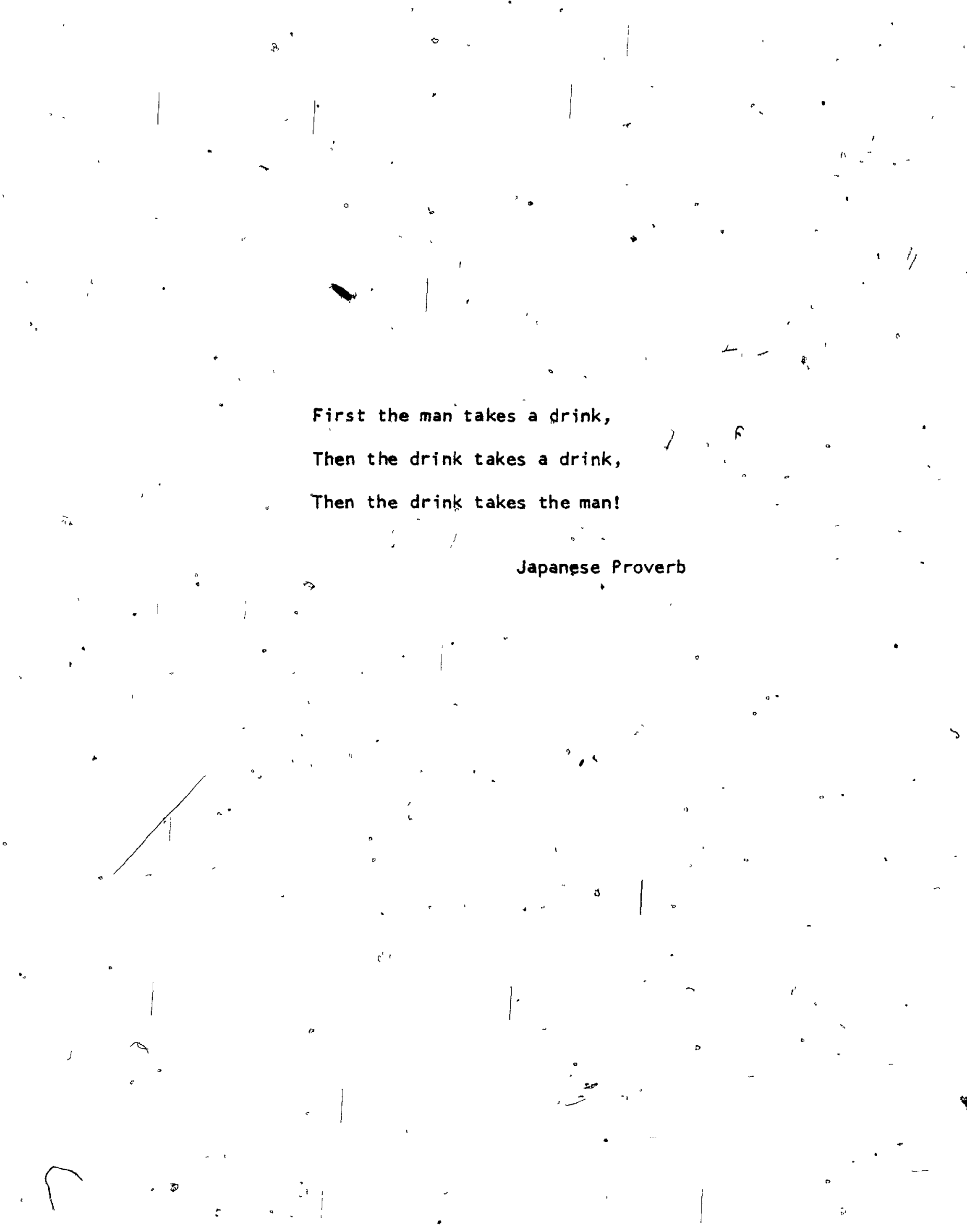


It has frequently been observed that alcoholics appear to be unable to control their consumption of beverage alcohol once they have begun to drink. This experience has, in fact, been so widely shared by members of Alcoholics Anonymous (A.A.) that they coined the phrase "loss of control" (LOC) to describe it. Although numerous definitions of LOC have appeared, in the literature, most are in general agreement with the following description given by Jellinek (1952):

Loss of control means that any drinking of alcohol starts a chain peaction which is felt by the drinker as a physical demand for alcohol. This state, possibly a conversion phenomenon, may take hours or weeks for its full development; it lasts until the drinker is too, intoxicated, or sick to ingest more alcohol. The loss of control is effective after the individual has started drinking, but it does not give rise to the beginning of a new bout. The drinker has lost * the ability to control the quantity once he has started, but he can still control whether he will drink on any given"
occasion or not (pp. 679-680).

Thus, LOC manifests itself both subjectively, in the form of a "physical demand" or craving for more alobhol, and behaviorally, in the form of continued alcohol consumption. It should be noted, parenthetically, that the term "craving" is used to refer to the alcoholic's desire for alcohol both after the initiation of drinking and during periods of abstinence (Keller \& McCormick, 1968), but 
that only the former is usually considered a manifestation of LOC. Traditional approaches to the diagnosis and treatment of alcoholism as well as the concept of the disorder as a disease stem largely from reports and clinical observations of LOC. E. M. Jellinek, in two classical surveys of the drinking histories of A.A. members (1946, 1952), concluded that LOC marks the onset of alcohol addiction - and that preceding symptoms, such as blackouts, increased tolerance and preoccupation with alcohol, are indicative only of prealcoholic stages. So influential were Jellinek's writings and the A.A. support they received that thirty years later, LOC is still regarded by many as the pathognomonic sign of alcoholism (Keller, 1972). Moreover, since alcoholism is considered to be irreversible, the concept of LOC has been the basis for the widespread adoption of abstinence, rather than moderate or controlled drinking, as the goal of treatment of the alcoholic (Lloyd \& Salzberg, 1975). Of even greater importance, however, are the implications of LOC for the concept of alcoholism itself. Repeated observations of apparently uncontrollable drinking and its self-destructive consequences have led to the conclusion that alcoholism constitutes a disease process (World Health Organization, 1955). The LOC concept, therefore, has not only guided practitioners in diagnosing and treating alcoholics, but it has also provided the original basis for the disease model of alcoholism.

After the LOC concept was formally introduced the literature on alcoholism in 1946, numerous theories have been proposed to account for the phepomena to which it referred. For the most part, these theories focused on interactions between the acute physiological effects 
of alcohol and a host of hypothetical hereditary and constitutional. factors presumed to be characteristic of alcohol abusers. LOC, for example, has been attributed to such conditions as an alcohol-specific allergy (Alcoholics Anonymous, 1944), genetically-determined nutritional deficiencies (Williams, 1954), derangement of a hypothalamic center presumed to control alcohol consumption (Williams, 1959), altered cellular metabolism presumed to be associated with tolerance (Jellinek, 1960), and brain damage and "anesthesia" of the inhibitory centers of the brain (Lemere, 1956). However, there has been no substantial research support for any of these theories. On the contrary, a considerable body of research has accumulated in recent years which seriously calls into question the existence of the LOC phenomenon. Since the mid-1960's, when the drinking behavior of alcohol abusers first became the subject of objective experimental analysis, numerous laboratory studies have been reported in which chronic alcoholics appeared to have exercised considerable control over their drinking despite the availability of large amounts of beverage alcohol (Allman, Taylor \& Nathan, 1972; Bigelow \& Liebson, 1972; Cohen, Liebson \& Faillace, 1971; Gotthei 1, Corbett, Grasberger \& Corne1ison, 1971; Nathan \& O'Brien, 1971; Nathan, Titler, Lowenstein, Solomon \& Rossi, 1970; Schaefer, sobell \& Mil1s, 1971). Moreover, studies in which alcoholics were administered small amounts of alcohol have generally failed to demonstrate that it has any significant effect on subsequent a lcohol consumption (Marlatt, Demming \& Reid, 1973), alcohol acquisition (Cutter, Schwaab \& Nathan, 1970) or craving (Engle E Williams, 1972). Although these findings have led at least one 
investigator to propose that the LOC concept be discarded laltogether (Mello, 1971), it has also been suggested that cognitive and environmental factors could account for the discrepancy between these laboratory observations and the testimonials of countless A.A. members who have attempted, unsuccessfully, to drink in moderation.

In their recent theoretical article, Ludwig \& Wikler (1974) have proposed that the alcoholic's mental set and. physical surroundings are crucial variables for the expression of craying and LOC. More specifically, they have hypothesized that it is only when these cognitive and environmental factors conform to those of the alcoholic's natural drinking setting that he will subjectively label an internal physiological state as a craving for alcohol. According to their model, it is this cognitive label which identifies beverage alcohol as the alcoholic's only source of satisfaction. This general hypothesis seems entirely plausible in view of what is known about the effects of cognitive and social factors on the perception of drug-induced physiological arousal (Schachter, 1964; Pliner \& Cappe11, 1974). Moreover, there is evidence that craving in alcoholics is increased by external alcohol-related stimuli (Ludwig \& Stark, 1974; Ludwig, Wikler \& Stark, 1974), and by such cognitive factors as expectations regarding the effects of a lcohol (Engle \& Williams, 1972; Maisto, Laverman \& Adesso, 1977) and anticipation of alcohol availability (Funderburk \& Allen, 1977).

Two questions remain, however. What physiological state initiates the labelling process and why is it jdentified as craving for alcohol? It is at this point that the theory advanced by Ludwig and Wikler 
becomes much less compelling. They suggest that consumption of a small amount of beverage alcohol or exposure to alcohol-related stimuli can produce in a chronic alcoholic physiological changes resembling those which had been experienced during previous episodes of alcohol withdrawal and which had been associated wi th recovery. following a lcohol consumption. Ludwig and wikler hypothesize that these unspecified physiological changes elicit a "sub-clinical conditioned withdrawal syndrome," the subjective component of which is a craving for alcohol. Although this conception allowsik for the experience of craving during periods of abstinence and intoxication, and for increased craving and continued alcohol ingestion following initial alcohol consumption, it does not identify the conditioned withdrawal syndrome or specify the physiological effects of alcohol responsible for eliciting it.

The literature on the effects of acute alcohol ingestion on fluid and electrolyte metabolism, however, suggests a physiological mechanism which may contribute to the LOC phenomenon. Shortly after moderate amounts of alcohol are consumed, they produce a state of dehydration in human subjects by simultaneously producing hyperdiuresis and solute retention (Beard \& Knott, 1971). If such alcohol-induced dehydration is sufficient to produce the subjective experience of thirst and to increase fluid intake, it may well be relevant to the LOC phenomenon in alcohol abusers. Since craving can be viewed as a subjective aspect of thirst and alcohol consumption can be viewed as a behavioral aspect of fluid intake, the implications of such a finding are readily appôrent. When alcohol abusers become dehydrated after 
consuming beverage alcoho'l in naturalistic drinking settings, social and cognitive aspects of their environments may lead them to perceive this physiological state as a specific thirst for alcohol, ie.,

craving. This misperception in turn would likely lead them to consume additional alcohol. Although this theoretical model does not account for the occurrance of craving in the absence of dehydration, such as during periods of abstinence and immediately following alcohol ingestion, nor for the fact that only alcoholics experience LOC, it ifs worthy of investigation because it suggests yet another factor. which may contribute to the maintenance of alcohol consumption in alcoholics.

There is, höwever, no firm experimental evidence to support either of the two basic assumptions underlying this model: (1) that a moderate amount of alcohol produces thirst and increases fluid intake within a short period after it is consumed; and (2) that alcoholics in naturalistic drinking settings misperceive the state of dehydration produced by acute alcohol consumption as a specific thirst or craving for alcohol. The major focus of this thesis, therefore, will be to investigate the first of these two assumptions. In addition, the effect of alcohol on craving will be investigated in alcoholics.

Following a review of the effects of a 1 cohol on thirst and nonalcoholic fluid intake, the effects of alcohol on craving and subsequent alcohol consumption wi 11 be examined. Finally, a brief overview of the literature relating thirst and craving will be presented. 
The Effects of Alcohol on Thirst and Fluid Intake

Alcohol has traditionally been regarded, as a potent thirstinducing substance (Fitzsimons, 1972). As early as 1751 Jessen noted that thirst and dryness of the mouth and throat can occur both during the consumption of large quantities of beer and for some time afterward (Wolf, 1958). These early observations, moreover, were consistent with the old notion that alcohol, because of its affinity for water, could produce a generalized dehydration of the body. More recently, thirst has also been associated with acute withdrawal from alcohol. Indeed, the current widespread use of intravenous fluids and électrolytes as the treatment of choice for alcoholics in acute withdrawal is based largely upon the common clinical observation that these patients have dry mouths and are thirsty (Beard \& Knott, 1971).

Although it has been recognized since 1821 that alcohol can induce thirst and drinking (Wolf, 1958), the literature on the subject is surprisingly limited. An exhaustive search of the experimental literature has, in fact, revealed only 12 relevant studies, half of which were conducted with animals. In view of the difficulties in comparing the animal with the human research, these areas of the literature will be reviewed separately. It should also be emphasized that, in practically every case, the relevant research used primarily physiological indices and that measures of thirst and fluid intake were only of secondary importance to the investigators.

Research with animals. In an investigation of the effect of alcohol on the growth of chicks, Elhardt (1930) reported that those chronically administered a $30 \%$ solution drank more water than those 
receiving half as much alcohol or none at all. This anecdotal report is one of the earliest suggestions in the experimental literature that alcohol increases fluid intake.

Among the first studies to compare baseling fluid intake in 4 animals with intake during and following periods of alcohol administration are three investigations conducted by Baisset and Montastruc $(1961,1962 \& 1963)$. In their first two studies, 300 cc of a $20 \%$ alcohol solution were administered daily to three free-feeding dogs for periods of 10 days and 6 months respectively. In the first study, ad lib intake of water during the period of alcohol administration was found to be 3.5 times greater than that during a preceding baseline period. In their second study, a comperison of alcohol intake before and after the period of alcohol administration revealed an eleven-fold increase in the consumption of a $20 \%$ alcohol solution. In their third study, Baisset and Montastruc comparied water intake during four. 10-day periods during which five free-feeding dogs were administered daily equivalent volumes of beverages differing in their alcohol content. Although intake associated with the administration of a $3.9 \%$ alcohol solution was essentially identical to that associated with the adninistration of two nonalcoholic beverages, intake doubled when a $10.5 \%$ al,cohol solution was given.

Although these findings, suggest that alcohol consumption increases fluid intake, several methodological limitations of their work should be noted. All animals in each of the studies were administered alcohol 5 during the same period thereby confounding the effect of alcohol with a possible order effect; nonalcoholic control beverages were administered 
only in the most recent study; and no statistical analyses of the data were presented in any of their 'studies. Moreover, the fluid intake was so small as to suggest that additional, uncontrolled sources of fluid were available during their studies.

To a large extent these limitations also apply to their conclusions regarding the effect of vasopressin, which was also investigated in these studies. When it was administered with alcohol, both concurrent Asubsequent fluid intake were comparable to observed during baseline periods, and urine outplet was considerably less than when alcohol was administered alone. The investigators concluded from these findings that alcohol, by inhibiting the secretion of antidiuretic hormone, produces a polyuria-polydipsia syndrome which can be counteracted by the administration of vasopressin (Baisset \& Montastruc, $1961 \& 1962)$.

In an investigation of the effects of repeated alcohol ingestion on fluid and electrolyte balance, Beard, Barlow and Overman (1965) also measured fluid intake in dogs. Following a two-week baseline period, two animals were administered $5 \mathrm{gm}$ of alcohol/kg body weight daily for a period of 8 weeks. It was found that mean daily fluid intake increased dramatically during the peripd of alcohol adminiṣtration. In addition, there were substantial reductions in urinary electrolytes and a marked increase in both urine volume and positive fluid balance during this period. Although all these effects of alcohol appear to be interrelated, no precise explanation of a cohol's effect on fluid intake was proposed. 
The only study in this review of the animal literature which presented a statistical analysis of the effect of alcohol on fluid intake was conducted by Wallgren and his colleagues (Wallgren, Ahliquist, Ahman \& Suomalainen, 1967). Their investigation permitted four jndependent comparisons of water intake among three groups of pair-fed rats, including one which was administered $5 \mathrm{mg}$ of alcohol/gm body weight on alternate days for 6 months, and two control groups. In every case, fluid intake was s,ignificantly greater in the group administered alcohol, an effect which the investigators attributed to an intoxication-induced disturbance in the maintenance of water balance by the pituitary.

In summary, the animal literature includes one anecdotal observation (Elhardt, 1930), three brief reports and one study in which fluid intake data were not statistically analyzed (Baisset \& Montastruc, 1961, 1962, \& 1963, \& Beard et a 1., 1965), and one carefully analyzed experiment in which fluid intake was significantly increased in rats chronically administered a high dose of alcohol (Wallgren et al., 1967). Despite considerable variability in the procedures, species and dosages employed, the animal literature is consistent in its support for the notion that alcohol increases fluid intake. Moreover, the two teams of investigators who suggested a physiological basis for this effect were in general agreement that it results from alcohol's effect on pituitary function (Baisset \& Montastruc, 1961 \& Wallgren et a 1., 1967).

Research with human subjects. The experimental literature relevant to an investigation of the effects of alcohol on thirst and 
nonalcoholic fluid intake in human subjects can be divided into three general categories according to the chronicityr of alcohol consumption:

(1) acute experimental administration, (-2) repeated experimental

administration, and (3) chronic self-administration.

Two studies suggest that the acufe administration of alcohol leads to thirst and increased drinking in human subjects. In the first (Flynn, 1958); ad lib water intake by five students was recorded for 8-hour periods beginning $1 \frac{1}{4}$ hours after the consumption of an a lcoholic beverage containing $2.5 \mathrm{ml} / \mathrm{kg}$ of 90.4 proof alciohol, and after a control beverage containing an isocaloric amount of dextrose. Although Flynn reported anecdotally that all of his subjects complained of thirst during the interval between alcohol administration and ad lib drinking, intake was actually less during the first $1 \frac{1}{2}$ hours of ad lib drinking in the alcohol than in the control condition. Noting that all his subjects slept at this time, Flynn attributed this discrepancy to an alcohol-induced "decrease in the ability to react to thirst" (p. 52). During the last $6 \frac{1}{2}$ hours after alcohol, however, there was a non-significant increase in dripking.

In attributing this latter finding to a coincidental increase in intracellular dehydration, Flynn is in agreement with Lolli, Rubin and Greenberg (1944). They observed in rats a marked shift in body water from the intracellular to the extracellular fluid compartment at 4 hours and again at 20 hours after the administration of alcohol. Although their study did not include measures of filuid intake, they suggested that cellular dehydration could account for thirst during and after alcohol intoxication. Wolf (1958), however, after reviowing 
these findings and those of other investigators, concluded differently: "While the physiologic picture following alcohol suggests that this drug leads to or favors a state of cellular and/or osmometric dehydration, the pattern is not remarkable either quantitatively or temporally" (p. 127). He proposed instead that alcohol's effect on thirst is the direct result of its effects on central nervous system structures which regulate fluid intake.

Roberts' ${ }^{\circ}(1963)$ investigation of alcohol diuresis also suggests that acute alcohol administration induces thirst. She reported anecdotally that her subjects, 20 nonalcoholic male patients who had been administered $6-8 \mathrm{oz}$. of 100 proof alcohol, complained of thirst after the alcohol had been metabolized. However, since none of her subjects reported thirst or drank any water during a 3 -hour postingestion period, she suggested that the sensation of thirst is temporarily inhibited by alcohol. In addition she noted that when sodium chloride was administered with alcohol, the typical diuresis did not occur nor were there any subjective reports of thirst or drinking. On the basis of these findings she suggested that thirst and!. other symptoms of the "hangover" are a function of the "dehydrate state" produced by alcohol.

Although this account of alcohol's effect on thirst differs somewhat from that proposed by Flynn (1958), it is consistent, with the view espoused by Fitzsimons (1972). Alcohol, he noted, is diuretic both because it is typically consumed with a quantity of fther fluid and because of its inhibitory effect on the secretion of antidiuretic hormone. This latter effect results in a state of dehydration by 
producing a diuresis in addition to that produced by the ingestion of fluid. Thus, according to Fitzsimons, thirst after alcohol is "secondary to loss of body fluid" (p. 532). Measures of fluid intake have also been included in two studies involving repeated experimental alcohol ingestion. In the first, Baisset, Montastruc and Garrigues (1965) compared fluid intake in 5 alcoholics and 4 nonalcoholic controls who, for a 6-day period had been maintained on identical diets including $220 \mathrm{mg}$ of red wine at each meal. Over the 5 days for which measures were reported, the mean fluid. intake, between meals, of the alcoholics was $172 \%$ greater than that of the control subjects. Moreover, in the alcoholics there was such a strong positive relationship between fluid intake and urine output that the investigators characterized this group as having a polyuriapolydipsia syndrome. Further investigation of their subjects led Baisset and his colleagues to suggest that this syndrome results from an antidiuretic hormone insufficiency produced by chronic alcohol consumption.

Although it is impos'sible to assess the effect of alcohol on the drinking behavior of either group in this study, the alcoholics' data are of interest in that they are consistent with the notion that fluid intake after alcohol is primarily a function of the loss of body fluid (Roberts, 1963; Fitzsimons, 1972). Indeed, the investigators themselves suggested that thirst and increased fluid intake after excessive drinking results from a generalized state of dehydration produced by fluid loss and maintained by alcohol's inhibitory effect on the secretion of antidiuretic hormone. It is also noteworthy that 
antidiuretic hormone insufficiency, the explanation offered to account for the polyuria-polydipsia syndrome observed in this study, is consirstent with the more recent suggestion that chronic alcohol consupption reduces the sensitivity of the neurological struttures which †egulate diuresis (Soulairac, Aymard and Dalle, 1972).

A Glinical case study reported by Gwinup, Chelvam, Jabola $\varepsilon$ Meister (1972) also included measures of nonalcoholic fluid intake after repeated alcohol administration. To explore the mechanism underlying hyponatremia in their patient, a 46 -year old chronic alcoholic, - the investigators maintained him general diet, without fluid or salt restrictions, and systematically manipulated his consumption of alcohol. The patient was administered daily either a di lute alcoholic beverage, water, or a concentrated alcoholic beverage, for each of three week-long assessment periods. Unlike the studies by Flynn (1958) and Roberts (1963), however, there was no suggestion of increased - thirst or drinking after alcohol. In fact, mean daily fluid intake was actually greatest during the second assessment period when water was administered. However, since the subject was diagnosed as having a pathological condition characterized by the inappropriate production of antidiuretic hormone, it is clear that the data from this patient cannot be generalized.

Indications of thirst and drinking have also been reported in studies of alcoholics following chronic excessive alcohol consumption. In two of their investigations of, fluid and electrolyte balance during - acute wi thdrawal in chronic alcoholics, Beard $\varepsilon$ Knott reported that 50 of their 60 patients complained of a dry mouth within 18 hours after 
their admission to 'hospital (Beard \& Knott, 1968; Knott \& Beard, 1969). In view of Soulairac, Aymard and Dalle's (1972) failure to distinguish between detoxified alcoholics and nonalcoholics in terms of thirst ratings or fluid intake, however, it would appear that the symptom of dry mouth following chronic excessive alcohol consumption

$=$ is limited to the period of acute withdrawal.

$-$

Since none of their patients was dehydrated, Beard and Knott

atributed the complaints of dry mouth to two other factors: (1) a drying effect on the mucous membranes of the mouth arising from the vaporous alcohol excreted via the lungs, and (2) increased viscosity

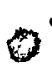
and decreased rate of salivary secretion associated with withdrawal.

It should be noted, however, that the extent to which these effects of alcohol enhance thirst and drinking is unknown.

It is obvious from the preceding review of the literature that very little is known about the effects of alcohol on thirst and fluid intake in human subjects, of the studies cited, only one investigated healthy subjects and compared fluid intake after alcohol with that after a control beverage (Flynn, 1958). The results of this study, though not significant, suggested that acute ingestion of a moderate amount * of alcohol can increase fluid intake during the "hangover" period. In - addition, two investigators reported anecdotally that their subjects experienced thirst following acute administration of alcohol, al though Fits latency differed markedly in the two studies' (Flynn, 1958; Roberts, 1963). Thus, while the acute effects of alcohol consumption on thirst and fluid intake have only begun to be explored, the existing evidence from research with human subjects is consistent with the animal. 
literature in supporting the view that alcohol is a dipsogenic substance.

Although it remains to be demonstrated that acute alcohol consumption significantly increases thirst and fluid intake, three different factors have, been proposed to mediate such an effect: (1) generalized, dehydration (Roberts, 1963; Baisset et al., 1965); (2) intracellular dehydration (Flynn, 1958; Lolli et al., 1944); and (3) disturbance of the regulatory function of central nervous system structures which control fluid intake (Wolf, 1958). In contrast, the symptom of dry mouth, which has been associated with acute withdrawal, is thought to result entirely from local effects of alcohol consumption on the mouth and throat (Beard \& Knott, 1971). It has also been suggested that chronic excessive alcohol ingestion results in a prolonged disturbance of fluid and electrolyte metabolism due either to antidiuretic hormone insufficiency (Baisset et a 1., 1972) or to reduced sensitivity of the neurological structures which regulate diuresis (Soulairac et al., 1972).

The Effects of Alcohol on Craving and Subsequent Alcohol Consumption

An assumption central to the hypothesis outlined in the introduction is that craving and alcohol consumption can be viewed as aspects of thirst and fluid intake. To the extent that this assumption is valid, research on alcohol's effect on subsequent alcohol self-administration, including laboratory analogue studies of $L D C$, can also be viewed more generally as investigations of alcohol's effect on the disposition to drink: To facilitate an evaluation of this evidence, those studies 
which support the hypothesis that alcohol increases subsequent drinking will be reviewed separately from those which do not.

Cutter, Schwaab \& Nathan (1970) compared the effects of whiskey *ersus ice water, in amounts ranging from 44 to $87 \mathrm{ml}$, on alcohol acquisition in both alcoholics and nonalcoholics. Their results indicated that neither subject group nor preloading beverage had any significant effect on acquisition or subsequent consumption of alcohol. Although these findings led the investigators to express.some reservations concerning the validity of their measures, they suggested that craving is unaffected by the ingestion of a single drink, but that it may be related to "the interaction of intermal physiological and psychological states with social-environmental cues..." (p. 377).

Negative findings regarding the effect of alcohol were also reported in two studies in which cognitive and pharmacological factors associated with alcohol consumption were assessed independently. Both Engle E Williams (1972) and Marlatt, Deming \& Reid (1933) employed a $2 \times 2$ design which involved the administration of an alcoholic beverage containing one ounce of $i$ iquor to half of the subjects and a nonalcoholic beverage to the others. Half of each of these groups was told that the beverage contained alcohol and the others were led to believe that it did not. No significant effect of alcohol was found on either subjective desire or requests for alcohol in hospitalized alcoholics (Willians, 1970; Engle \& Williams, 1972), or on intake during a 15 -minute beverage-rating task by either alcoholics or nonalcoholics in a laboratory setting (Marlatt et al., 1973). In both studies, however, the belief that alcohol had been consumed was a 
significant determinant of subsequent disposition to drink. Although neither group of investigators ruled out the possibility that the physiologica 1 effects of greater amounts of alcohol could affect subsequent drinking, both concluded that the effects of small amounts are primarily a function of cognitive factors.

As Keller (1972) and Ludwig and Wikler (1974) have pointed out, one of the papers most often cited in refuting the concept of LOC" actually presents findings to support it. In a double-blind experiment reported by Merry (1966), ratings of craving were obtained from hospitalized alcoholics after the administration of three "vitamin mixtures" which varied in alcohol content. Although craving was unaffected by the administration of 1 oz. of 1 iquor, it was significantly greater after $20, z$. Merry largely overlooked the latter finding, however, and suggested that psychological and environmental factors may be more important than the effects of alcohol in initiating LOC. In two other studies, alcoholic preloading beverages increased subsequent alcohol self-administration by hospitalized alcoholics. While continuing to provide a pre-determined minimum incentive for the maintenance of abstinence in their subjects, Cohen, Liebson, Failllace and Speers (1971) administered preloading beverages containing from 0 to $300 \mathrm{ml}$ of liquor. Behavioral contingencies were also used in a study by Bigelow, Griffiths and Liebson (1977) to suppress alcohol consumption durling the administration of preloading beverages contain, ing 0 to $77.7 \mathrm{gm}$ of alcohol. In spite of these restraints, alcohol self-adpinistration increased in both studies in proportion to the $i^{\prime}$ amount of alcohol in the preloading beverages. In the latter study, 
however, it was clear that subjects readily distinguished between the preloading beverages which contained alcohol and those which did not, despite the single-blind preload administration. In view of these findings, the investigators cautioned that the effect of alcohol on subsequent drinking may be mediated by psychological variables, such as expectancy, as well as by the pharmacological actions of alcohol. In a recent study by Funderburk and Allen (1977), hospitalized alcoholics worked at a key-pressing task to advance the time at which an alcoholic beverage was served. This measure of "disposition to drink" was obtained early each morning for a period of 20 days during which subjects were administered 1 iquor in amounts increasing from 0 to $900 \mathrm{cc}$ daily. The results indicated that disposition to drink was significantly increased both by anticipation of alcohol administration, occasioned by instructions regarding the imminent beginning of the experimental intoxication protocol, and by alcohol administration itself. On' the basis of these findings, the investigators suggested that drinking in chronic alcoholics is, at least in part, a function of prior alcohol consumption.

In the only study to investigate the effects of both prior alchol consumption and alcohol-related environmental stimuli, Ludwig, Wikler and Stark (1974) found significantly greater craving and alcohol acquisition in hospitalized alcoholics after alcohol than after placebo and in those exposed to the alcohol-related stimuli than in the corresponding control group. Moreover, there appeared to be an interaction between dosage and stimulus condition, measures of craving and alcohol acquisition being greatest among those who received an 
alcohol preload in the presence of alcohol-related stimuli. While the investigators derived support for their hypothesis that craving is a function of both alcohol consumption and environmental factors, no conclusive data were obtained to substantiate the existence of a "subclinical conditioned withdrawal syndrome".

In the preceding review all the studies in which only a small amount of alcohol was administered failed to show any effect of beverage, while those which employed more potent preloads revealed significantly greater craving and/or alcohol consumption after a cohol. Although this would appear to suggest that the effect of alcohol is physiologically mediated, the available evidence does not rule out the possibility that it is mediated psychologically.

In addition to the anticipation of alcohol availability (Funderburk \& Allen, 1977), and the presence of alcohol-related stimuli (Ludwig et a1., 1974), the belief that alcohol has been cons?med has been shown to exert a significant effect on alcoholics' desire for alcohol and on their actual drinking behavior (Engle \& Williams, 1972; Marlatt et al., 1973). Although all of the studies showing significant beverage effects appear to have adequately eintrolled for the first two of these factors, some question remains regarding the extent to which expectancies may have contributed to their findings. Although most, if not all, of these studies employed a placebo condition, the only one to report on the adequacy of this deception indicated that subjects readily discerned the presence or absence of alcohol in their preloading beverages (Bigelow et al., 1977). Thus, the finding that higher dosages of alcohol increase craving and subsequent alcohol 
consumption, while lower dosages do not, may simply reflect the greater discriminability of alcohol in preloading beverages containing higher dosages. Moreover, subjects in all but one of the studies were aware that alcohol would be available following administration of the preloading beverages. There is, therefore, very little evidence that a cohol administration, in the absence of anticipation of subsequent alcohol availability, has a significant effect on craving. Finally, it should be noted that, despite numerous theories of LOC which emphasize physiological mediating processes, no alcohol-induced physiological effect other than blood alcohol level has been shown to correlate significant ly with subsequent fluid intake among alcohol abusers. Thirst and Craving for Alcohol

It was proposed in the introduction that alcohol consumption produces a physiological state of dehydration which is ordinarily perceived as thirst, but which in naturalistic drinking settings can be cognitively mislabelled by alcoholics as a specific thirst or craving for alcohol. Although it remains to be demonstrated that moderate amounts of alcohol do, in fact, increase thirst and fluid intake, the clinical significance of such a finding would be enhanced considerably by évidence of a relationship between thirst and craving for alcohol.

Thirst has long been thought to play a role in craving and alcohol consumption among alcoholics. Marconi (1959), in reviewing the evolution of the concept of alcoholism, noted that dipsomania (uncontrollable desire for alcoholic beverages) was attributed as early as 1899 to a dysfunction of the brain mechanisms which control thirst. 
This position was revived in 1946 by Charlin, Gardien and Marty and later extended by Williams (1959) and Marconi, Poblete, Palestini, Moya and Bahamondes (1970), who proposed that craving and alcohol consumption are regulated by a hypothalamic center similar to that which controls thirst and fluid intake.

An exhaustive search of the literature, however, revealed only two papers in which it was explicitly suggested that alcoholics mis perceive the sensation of thirst as a craving for alcohol. In the first, Baldie (1931) described craving as a "misinterpretation of natural thirst" and suggested that it could be avoided simply by the periodic consumption of "aqua pura". ' In the second, silkworth and Texon (1950) suggested that craving for alcohol results from a physiological state of thirst produced by the alcoholic's drinking. This suggestion stemmed from their finding that alcoholics who report craving on admission to hospital have significantly lower blood chloride levels than alcoholics who do not. Since such electrolyte depletion can result from chronic excessive alcohol consumption and can provoke the sensation of thirst, these investigators suggested that thirst motivates continued alcohol consumption in craving alcohotics. Other investigators have also suggested that an alcohol-induced physiological state of thirst contributes to LOC, although without specifically referring to craving as a misperception of thirst. Baisset, Montastruc and Garrigues (1965), whose demonstration of s polyuria-polydipsia in alcoholics has already been cited, strongly emphasized the importance of alcohol's alleged thirst-inducing properties in maintaining alcohol consumption in alcoholic's: 


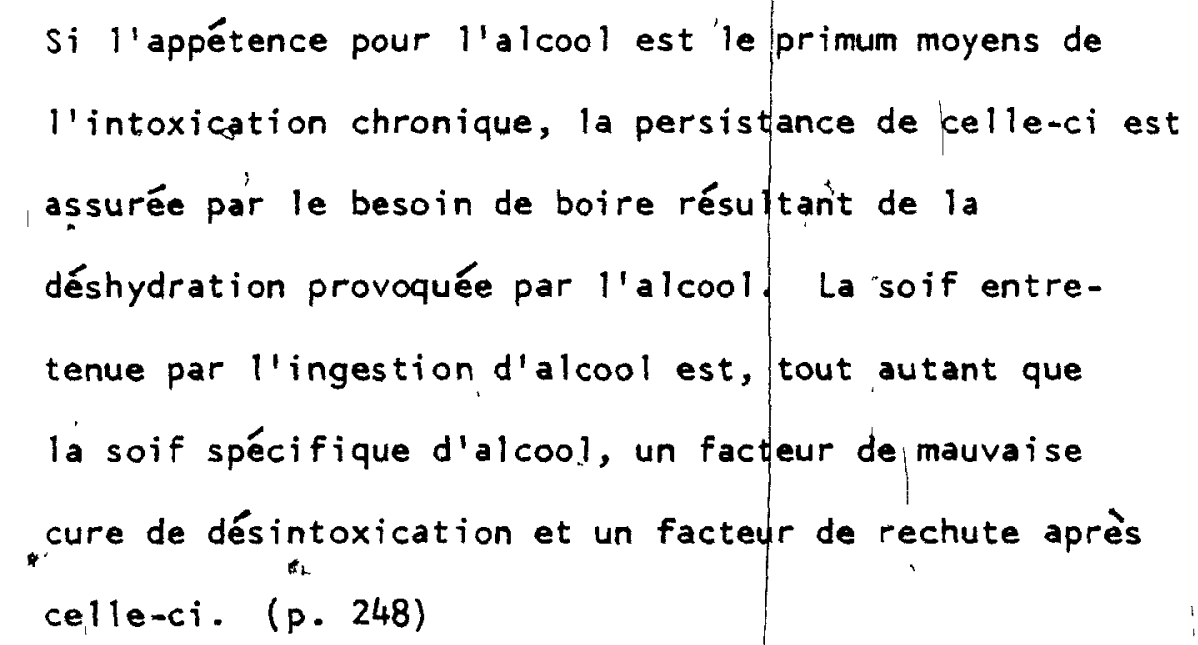

It has also been reported (Sansweet, 1975) that Patrick Frawley, founder of Schick Laboratories which have provided treatment to count-. less alcoholics, espouses a personal theory of alcoholism which emphasizes the exaggerated responsivity of alcoholics to fluid loss. According to Frawley, maintenance of alcohol consumption by alcoholics is largely a result of the diuretic and thirst-inducing properties of a) cohol.

Despite these suggestions of a relationship between thirst and craving, this area of research appears to be almost entirely unexplored. With the exception of the work by Silkworth and Texon and by Baisset and his colleagues, two surveys of craving experiences by alcoholics appear to be the only empirical sources to provide even a suggestion of such a relationship. In the first (Hore, 1974), 17\% of the" descriptions of craving included specific reference to thirst or dry mouth. In the report of the second survey (Ludwig \& Stark, 1974), several examples given of the respondants' descriptions of craving included specific reference to thirst or "hunger for a drink". 
While it is clear that such findings are suggestive of a relationship between thirst and craving only among a small proportion of alcoholics, it must also be remembered that these surveys were intended primarily as exploratory investigations and were not specifically designed to evaluate the contribution of thirst to the experience of craving. Moreover, since the role of thirst may depend on temporal... factors rerated to both drinking sequence and drinking history, careful selection and/or categorization of alcoholic respondants might provide more evidence for this relationship. It is evident that an experimental investigation involving the manipulation of thirst and systematic assessment of craving would provide considerably more research precision. Until such research strategies are employed, however, the relationship between thirst and craving will remain highly speculative. Summary and Statement of the Problem

It is clear from the preceding review that the theoretical model of LOC proposed in the/introduction is a lmost entirely lacking in empirical support. Although chronic alcohol consumption appears to result in increased fluid intake in animals, the paucity of adequately controlled experiments with human subjects precludes any definitive statement regarding the effects of alcohol on thirst and drinking in. man. More significantly, there is no firm evidence that acute administration of a moderate amount of alcohol increases thirst, craving or consumption of either nonalcoholic or alcoholic beverages in human subjects. The only adequately controlled investigation of alcohol's effects on nonalcoholic fluid intake suggested that alcohol 
differentially affects thirst and drinking, but failed to demonstrate a significant effect on either (Flynn, 1958). Although alcohol's effects on subsequent alcohol self-administration have been more thoroughly investigated, the results of this research are equivocal. Carefully controlled studies in which small amounts of alcohol were administered have consistently failed to obtain a significant beverage effect. Studies employing larger doses, while observing significantly greater craving and alcohol consumption afterward, have generally failed to provide adequate control for cognitive factors associated with alcohol consumption. Thus, it can be concluded that the first assumption, regarding the effects of acute alcohol ingestion on thirst and fluid intake, remains to be demonstrated.

The second assumption, that alcoholics can perceive alcoholinduced dehydration as craving rather than thirst, is similarly without empirical support. Despite numerous theoretical accounts relating uncontrolled alcohol consumption to dysfunctions of fluid-regulating mechanisms located in the brain, investigators have largely.overlooked the possibility that a physiological state which ordinarily provokes thirst and drinking could also pravoke craving and alcohol selfadministration. Although alcoholics' definitions of craving occasionally incilude references to thirst and dry mouth, the finding most suggestive of a relationship between thirst and craving consists of the demonstration that electrolyte depletion in alcoholics following prolonged alcohol ingestion is associated with reports of craving. There appears to be no evidence whatsoever which associates the physiological state 


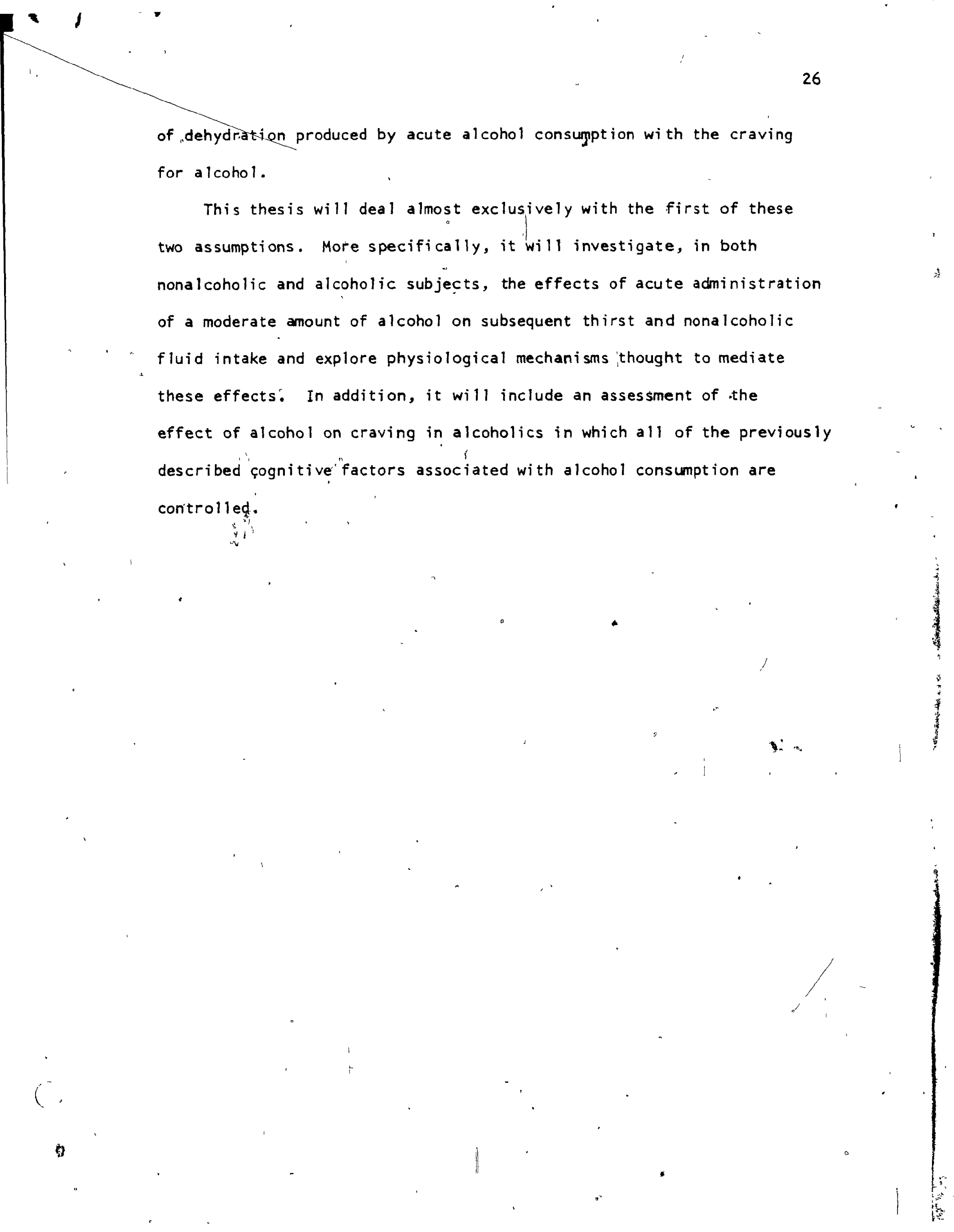




\section{Study 1}

Method

Subjects and setting. Fourteen male social drinkers between the ages of 18 and 27 years (mean $=22$ years) were selected from those responding to an advertisement posted on the university campus. Prospective subjects, all of whop were students, were interviewed in order to exclude from the study anyone having a history of drug addiction or any medical condition which would contraindicate the experimental administration of an alcoholic beverage. Similarly excluded were those under medical treatment or taking prescription medications at the time of the study.

The average age at which the subjects first consumed an alcoholic beverage was 16.4 years (range $=11$ to 20 years). At the time of the study they reported a mean weekly consumption of 6.5 drinks (range = 0 to 20 drinks), a drink being defined as an amount of beverage a lcohol equivalent to one ounce of 80 proof liquor. None drank beverage alcohol on a daily basis or had been treated for alcoholism or for any related medical disorder. Each was paid $\$ 2 /$ hour for his participation in the study which was conducted in the Alcohol Behávior Research Laboratory at Rutgers University. (Further details on individual subjects and a floor plan of the laboratory are presented in Appendix A.)

the

Experimental design. A within-subjects design was employed in which each subject participated in two experimental sessions scheduled 
at least two days apart. During one session subjects' fluid intake was measured after they had been administered an alcoholic beverage. During the other session, fluid intake was recorded after a placebo of equal volume had been consumed. The order in which the beverages were administered was counterbalanced.

Procedure. The experiment was presented as an investigation of the effects of alcohol consumption on urine output, urine specific gravity and blood alcohol level. Subjects were instructed not to take any drugs, including alcohol, during the 24-hour period preceding each session and not to eat or drink anything for 8 hours beforehand. Failure to observe these restrictions, subjects were told, would likely be evident from breath and urine tests conducted at the beginning of each session.

On their arrival at the laboratory for the first session, volunteers were given a detailed description of the experimental procedures and were shown through the laboratory. For the purposes of medical screening, each vallunteer's vital signs (pulse, blood pressure, respiration, and temperature) were taken by a staff nurse. Those who expressed an interest in participating in the stidy and whose vital signs were within normal limits were accepted and asked to sign a consent form (Appendix B). Subjects were then queried to determine whether they had followed the instructions to fast and to abstain from drugs and fluids. As an addi tional check, breath samples were analyzed (Breathalyzer, Model 900, Smith \& Wesison Electronics Co.) to ensure that subjects did' not have a positive bilood alcohol level (BAL). Those who had not followed the instructions were rescheduled. Subjects were 
then weighed and asked to leave with a staff member any food or smoking materials they may have brought with them to the laboratory.

A schema of the experimental sessions is presented in figure 1. At $8 \mathrm{a} \cdot \mathrm{m}$. , after control BAL determinations were made, subjects were instructed to void completely, and at 30 -minute intervals for the next hour, urine specimens were collected to determine control values of urine outpux and urine specific gravity. These measures were taken using a $250 \mathrm{cc}$ graduate cylinder and Squibb Urinometer (No. A-2740). During the intervals between urine samples and all subsequent physiological measures, subjects remained in their individual rooms where they could watch television, read or work at a table. Room temperature was monitored periodically and appropriate thermostatic adjustments were made to maintain it at $70^{\circ} \mathrm{F}$. Subjects were instructed not to smoke, lie down or to engage in any vigorous physical activity at any time during the sessions. To inșure compliance with these and subsequent instructions, subjects were continuously monitored on closed-circuit television. Shortly before the second control urine specimen was taken, subjects were asked to indicate how they felt by rating themselves on a 5-point scale in terms of 20 somatosensory items including self-ratings of thirst and dry mouth (Appendix C).

During the $1 \frac{1}{2}$-hour period immediately following collection of the control urine specimens, subjects consumed their drinks which were "

$\therefore$ administered in three equal portions at half-hour intervals. Subjects were instructed to pace their drinking using a timer and to finish each portion within 30 -minutes. Collection of urine specimens continued at half-hour intervals during the drinking period and for one hour 


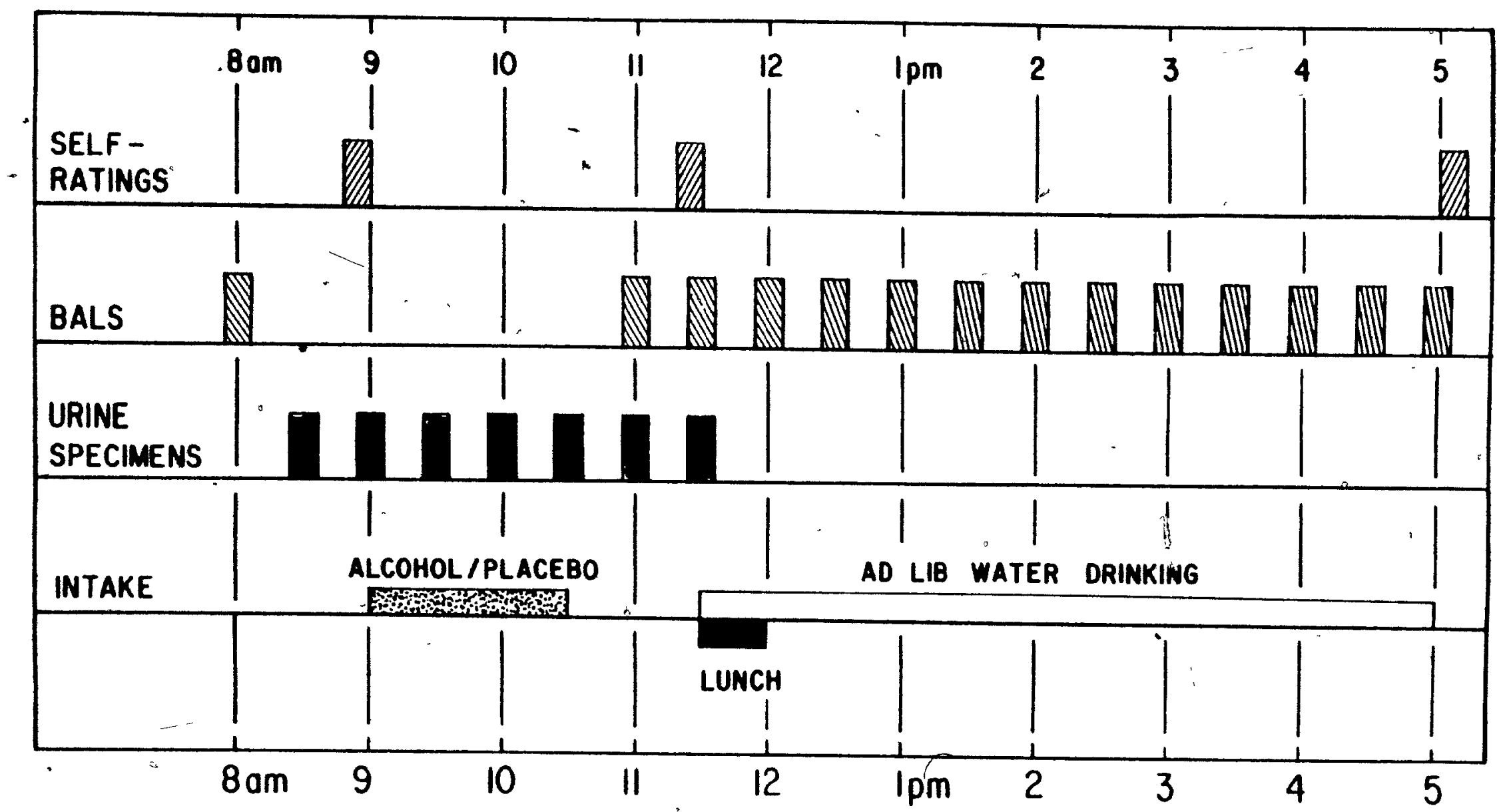

Fig. 1. Schema of experimental sessions. 
afterward. The alcoholic beverage consisted of $0.8 \mathrm{gms}$ of ethanol per $\mathrm{kg}$ body weight in the form of 80 -proof whiskey (Canadian Mist) which, mixed in a $1: 2$ ratio with Diet $7-U_{p}$, yielded a $13.3 \% \mathrm{v} / \mathrm{v}$ ethano 1 solution. The dosage and the drinking period were selected to approximate those found by $F$ lynn $(1958)$ to produce a significant reduction in total body water in human subjects.

The placebo contained only a trace of whiskey equivalent to 0.05 $\mathrm{gm} / \mathrm{kg}$ of ethanol, which previqus research has indicated is sufficient to impart an alcoholic taste, but which does not produce a measurable BAL (Briddell \& Wilson, 1976). The whiskey used in the preparation of the $p$ lacebo was mixed in a $1: 47$ ratio with Diet 7 -Up yielding a $10.83 \% \mathrm{v} / \mathrm{v}$ ethanol solution equivalent in volume to the alcoholic beverage. To enhance the credibility of the placebo, it was tinted with food coloring to approximate the color of the alcoholic beverage and it was served in an 240-ml'styrofoam cup the inside of which had d been smeared with whiskey. Thirty minutes after the final portion of the drink was consumed and at half-hour intervals for the remainder of each session, subjects were given Breathalyzer tests in the Nursing Station.

One hour after finishing their drinks subjects completed the rating uscales a second time and were served a standardized lunch in their rooms. It consisted of the following: $227 \mathrm{gm}$ of pork and beans; 1 . ham and cheese sandwich, including 16 -gm pat of lightly salted butter, 222 -gm slices of white bread, $235-\mathrm{gm}$ slices of ham and $118-\mathrm{gm}$ slice of Swiss cheese; a $46 \mathrm{gm}$ brownie and a pitcher of cold tap water. The pitcher had previously been filled with approximately $780 \mathrm{ml}$ of water, 
sufficient to bring its total weight on a triple-beam balance (Ohaus Scale Corp.) to $2600 \mathrm{gm}$. As the meal was served subjects were given the following instructions:

This is your lunch. We must ask that you eat all of it because $i t$ is the only way we can standardize the meal for all subjects. It makes no difference how much or how little water you drink, though, so just help yourself.

When the subjects left their rooms for the next Breathalyzer test, their lunch trays were first checked to ensure that everything was eaten and then removed, together with their water pitchers and cups. Immediately after subjects returned to their rooms, another premeasured pitcher of water and plastic cup were delivered to their rooms with the following instructions:

The measures to be taken for the rest of the session won't be affected if you drink water, so help. yourself if you are thirsty. You still can't have anything more to eat or smoke though. As soon as the session is over we'll return your cigarettes and serve supper, OK? During all subsequent Breathalyzer tests the weight of each subject's pitcher and any water in his cup was unobstrusively measured and recorded by a research assistant. If, when the subject was asked to go to the Nursing Station for a Breathalyzer test the height of the water remaining in his pitcher was less than $5 \mathrm{~cm}$, the research assistant casually picked it up and said to the subject: "Let me get you some more water." After the subject had returned to his room he was taken another premeasured pitcher of water. 
After the last Breathalyzer test, subjects completed the rating scales for the third time, any cigarettes or candy they had brought with then were returned, and they were offered dinner. At the end

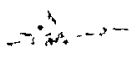
of their final session subjects were also asked to complete a PostExperimental Questionnaire (Appendix 0 ) designed to assess whether they were aware that their fluid intake had been measured.

\section{Results}

Data analysis. Preliminary $F_{\max }$ tests were conducted on all the data before analyses of variance (ANOVA) were conducted and in every case the results indicated that the variances across periods were heterogeneous. For uniformity of presentation, the square root transformation which most effectively'reduced the heterogeneity of variance of the fluid intake data was also applied to the data from both studies on urine output and urine specific gravity. Although significant differences among the variances of these latter data sets remained even after this transformation was used, the results were the same as those obtained using other, more appropriate transformations. When predictions were made, one-tailed tests of significance were employed. (Tables for the ANOVAs and correlations to be reported in this section can be found in Appendix E.)

Blood al cohol level (BAL). The control BALs for all subject in both beverage conditions were $0 \mathrm{mg} \%$, In the alcohol condition the mean peak BAL was $76 \mathrm{mg} \%$ which, with one exception, was obtained from the subjects during their first post-ingestion Breathalyzer test. No positive BALs were obtained from any subject following administration of the placebo. 
Urine output. 'The mean volumes of the combined control urinel specimens in each of the two beverage condithns were first compared to detect any pre-existing differences in the subjects' urine outputs. A $t$-test for correlated samples indicated no significant difference between these values $(t=1, d f=13)$. Thus, the subjects' controt urine outputs did not differ in the two beverage conditions.

Prior to the three-factor ANOVA of post-ingestion urine output (order $x$ beverage $x$ period), the data from one subject were deleted because he had produced less than one half of the scheduled number of specimens and the remaining data were transformed by taking the square root of the sum of the urine volume and 1 . The results of this analysis revealed highly significant main effects for beverage $(F(1,11)=$ $50.097, p^{<.0001)}$ and period $\left(F(4,44)=41.797, p^{<.0001)}\right.$ and a significant beverage $x$ period interaction $\left(F(4,44)=7.299, P_{<} .0003\right)$. There was no order effect $(F(1,10)<1)$. As illustrated in Figure 2 urine volumes were significant ly greater after alcohol than after placebo. It is also evident from this figure that urine volumes increased significantly across periods until 2 hours after the beverages were first administered, after which urine volumes in both beverage conditions decreased. The rate of increase in urine output over periods, however, clearly differed in the two beverage conditions as indicated by the significant beverage $x$ periods interaction. Urine output increased at a much greater rate in the alcohol than in the placebo condition.

Urine specific gravity. Four subjects failed to produce even one measurable control urinf specimen in each session. For the remaining ... 
a

35

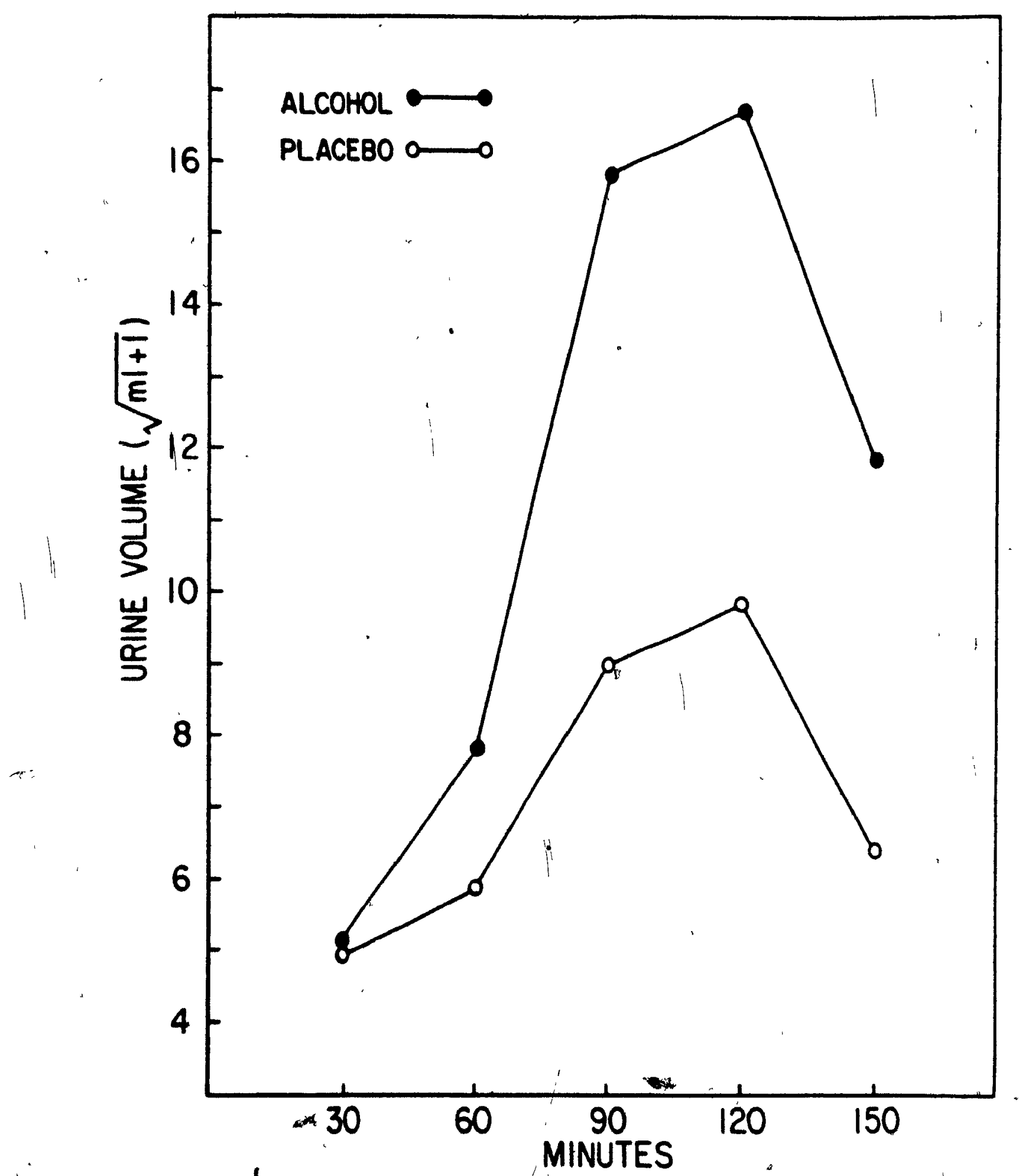

Fig. 2. Mean urine volume at 30 minute intervals following the - administration of alcohol and placebo in Study 1. 
10 subjects, however, the mean specific gravities of the contro, specimens in the two beverage conditions were identical (mean $=1.021$ ). Thus, differences between the two beverage conditions in specific gravity of specimens collected after the beverages were administered cannot be attributed to differences between the control values.

Two subjects were excluded from the analysis of urine specific gravity because they failed to produce three or more measurable specimens in each session after the drink was administered. For subjects who had only one or two missing values per session, estimates of their urine specific gravities were made by the method of least squares. Before they were analyzed the data were transformed by taking the square root of the sum of the specific gravity and 1 .

The results of a three-factor ANOVA (order $x$ beverage $x$ period) revealed highly significant main effects for beverage $(F(1,10)=$ $\left.16.120, p_{<} .003\right)$ and periods $(F(4,40)=53.724, p<.0001)$. Neither the order effect $(F(1,10)<1)$ nor the beverage $x$ trails interaction was significant $(F(4,40)=1.644, P<.20)$. As illustrated in Figure 3 , urine specific gravities decreased in both beverage conditions reaching their lowest points $1 \frac{1}{2}$ hours after the administration of alcohol land 2 hours after placebo: It is also evident from this figure that the urine specific gravities were significantly and consistently lower after alcohol than after placebo.

Fluid intake. Responses on the Post-Experimental Questionnaire and during subsequent debriefing indicated that no subject misunderstood the instructions regarding ad lib drinking or was aware that his fluid intake was being recorded, It would appear, therefore, that subjects' 

fluid intake was in no way affected by demand characteristics.

Since a preliminary $F_{\max }$ test of the fluid intake data revealed that the variances across trials were heterogeneous $\left(F_{\max }(22,13)=\right.$ 39), a non-parametric statistjc, the Wilcoxon matched-pairs signed ranks test, was used initially to assess the difference in total fluid intake. in the two beverage conditions. The results indicated a significantly greater intake after alcohol than after placebo $(T=14, \mathrm{df}=14$, $p<.01$ for one-tailed test).

The mean and cumulative fluid intake of subjects at half hour intervals",during the ad lib drinking period are presented in figures 4 and 5 respectively. It is clear from these data that the difference - in intake between the two beverage conditions is due primarily to the differences which occurred during the first $1 \frac{1}{2}$ hours. To investigate this apparent interaction, a three factor ANOVA (order $x$ beverage $x$ trials) was performed after the data had been transformed by taking the square root of the sum of the fluid intake in gm plus 1. A $F_{\text {max }}$ test of the transformed data had indicated that the assumption of homogeneity had been met $\left(F_{\max }(22,13)=5.16\right)$.

Although this analysis revealed a significant effect for trials $(F(10,120)=19.479, p<.0001)$ and a marginally sign jcant beverage $x$ trials interaction $\left(F(10,20)=1.869, P_{<} .056\right)$, the beverage effect indicated only a trend in the predicted direction $(F(1,12)=2.506$, $p<.137)$. To explore the interaction, the intake data for the first $1 \frac{1}{2}$ hours were analyzed separately from the data for the last 4 hours. The results of these post hoc tests indicated substantial effects for beverage $(F(1,12)=14.835,(P<.003)$ and trials $(F(2,24)=30.081$, 


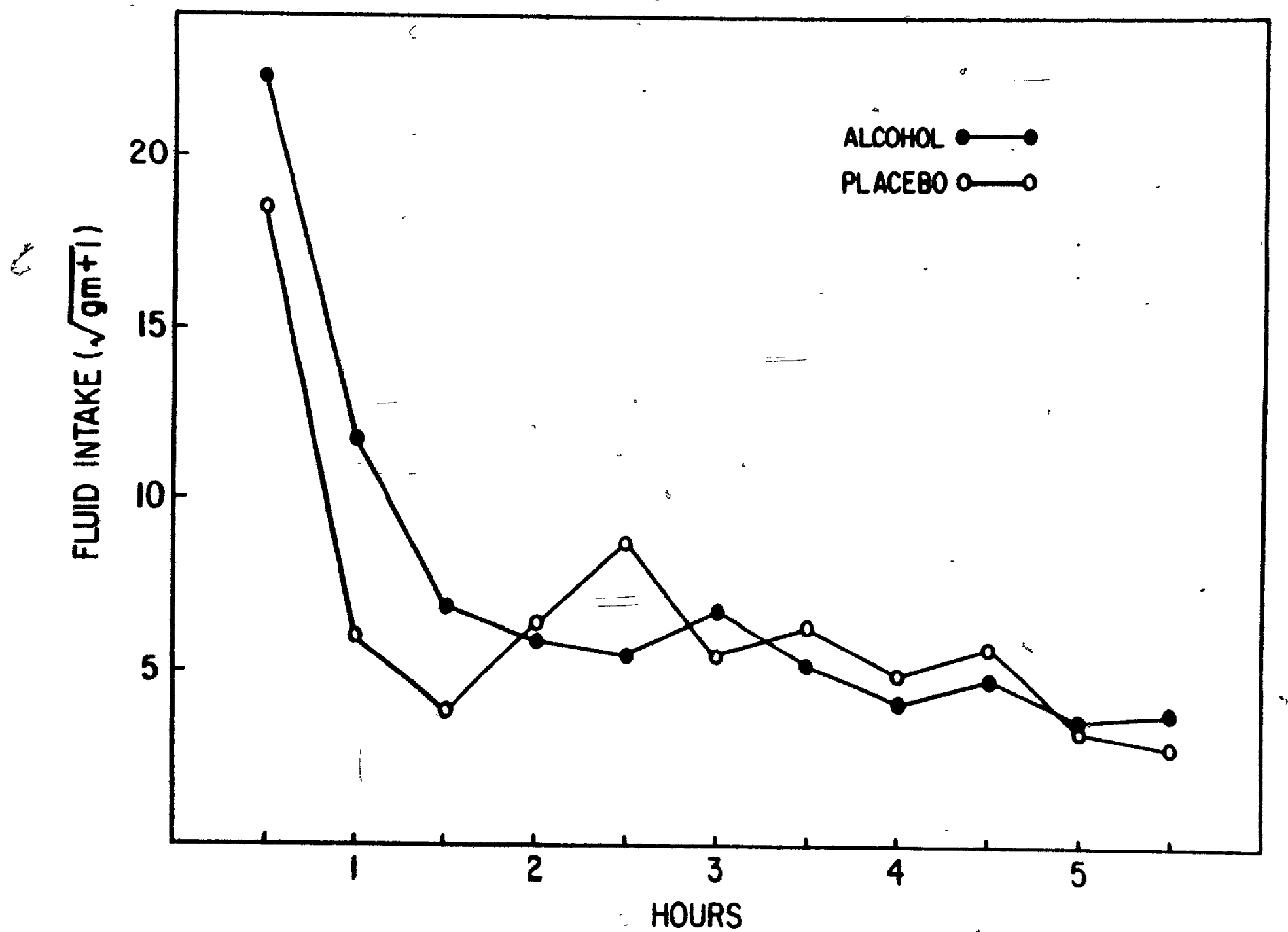

Fig. 4. Mean fluid intake at 30 -minute intervals following the administration of alcohol and placebo iti study 1 . 


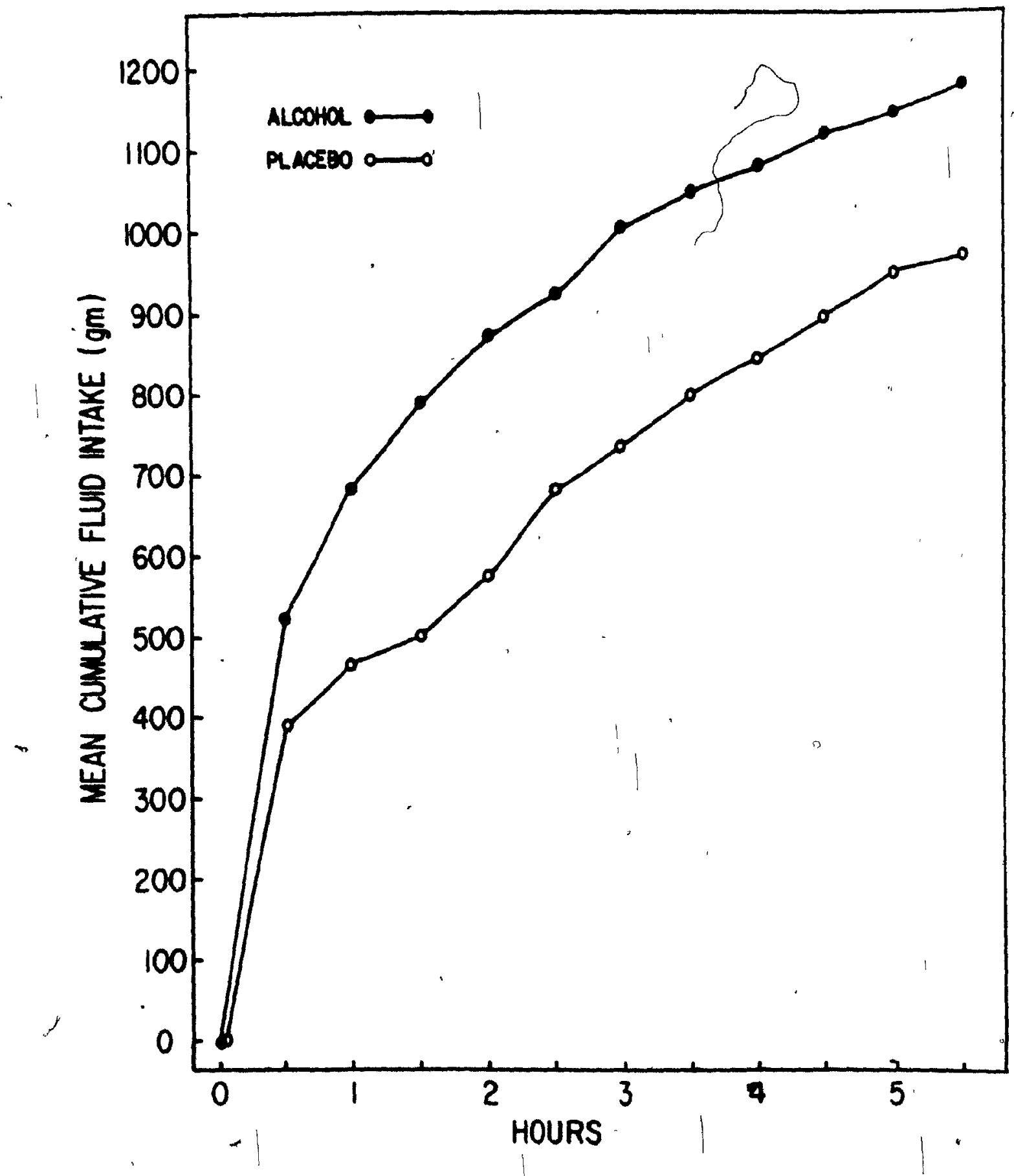

Fig. 5. Cumulative fluid intake at 30 -minute intervals following the administration of alcohol and placebo in study 1. 
$p<.0001$ ) during the first $1 \frac{1}{2}$ hours and no significant main effects or interactions during the latter portion of the ad lib drinking period. Thus, it would appear that the discrepancy between the non-parametric test and the first ANOVA in terms of the significance of the beverage effect is due to the beverage $x$ trials interaction. Since the results of the post hoc ANOVAs are consistent with the non-parametric test, it seems reasonable to conclude that alcohol ingestion resulted in a significantly greater fluid intake if only during the first 90 minutes of ad lib drinking.

Fluid balance. Fluid balance was calculated by deducting each subjects' total urine volume during the $2 \frac{1}{2}$ hour interval after the administration of the beverages from the volume of his beverage. Eleven of the 14 subjects had a negative fluid balance after alcohol (mean $=-227.643 \mathrm{ml}$ ) and all but one subject had a positive fluid balance after placebo (mean $=+269.357 \mathrm{ml}$ ). A t-test for correlated samples indicated that the difference in mean fluid balance Between the two beverage conditions is highly significant $(t=5.58, \mathrm{df}=13$, $p<.0005$, one-tail led test).

Self-ratings of thirst and dry mouth. Unfortunately, due tó an oversight during one of the sessions, only 11 of the 14 subjects actualty completed the rating scales three times during each session. These subjects' self-ratings of thirst and dry mouth were analyzed using three sign tests which compared the responses in the two beverage conditions for each administration of the scales. The only significant finding was in self-ratings of thirst on the second ocgasion the scales were completed. One hgur after consuming the alcoholic beverage, the subjects' 
self-ratings of thirst were significantly greater than at the same time after consuming the placebo $(p=.03$, one-tailed test $)$.

Self-ratings and fluid intake. In order to assess the relationships among fluid intake and self-ratings of thirst and dry mouth, correlations were computed for the ratings on each of the three occasions the scales were completed with. subjects' cumulative fluid intake at each period during eaçh of the two sessions. Since the distribution of ratings was extremely sma $f_{1}$, the data were dichotomized. Those responses which indicated that subjects were "not at all thirsty" or that their mouths were "not at all dry" were assigned a value of zero and those which indicated any degree of thirst or drynes's were assigned a value of one. The only significant correlations were between post-ingestion ratings and intake after alcohol consumption. With the exception of one half-hour interval, the second self-rating of thirst correlated significantly with intake during the last 3 hours of ad lib drinking, the highest correlation being with total fluid intake $\left(r_{p b i}=.617, t=2.479, d f=10, p<.025\right.$, one-taipled, test $\left.t\right)$. In addition, the third,self-rating of thirst correlated/significantly with intake during the last 4 hours of ad lib drinking, the highest correlation in this case being wity intake after 2 hours ( $r_{p b i}=$. $.581, t=2.473$, df $=12,0<.025$, one-tailed test). Ratings of dry mouth obtained at the end of the ad lib drinking period also correlated significantly with prior fluid intake, the highest being with intake after the first 2 hours $\left(r_{p b i}=.618, t=2.723, \mathrm{df}=\right.$ 12, $p<.01$, one-tailed test). Thus, post-ingestion ratings of thirst and dry mouth were significantly related to ad lib fluid intake after alcohol. 
Fluid intake and physiological effects of prior beverage administra-

tion. Product moment correlations between fluid intake and several physiological measures were computed for both sessions to determine what factors may have mediated the dipsogenic effect of, alcohol. Correlations with cumulative fluid intake at each half hour of the ad lib drinking period were computed for each of the following physiological indices, peak BAL, blood alcohol elimination time, mean urine specific gravity, peak urine output over a 30 aminute period and fluid balance immediately prior to the ad lib drinking periods. Although none of . the correlations in the placebo condition even approached significance, two of the physiological measures correlated significantly with fluid intake after alcohol. The correlation between peak blood alcohol level and fluid intake was significant after its hours of ad lib drinking $(r=.469, d f=12, p<.05$, one-tailed test) and that between fluid balance and fluid intake was/significant after one hour $(r=-.462$, $d f=12, p<.05$, one-tailed test). Thus, subjects with the highest peak blood alcohol levels and the lowest fluid balance values drank the greatest amounts of water during the initial phase of the ad lib drinking period.

In addition, scotter diagrams revealed that data from an atypical 1 subject had obscured a significant relationship between mean urine specific gravity and fluid intake in both beverage conditions. To illustrate this point, al scatter diagram of this relationship after $1 \frac{1}{2}$ hours of ad lib drinking in the alcohol condition'is presented in Figure 6. It is clear from this figure, which is representative of the relationship throughout the remainder of the ad lib drinking period, 


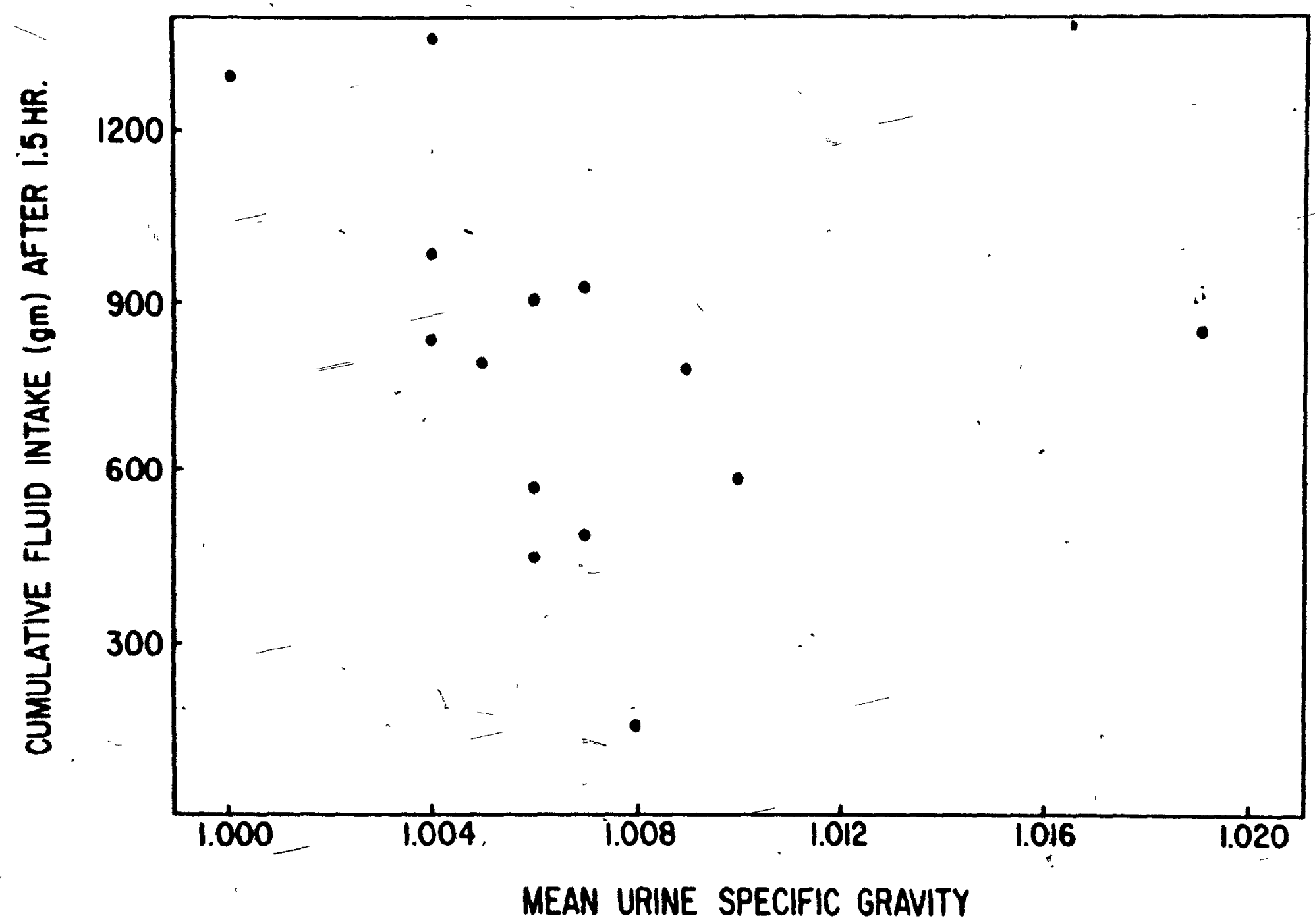

Fig. 6. Scatterdiagram of the relationship between mean urine specific gravity and 1.5 -hour fluid intake following the administration of alcohol in Study 1 . 
that the subject with the highest mean urine specific gravity represents a gross departure from what qtherwise appears to be an inverse 1 inear relationship between fluid intake and prior mean urine specific gravity. Indeed, when the data from this subject alone are deleted, the correlation between these variables, which was originally nonsignificant $(r=0.332$, df $=12, p>.10)$, becomes highly significant $(r=-.668, d f=11, p<.01$, one-tailed test $t)$. Thus, with one exception, those subjects having the lowest mean urine specific gravities drank significantly more than those with higher mean urine specific gravities.

Inspection of the correlations obtained for blood alcohol elimination time revealed that they never approached significance or showed any definite trend across cumulative values of fluid intake. The correlation-between peak urine output and fluid intake in the alcohol condition, however, approached significance $(r=.402$, df $=$ $12, .10>p>.05$, one-tailed test) during the first 30 minutes of ad lib drinking, but showed a progressive decline with successive measures of cumulative fluid intake. There is, therefore, some suggestion that those subjects with the highest peak rates of urine output after alcohol subsequeht ly drank more water during the earliest phase of ad lib drinking than those with lower peak rates of urine output. Discussion

The results of this study indicate that a moderate amount of beverage brohol can have a significant dipsogenic effect, that this effect occurs in moderate drinkers within 2.5 hours after alconol is conșumed, that that it is accompanied by the subjective experience of 
thirst. Moreover, it was demonstrated that fluid intake after alcohol ingestion is significantly correlated with peak BAL, fluid balance and, with the exception of one atypical subject, with mean urine specific gravity.

The acute effects of alcohol on fluid intake and thirst observed in the present study are clearly at variance with the findings of the two previous studies which bear on this subject. Roberts (1963) reported that none of her 20 nonalcoholic subjects, who had been administered 6-8 oz of 100-proof alcohol, drank any water which was available ad libitum during her experiment and that none became thirsty until after the alcohol had been metabolized. In contrast, Flynn (1958) reported that all five of his subjects complained of . thirst short 1 y after consuming $2.5 \mathrm{ml} / \mathrm{kg}$ of 90.4 -proof alcohol, but that ad lib consumption of water within the first 3.5 hours after alcohol was actually less than affer the control beverage.

Differences in the results of these studies and the present study can to a large extent be attributed to differences in the procedures employed. In neither or the two previous studies was there any attempt to measure changes in the sensation of thirst. The only evidence offered to support the conclusions of these investigators was anecdotal reports from their subjects. Although Flynn's observation that his subjects complained of thirst after alcohol is consistent with the findings of the present study, he made no mention of their degree of thirst after the control beverage. Consequently, it is impossible to defermine what effect, if any, alcohol had on his subject's' perfeption of thirst. It should also be noted that flynn's 
subjects complained of thirst during the first 1.25 hours after alcohol ingestion, when ad 1 ib drinking was not permitted.

Although the design of Roberts' study (1963) precluded any comparison between the effects of alcohol and a control beverage on subsequent fluid intake, it is surprising in view of the present findings that her subjects did not drink during her experiment which continued for as long as 3 hours after alcohol had been consumed. Apart from the fact that her subjects were patients and presumably hospitalized, Roberts' study differs in at least three other respects from both the present investigation and Flynn's in which drinking was observed after alcohol. The first is its relatively short duration. Measures of ad lib drinking continued in the present study for 5.5 hours after alcohol was consumed and in Flynn's study for 8 hours. It is conceivable that in Roberts' study subjects merely waited to drink until the session was over at which time more preferred beverages may have been available.

The second difference is that subjects in both the present study and in Flynn's were fluid deprived for 8 hours prior to alcohol administration, whereas Roberts' subjects were "adequately hydrated" at the time alcohol was given. Thus, subjects in "Roberts' study may have been in greater positive fluid balance than subjects in either of the other studies. If this was, indeed, the case and if it can also be assumed that alcohol-induced dehydration occurs more slowly under these conditions, then alcohol's effect on fluid intake may well have been delayed beyond the period during which measures were taken. 
The third difference is that no meal was scheduled during the ad lib drinking period of Roberts' study. In both the present investigation and in Flynn's study, the time at which alcohol began to exert a dipsogenic effect appeared to coincide with or to follow a meal. The suggestion that acute alcohol ingestion differentially affects pre- and post-prandial drinking is also supported by data from the animal literature. 'Wallgren and his colleagues (1967), in a study previously reviewed, reported that fluid intake of rats subjected to repeated intoxication was significantly greater than that of controls both during the day and at night, but that the maximal. difference between these groups occurred at night. Since this is the time when rats typically feed, it suggests that the effect of alcohol on fluid intake may be enhanced during the post-prandial period. It is noteworthy also that Lolli and his colleagues (1944), who proposed that thirst after alcohol intake results from shifts of intracellular w fluid tol the extracellular space, found an increase in extracellular fluid after alcohol in both free-feeding and deprived rats, but reported a greater increase in the former group. . Thus, to the extent that Roberts focused exclusively on a pre-prandial interval, she was perhaps less likely to observe the effect of alcohol.

The physiological effects of alcohol observed in the present study replicate the findings of previous investigators. It has long been established that alcohol is a diuretic agent (Miles, 1922; Murray, 1932) and that alcohol diuresis only occurs when the BAL is increasing (Haggard, Greenberg \& Carro11, 1941; Eggleton, 1942). Although no direct assessment was made in the present investigation of the effect 
of alcohol on urinary excretion of electrolytes, the effect observed on urine specific gravity is consistent with an increase in free water clearance which is widely recognized as characteristic of alcohol diureșis (Rubini, Kleeman \& Lamdin, 1955; Strauss, Rosenbaum \& Nelson, 1955; Beard \& Knott, 1971).

The correlations obtained in the present study between flúid intake after alcohol and both fluid balance and mean urine specific gravity istrongly suggest that the mechanism responsible for the observed ,effect of alcoholiz on fluid intake is much the same as that presumed to underlie the increased thirst and drinking characteristic of the hangover period. Roberts (1963), for example, who reported that thirst did not occur until after the alcohol had been metabolized, attributed it to an alcohol-induced state of dehydration. This view of alcohol's effects on thirst is also shared by Fitzsimons (1972). The significant correlation obtained in the present study between fluid balance and subsequent fluid intake is entirely consistent with this account.

The correlation obtained between mean urine specific gravity and fluid intake is consistent with a more complex theoretical acdount of alcohol's effect on thirst and fluid intake. It will be recalled that Flynn (1958) attributed the relatively greater fluid intake by his subjects during the "recovery phase" after alcohol to the relatively but not significantly greater intracellular dehydration which occurred at the time. In both the alcohol and the control conditions, Flynn observed a shift in body water from the intracellular to the extracellular fluid space. Such reductions in intracellular volume, Flynn noted, ordinarily occur by osmotic loss of water. Since this yprocess 
appeared to have been intensified by alcohol, Flynn concluded that alcohol provokes thirst because it contributes to intracellular dehydration, a view proposed earlier by Lolli, Rubin and Greenberg (1944). The significant negative correlation obtained between mean urine specific gravity and subsequent fluid intake is clearly consistent with this hypothesis. To the extent that a reduction in urine specific gravity reflects solute retention, lower urine specific gravities will be associated with higher serum osmolality (Roberts, 1963), which in turn will provoke a greater shift of body water from. the intracellular to the extracellular fluid compartment.

Apart from Flynn's observations; the only suggestion in the literature that increased thirst and fluid intake after alcohol might occur before the hangover period was made by Wolf (1958) who commented that "in some individuals, strong alcoholic drinks appear to excite thirst shortly, and in a different manner from the well-known delayed effect" (p. 119). To account for this phenomenon, Wolf' suggested that the effect of alcohol on thirst is also a function of its action on the central nervous system. In much the same way as destruction of the ventromedial nucleus results in hyperphagia, Wolf proposed that the thirst which may occur shortly after alcohol ingestion represents an inhibition of a satiety center which controls fluid intake. Although this disinhibion-of-satfety hypothesis is contrary to both Roberts' (1963) suggestion that thirst is initially inhibited by a)cohol and to Fitzsimons' (1972) contention that alcohol effects thirst only indirectly by producing a reduction in body fluid, there is some evidence from electrophysiological studies that alcohol also 
has a direct effect on those areas in the brain which regulate drinking. Wayner (1973) has demonstrated that alcohol selectively affects those cells of the latera 1 hypothalamus which appear to exert an inhibitory influence over cells which are apparently involved in the specific act of drinking and in pon-specific motor arousal.

The disinhibition-of-satiety hypothesis of alcohol's effect on thirst, though speculative at best, does account for the high positive correlation observed between peak BAL and fluid intake. Since the concentration of alcohol in the brain forresponds closely to its concentration in the blood (Richie) 1970), higher BALs would result in a reduction of the inhibitory activity and an increase in excitatory activity of hypothalamic thirst centers, and would thereby be associated with greater fluid intake. While it is entirely possible that the correlation obtained between peak $B A d$ and fluid intake may simply reflect the operation of a third unspecified variable, it should be noted that the correlationstbetween peak BAL and the other two predictors of fluid intake, fluid balance and hean urine specific gravity, were not significant. Thus, the relationship observed between peak BAL and fluid intake cannot be attributed to incidental intercorrelations among these variables.

The results of the present study confirm the prediction that a moderate amount of alcohol produces thirst and increases fluid intake within a short period after it is consumed. Self-ratings of thirst recorded one hour after the beverages were consumed mere stgnificantly greater in the alcohol than in the control condition, and during the first 90 minutes of ad lib drinking the mean cumulative fluid intake 
after alcohol was significantly greater than that after the placebo. These findings not only constitute the first demonstration of alcohol's dipsogenic effect prior to the hangover period, they also have important implications for the LOC phenomenon in alcoholism. As mentioned previously, it has been proposed that alcohol consumption is related to thirst and that craving for alcohol is merely a misinterpretation or mis labelling of this physiological state (Baldie,. 1931; Silkworth \& Texon, 1950). To the extent that thirst does contribute to alcohol consumption and to craving for alcohol, the findings of the present study indicate that initial alcohol consumption may precipitate LOC by virtue of $i$ ts effects on fluid and electrolyte balance. This speculation, however, presupposes that alcohol exerts a dipsogenic effect on alcoholics as well as on nonalcoholics. Accordingly, a second study was conducted in an attempt tó replicate these findings with alcoholic subjects. 


\section{Study 2}

Method

Subjects and setting. Sixteen male alcoholics between the ages of 29 and 48 years (mean $=36$ ) were selected from those responding to an advertisement placed in a metropolitan newspaper. Volunteers were offered $\$ 60 /$ wk to participate in a series of studies which required. that they live in the Alcohol Behavior Research Laboratory for approximately 3 weeks.

All subjects met the following selection criteria: (1) mean daily consumption of at least one pint of 80 -proof liquor or its equivalent; (2) evidence of physical dependence on and tolerance to alcohol; (3) a history, of more than 2 years of problem drinking; (4) good physical health, with no signs of liver or kidney damage; (5) no evidence of psychosis or chronic brain syndrome; (6) no current medical treatment or use of prescription medication or nonmedical drugs at the time of the research. A series of medical tests was conducted on all subjects and they were given in addition, a complete physical examination.

These subjects had histories of problem drinking averaging 10.1 years and reported an average daily intake of 31 ounces of 80 -proof liquor or its equivalent. All but one subject drank beverage alcohol on a daily basis, the sole exception having indicated that he could afford to drink only an average of 3 days/wk. Seven of the subjects had previously been hospitalized for alcoholism and four others had either been treated on an out-patient basis or had attended Alcoholics. 
Anonymous meetings. The average Alcadd Test score for the group was 33, all subjects having scored above the critical cut-off used to differentiate alcoholics from nonalcoholic social drinkers (Mansón, 1965). The subjects had completed an avarage of 11.4 years of formal education and all węre unemployed at the time of the study. (Further details on individual subjects are presented in Appendix F.)

Experimental design and procedure. The experimental design of this study was identical to that of Study 1 and the procedure differed only in the following respects: (1) a gas chromatograph, the Intoximeter Mark IV (Intoximeters Inc., st. Louis, Missouri), was used in place of the Breathalyzer to measure BAL; $(2)$ an additional rating scale was included on which subjects indicated their degree of craving. for alcohol (Appendix G); (3) subjects were required to est imate the amount of whiskey in the beverage administered during each session (Appendix H); and (4) subjects resided in the laboratory during the experiment and for 9 days beforehand thereby permitting strict control over their intake of food, flùid and drugs in accordance with the restrictions imposed in Study 1. Residency in the laboratory for this period was also intended/to ensure an adequate interval since their initial withdrawal from alcohol for the restoration of normal fluid and electrolyte balance (Beard \& Knott, 1968). Results

Data analysis. The same tests of significance and data transformations as were used in the data analysis in Study 1 were also used in Study 2. (Tables for the ANOVAs and correlations to be 
reported in this section can be found in Appendix I.)

Blood alcohol level (BAL). The control BALs for all subjects in both beverage conditions were $0 \mathrm{mg} \%$. In the alcohol condition the mean peak BAL was $84 \mathrm{mg} \%$ which, without exception, was obtained from the subjects during their first post-ingestion breath test. No positive BAL was obtained from any subject following administration of the placebo.

Estimates of alcohol consumption. To assess the extent to which subjects discriminated between the alcoholic content of the beverages they were administered, a $t$-test was performed on their estimates of the total amount of 80-proof liquor consumed in each session. Although subjects' estimates were significantly greater in the alcohol condition $(t=6.329, d f=15, p<.001$, two-tailed test), it is noteworthy that all subjects overestimated the alcohol content of the placebo. The mean estimate in the placebo condition, in fact, was 3 oz. (range $=1-5.5 \mathrm{oz}$.$) . Thus, while all subjects recognized the$ greater potency of the alcoholic beverage, the placebo manipulation was successful to the extent that all subjects indicated that they had been administered. an alcoholic beverage during both sessions of the experiment.

Urine output. The difference in control urine volumes between the two beverage conditions was not significant $(t=1.542$, df $=15$, $p>10$, two-tailed test). The results of a three-factor ANOVA (order $x$ beverage $x$ period) of the post-adninistration data, however, revealed highly significant effects for beverage $(F(1,14)=35.739, P<.0001)$ and periods $(F(4,56)=30.555, p<.0001)$ and a significant beverage $x$ f 
periods interaction $(F(4,56)=5.301, p<.0015)$. As illustrated in Figure 7, urine output was significantly greater after alcohol than after placebo and showed a progressive increase in both beverage conditions for a period of two hours after the beverages were first administered. It is also evident from this figure that the significant beverage $x$ period interaction is due to the much greater rate of increase in urine output after alcohol.

Urine specific gravity. Two subjects were excluded from a, comparison of mean control urine specific gravities between the two beverage conditions because they failed to produce even one measurable control urine specimen during each session. A t-test on the data of the remaining 14 subjects, however, indicated that the difference between the mean control values in the two beverage conditions approached, but did not attain statistical significance $(t=1.948$, $d f=13, .05<p<.10$, two-tailed test). This finding is of no practical significance, however, because the initial difference in mean control values was not in the direction predicted for the experimental values (mean before alcohol $=1.020$, mean before placebo $\left.=1^{3} .018\right)$.

One subject was excluded from the analysis of post-ingestion urine specific gravity because he produced measurable urine samples on fewer than one half of the occasions when specimens were collected. For subjects who had only one or two missing values per session, estimates of their urine specific gravities were made by the method of least. squares. 


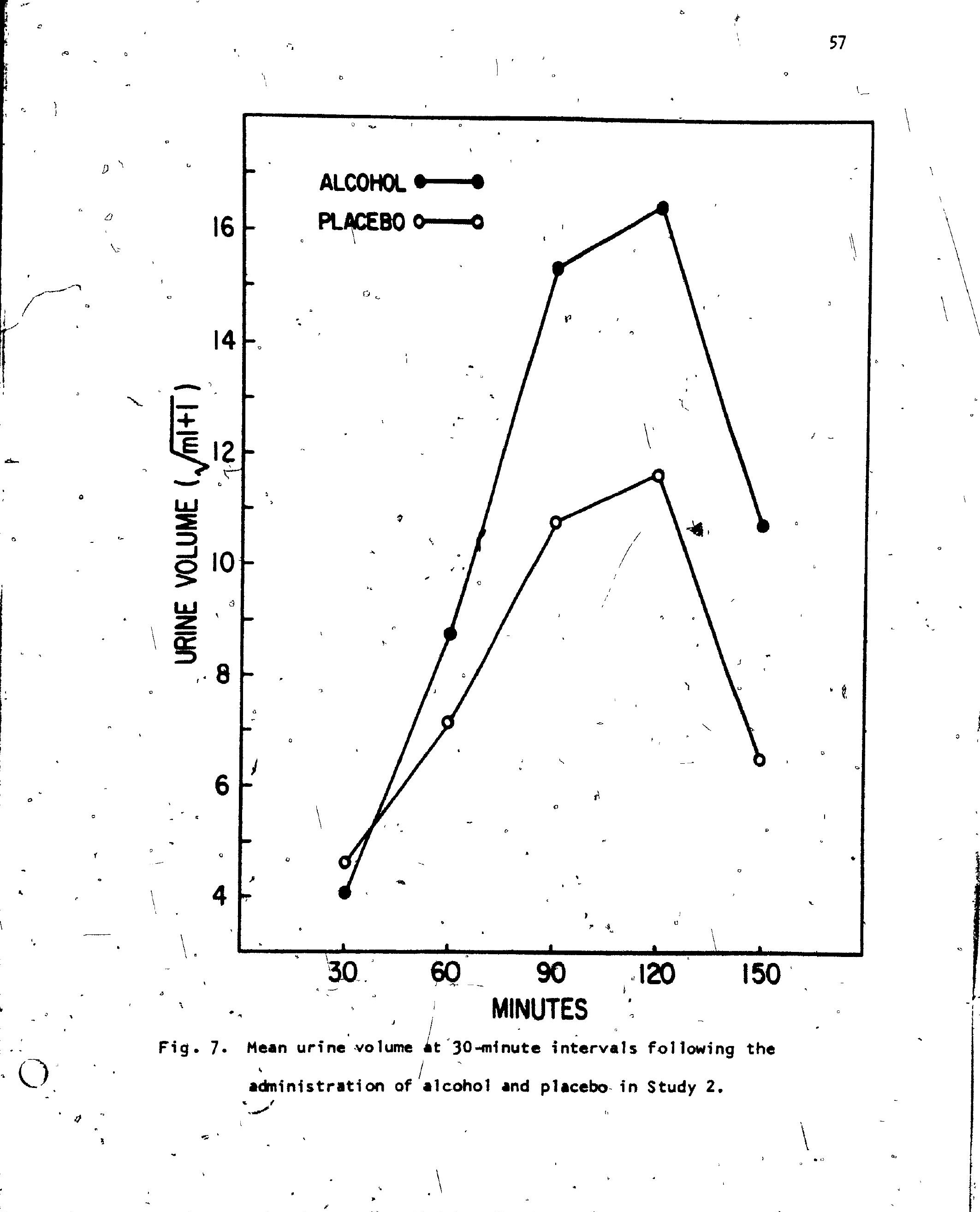


A three-factor ANOVA (order $x$ beverage $x$ period) of the transformed data revealed highly significant main effects for beverage $(1,13)=$ $20.375, p<.001)$ and periods $(F(4,52)=31.549, p<.0001)$. As shown in Figure 8 , urine specific gravities decreased significantly during the 2-hour interval following the administration of both beverages; and were consistently lower in the alcohol than in the placebo condition.

Fluid intake. Responses on the Post-Experimental Questionnaire and information obtained during debriefing interviews indicated that no subject misunderstood the instructions regarding ad lib drinking or was aware that his fluid intake was being recorded. Thus, it would appear that the subjects' fluid intake was not in any way affected by demand characteristics.

The mean and cumulative fluid intake of the alcoholic subjects at half-hour intervals during the ad lib drinking period are presented $x$ in Figures 9 and 10 respectively. The Wilcoxon matched-pairs signed rank test, which was used initially to assess the difference in total fluid intake in the two beverage conditions, indicated a significantly greater intake after alcohol than after placebo $(T \neq 22$, $d f=j 6, p<.01$ for one-tailed test).

A three-factor analysis of variance was also performed after a $F_{\max }$ test of the transformed data had indicated that the variances were homogeneous $\left(F_{\max }(22,15)=3.548\right)$. Consistent with the resuits of the nonparametric test, this analysis indicated that fluid intake after alcohol was significantly greater than after placebo $(F(1,14)=7.614$, p<.015). There was, in addition, a significant, effect for periods ( $F(10,140)=15.407, p<.0001)$ indicating that the fluctuations in fluid 
61

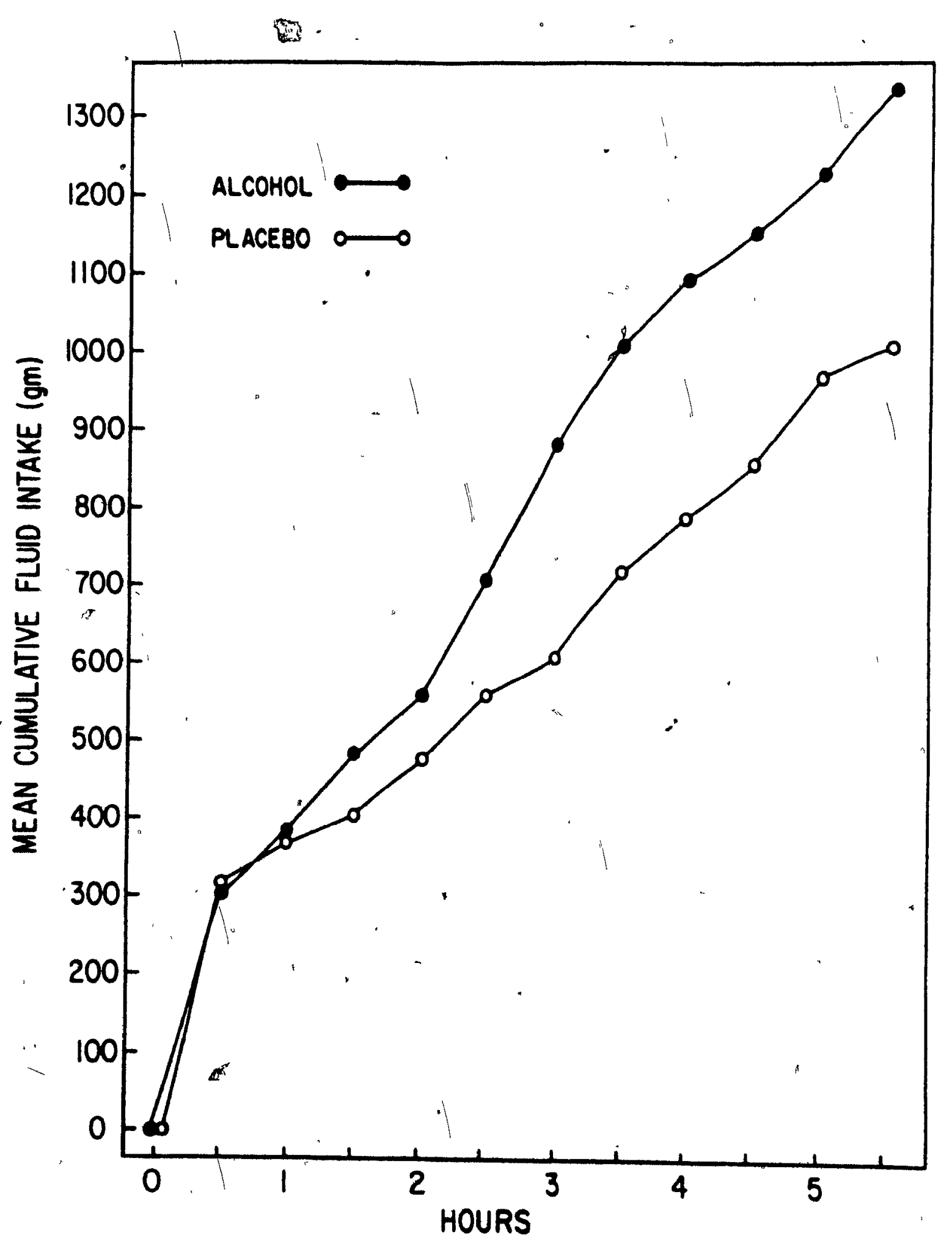

Fig. 10. Cumulative fluid intake of alcoholics at 30 -minute intervals following the administration of alcohol and placebo in Study 2. 
intake during the ad lib drinking period are statistically significant. Although the greatest differences in intake between the two beverage conditions clearly occurred between 2.5 and 3.5 hours after the beginning of ad lib drinking, the beverage $x$ trial interaction was not significant.

Fluid balance. As in study 1 , fluid balance was calculated by deducting each subject's total urine output, during the 2.5-hour interval after the administration of the beverages from the volume of his beverage. After alcohol, 11 of the 16 alcoholic subjects had a negative fluid balance $($ mean $=-198.688 \mathrm{~m} 1$ ) whereas after placebo, thirteen had a positive fluid balance (mean $=+198.313)$. This difference in mean fluid balance between the two beverage conditions is highly significant $(t=6.90, \mathrm{df}=15, \mathrm{p} \times .001$, two-tailed test). Self-ratings of thirst, dry mouth and craving. The ratings of thirst, dry mouth and craving were analyzedusing three sign tests which compared the responses in the two beverage conditions at each administration of the rating-scales. None of the comparisons, however, proved to be significant. Thus, despite their significantly greater fluid intake after alcohol, the alcoholic subjects did not discriminate on any of these subjective dimensions between the two beverage conditions.

To assess the relationships among these self-ratings, correlations were computed among them at each administration of the rating scales in both beverage conditions. Not unexpectedly, a strong relationship was observed between the ratings of thirst and dry mouth. Phi . coefficients for these ratings were significant after both alcohol and placebo, the highest in-each condition occupring during the second 
administration of the scales $(\phi=.733, p<.01$ and $\phi=.832, p<.001$ respectively). In contrast, there was no significant relationship between craving and either of the other dimensions at any point during the study.

Self-ratings and fluid intake. The relationships among fluid intake and the self-ratings of thirst, dry mouth and craving were assessed by computing correlations for the ratings on each of the three administrations of the scales with subjects' cumulative fluid intake at each period during each of the two sessions. As in study 1 , responsés which indicated the absence of thirst or dryness were assigned a value of zero and those which indicated their presence, to any degree, were assigned a value of one. The craving scores, which were obtained using a continum were not transformed.

In both the alcohol and-the placebo conditions, ratings of dry mouth obtained prior to the administration of the beverages correlated significantly with later ad lib intake. Ratings of dry mouth obtained before the alcoholic beverage was consumed correlated significantly with cumulative fluid intake throughout the ad lib drinking period, the highest correlation occurring after 2 hours $\left(r_{\mathrm{pbi}}=.553\right.$, $t=2.483, d f=14, p<.05$, two-tailed test). In the placebo condition, initial ratings of dry mouth correlated significantly with intake during the latter 4 hours of ad lib intake, the highest correlation occurring after 4 hours $\left(r_{\text {pbi }}=.525, t=2.308, \mathrm{df}=14, \mathrm{p}<.05\right.$, twotailed test). Subjects who indicated initially that their mouths were dry subsequeht ly drank more than the o'thers.

The only other significant correlations were in the placebo condition, between the rating of dry mouth obtained on the second 
administration of the scales and,both 30 -minute and 60 -minute intake $\left(r_{\mathrm{pbi}}=.50, t=2.160, \mathrm{df}=14, \mathrm{p}<.025\right.$, one-tailed test and $r_{\mathrm{pbi}}=$ $.463, t=1.954, \mathrm{df}=14, p<.05$, one-tailed test, respectively).

Although there was no comparable relationshịp between dry mouth and intake after alcohol, the correlation between ratings of craving obtained on the second administration of the scales and/intake during the first half-hour after alcohol approached significance $(r=\| .460$, $d f=15, p=.07$, two-tailed test). Thus, reports of dry mouth after placebo and craving after alcohol were both associated with greater subsequent ad $1 \mathrm{ib}$ drinking.

Fluid intake and physiological effects of prior beverage administration. To determine what physiological processes may have mediated the dipsogenic effect of alcohol, correlations were computed between cumulative fluid intake at each half-hour of the ad lib drinking period in both beverage conditions and each of the following measures: peak 8AL, blood alcohol elimination time, mean urine specific gravity, peak urine output (for a 30 -minute period) and fluid balance. Three of these measures correlated significaritly with fluid intake. The strongest relationship was with fluid balance. In fact, fluid balance was significantly correlated with cumulative fluid intake at every interval throughout the ad lib drinking period after both alcohol and placebo. In the alcohol condition, the correlation between fluid balance and fluid intake increased during the course of ad lib drinking, reaching its maximum after 4 hours $(r=-.775$, df $=14$, pr.0005, one-tailed tést). After placebo, the highest correlation with fluid balance was not observed until 3 hours after the start of 
ad lib drinking $(r=-.631$, df $=14, p<.005$, one-tailed test).

Subjects with the lowest fluid balance levels after both beverages subsequently drank significantly more than those with higher fluid balance levels.

A very strong relationship was also demonstrated between fluid intake and peak urine output. Fluid intake at every interval after alcohol and from the first hour of ad lib drinking after placebo was significantly correlated with peak urine output. The correlations in both beverage conditions increased over time and reached their maximum values after 5 hours of ad lib intake in the alconol condition $(r=.758, d f=14, p<.0005$, one-tailed test $)$ and after 3 houfs in the placebo condition $(r=.513$, df $=14, p<.025$, one-tailed test). After both beverages, subjects with the highest rates of urine output drank significantly more than those with lower rates of urine output.

The association between fluid intake and mean urine specific gravity, though weaker, showed similar time course. In both beverage conditions the correlation between these variables was significant only during the latter half of the ad lib drinking period. The highest correlations were obtained after 3 hours of ad 1 ib drinking in the alcohol condition $\left(r=-.466, d f^{\prime}=14, p<.05\right.$, one-tailed test) and after 4 hours in the placébo condition $(r=-.498$, df $=14$, $p<.025$, one-tailed test). Subjects with the lowest mean urine specific gravities subsequently drank significantly more in both beverage conditions than those with higher mean urine specific gravities.

There is also some evidence that both blood alcohol elimination time and peak blood alcohol level are associated wi th fluid intake. 
At four points during the ad lib drinking period the correlations between blood alcohol elimination time and cumulative fluid intake approached significance, the highest occurring after 2.5 hours $(r=-.469, \mathrm{df}=14, .10>p>.05$, two-tailed test $)$. The correlations Iwith peak blood alcohol level approached significance twice, during the interval between one and 1.5 hours after ad lib drinking began (the higher $r=-.462, d f=14, .10 \times p>.05$, two-tailed test). At these times, the cumulative fluid intake of subjects with the highest peak blood alcohol levels and the longest blood alcohol elimination imes tended to drink less than the other subjects.

These results strongly suggest that the dipsogenic effect of alcohol in alcoholic subjects is mediated by its effects on fluid and electralyte metabolism. More specifically, it lappears that changes in rate of urine output, urine specific gravity and in fluid balance rolsulting from prior beverage administration contribute to the differences in fluid intake between the alcohol and placebo conditions. Fluid intake after alcohol axso appears to be inversely related to blood alcohol elimination time and peak blood alcohol level. Discussion.

The results obtained in study 2 largely replicated the findings of the previous study. As in study 1, fluid intake and urine output were significantly greater and urine specific gravity significantly less after alcohol than after placebo. The studies differ, however, in terms of the period during which alcohol exerted its maximal dipsogenic effect. In study 1 fluid intake was significantly greater after alcohol ntake only during the first 1.5 hours of ad lib drinking, 
whereas in Study 2 the greatest increase in fluid intake occurred between 2.5 and 3.5 hours after alcohol ingestion. This difference between the studies, moreover, is statistically significant. Groups $x$ periods ANOVAs in which the fluid intake data of the two studies were compared in each beverage condition revealed a significant groups $\times$ periods interaction in the alcohol condition $(F(10,280)=$ $3.094, p^{<.0015)}$. The studies also differed in that thirst ratings after alcohol intake in Study 1 were significantly greater than ratings after placebo, and significantly correlated with subsequent fluid intake. In contrast, self-ratings of thirst in Study 2 were unaffected by the administration of alcohol and were unrelated to subsequent drinking behavior. The only post-ingestion ratings which correlated highly with subsequent fluid intake in Study 2 were ratings of dry mouth after placebo and ratings of craving after alcohol. These differences in the behavioral and subjective measures between the two studies are all the more curious in view of the similarity between them in terms of the physiological measures.

While such comparisons of the results obtained in studies 1 and 2 may be instructive, all differences between them must, of courše, be interpreted with caution since subjects in the studies differed I in at least two respects: those in Study 1 habitually consumed much less beverage alcohol; and they were younger than those who participated in Study 2. Differences between these groups, therefore, may be a function of factors relating to drinking habits or to age, or to both. To assess more fully the extent to which physiological factors may have contributed to the different results obtained in these two 
studies, additional analyses of the combined data from both groups. were conducted on each of the physiological measures. (Tables for the ANOVAs to be reported in this section can be found in Appendix $J$. ) These analyses included separate groups $x$ periogs ANOVAs on urine output and urine specific gravity for each beverage condition, a . group $x$ beverage ANOVA on fluid balance-and' a groups $x$ periods ANOVA on BAL after alcohol ingestion. The latter analysis included only data from the first 5.5 hours, however, because a majority of subjects had zero BALs during the last two measures. No significant differences between the groups were found in either beverage condition in terms of urine output, urine specific gravity or fluid balance. The groups differed only in their BALs, a significant groups $x$ periods interaction $(F(10,280)=5.213, p<.0001)$ indicating that subjects in Stud 2 had a greater rate of blood alcohol elimination than those in Study 1 .

Unfortunately, because of the absence of research in this area, no conclusive statement can be made regarding the contribution of age-related factors to the difference between the studies in the latency of alcohol's dipsogenic effect. Although it is assumed that patterns of rehydration become established during early development (Adolph, 1964), the only indication that they vary with age is in the clinical literature where a distinction is made between water and electrolyte homeostasis in infants and in the elderly (Bland, 1963). In view of the facts that the subjects in both studies were adults, and that recognition of differences in rehydration patterns is given only to those at the extremes of the age continuum, it would appear 
unlikely that the delayed occurrence of alcohol's dipsogenic effect in Study 2 is due simply to the fact that the subjęcts were older than those in Study 1 .

Another explanation is that subjects in Study 2 were overhydrated in comparison with those in study 1 prior to the administration of alcohol and that, as a consequence, it was longer before alcohol produced critical levels of cellular dehydration. A comparison of the groups in terms of their control urine specimens in the alcohol. condition lends some support to this hypothesis. Although the control urine specific gravities of the two groups were almost identical, control urine output was considerably greater in study 2 , suggesting that these subjects were in a state of isosmotic overhydration prior to the administration of alcohol. Moreover, in Study 2, there was a high positive correlation between control urine output and latency to maximal fluid intake after alcohol $(r=.44$, df $=14, .05<p<.10)$. The delayed effect of alcohol on fluid intake in Study 2, therefore, may have been due to the subjects' relatively greater body fiuid volumes.

It should be noted; however, that the difference between the studies in terms of control urine output in the alcohol condition cannot be attributed to subject factors since there was no comparable difference between the groups in the placebo condition. Nor is it likely that the greater control urine output reflects a failure to observe the preceding 8 -hour restriction on fluid intake, since the subjects in both studies produced a concentrated urine. A possible explanation would appear to be that subjects in Study 2 ate and drank 
more, or simply later, on the day prior to the administration of alcohol than did subjects in Study 1 .

It is also possible that the delayed effect of alcohol on fluid intake in study $\not 2$ is due to a differential sensitivity of the two groups to thirst-provoking stimuli. If it is assumed that the physiological state underlying alcohol's dipsogenic effect intensifies, with the passage of time, then the delayed effect may reflect a relative insensitivity of the subjects in Study 2 to internal stimuli associated with thirst. Previous research has indicated that alcoholics are less responsive than nonalcoholics to the internal stimuli associated with fluid deprivation and pre-loading (Brown \& Williams, 1975). Thus, al though no firm conclusion can be reached regarding the difference between the groups in their patterns of fluid intake after alcohol, the notion that alcoholics are slow to recognize and to respond appropriately to a physiological state of dehydration produced by acute alcohol consumption would appear to warrant further investigation. It is also noteworthy that this account is consistent with the hypothesis regarding the possible mislabelling of thirst in the LOC phenomenon.

As suggested above, the absence of an effect of alcohol on the thirst ratings of the subjects in study 2 may we 11 be related to its. delayed effect on their fluid intake. Thirst ratings in the first study were significantly greater only on the first post-ingestion administration of the rating scales in the alcohol condition. Since the ad lib drinking period began almost immediately afterward, selfratings of thirst in that study practically coincided with the 
maximal effect of alcohol on fluid intake. Subjects in the second study, in contrast, experienced the maximal dipsogenic effect of al cohol approximately 3 hours after completing the ratings. The absence of an effect for this group, therefore, may have resulted from a failure to obtain thirst ratings when the dipsogenic effect of alcohol was greatest.

It is also possible that alcohol consumption did not affect 'subjects' perception of thirst in study 2 at Bny time during the session. If this were confirmed it would indicate an obvious difference between the subjects in the two studies. Unfortunately, a lack of résearch in this area precludes any definitive statement regarding the extent to which this difference can be attributed to s.'

age-related factors. However, to the extent that recognition has ubeen given to differences in thirst only among three broad age groups, children," adults, and the aged (Wolf, 1958), it would appear unlikely that the absence of an effect on thirst in study 2 was due merely to the fact that subjects were, on the average; 14 years oflder than those in Study, 1.

There is, on the other hand, some evidence to suggest that this difference between the groups is related to differences in their z" drinking histories. Brown-and Williams (1975) have shown that alcoholics, in contrast to age-matched nonalcoholics, drank as much of a nonalcohọlic beveràge after foluid pre-loading as after fluid deprivation. Although thirst ratings wëre not obtained in their study, it is reasonable to assyme that the observed difference in fluid intake reflects a difference in the perception of thirst between 
alcoholics and nond lcoholics. Consistent with, this interpretation is the finding that thirst ratings obtained after the administration of alcohol correlated significantly with subsequent fluid intake in r Study 1, but not in Study 2. Thus, itwould appear that the absence of an effect of alcohol on thirst in study 2 may have resutted from the subjects' failure to recognize an internal state which is ordinarily associated with thirst.

The finding that alcohol did not affect the self-ratings of craving is consistent with the findings of several previous investigators who failed to observe a significant, effect of lesser dosages of alcohol on measures óf craving, alcohol acquisition and alcohot $+$ consumption fengle E Williams, 1972; Cutter et a1., 1970; Marlatt et a1., 1973). It is noteworthy, however, that the present findings are at variance with several investigations which employed dosages greater : than 1 oz. of 1iquor (Mérry, 1966; Cohen et al., 1971; Ludwig et a $1 .$, 1974; Bigelow et a1., 1977; Funderburk \& Allen; 1977). Although the subjects' ability to distinguish between alcoholic and nonalcoholic preloading beverages likely contributed to the positive findings in these latter studies, they do suggest that prevfous negative findings are the result of a strictly literal interpretation of the axiom "one drink, one drunk;" and that larger amounts of a tcotol do indeed increase craving in alcoholics. The results pf the present, study, however, suggest that the consumption of a moderate amount of alcohol" alone is insufficient to produce a significant increase in the perception of éraving in alcoholics./ 
Three explanations can be offered to account for the discrepancy between the findings of the present study and those in which alcohol was shown to inctease craving. The placebo in the present study, for example, may have been more successful in controlling for cognitive factors dssociated with drinking than the control beverages employed in other studies. This possibility would appear to be unilkely in view of the similarity between the present study and that by Bigelow and his colfeagues (1977) in terms of the subjects' ability to discriminate between the preloading beverages. Unfortunately, further comparisons cannot be made with each of the other studies because most investigators failed to evaluate the effectiveness of their " control beyerages.

It is also posstble that alcohol had a significant but transitory effect on craving in the present study, and that it was limited to the interval between successive ratings. Unfortunately, none of the research indicating that alcohol ingestion increases craving has fully explored the temporal parameters of this apparent effect. In a reanalysis of the study by Engle and Williams (1972), however, . Maisto, Lauermen and Adesso (1977) found no reduction in craving during the interval between 40 minutes and three hours after initial drinking among the alcoholics who were instructed that their preloading beverage contained alcohol. It was suggested on the basis of this finding that the desire for alcohol among alcoholics maxpersist for a considerable period of time aftex initial drinking. It is noteworthy also that the traditional concept of LOC includes reference to a physical need for alkpol which persists for ".. 
a.

hours or weeks...until the drinker is too intoxicated or sick to ingest more alcohol" ( Jellinek, 1952, p. 679). Thus, it would appear unlikely that alcohol thad a significant effect on craving at any time during Study 2 , for the available research and clinical evidence suggests that such an effect, had it occurred, would have been evident at the end of the session when the last ratings of craving were obtained.

The most obvious difference between the present stugy and those. in which alcohol consumption appeared to increase eitbler craving or its behavioral manifestations concerns the availability of alcoholic beverages and exposure to alcohol-related stimuli following administration of the preloading beverages. Subjects in the present study knew that additional alcohol would not be avaijable after they consumed the preloading beverages and were not subsequent ly exposed to external alcoho-related stimuli. Subjects iniall but one of the other studies, however, not only anticipated the availability of additional alcohol, but they also saw it being dispensed. Both of these factors, foreknowledge of alcohol availability and external alcohol-related stimuli, have been shown in previous studies to be significant i determinants of the disposition to drink in alcoholics (Funderbúrk' \& Allen, 1977; Ludwig et al., 1974). Thus, it would appear that the absence 'of an effect of alcohol on craving in the present study may well have been due to the fact that cognitive and environmental factors were incons"istent with continued alcohol consumption. To this extent, findings of the present study support the hypothesis first proposed by Ludwig and Wikipr (1974) that craving is the result of cognitive 
labelling processes which are determined by both pharmacological and environmental factors.

The on ly post-ingestion physiological measure which differs. between Studies 1 and 2 is the rate of blood alcohol elimination, the rate being significantly greater in the second study. The fact that different instruments were used to estimate BALs in the two studies is unlikely to account for the difference in elimination rates since validation studies with direct blood analysis using comparable instruments have not revealed systematic sources of error consistent with these findings (Breen, Siler \& Pearce, 1975; Coldwell \& Smith, 1959). Nor can the different elimination rates be attributed to the relative obesity of one of the groups since there was no significant difference between them $(t<1$, df $=28)$ in terms of their mean deviations from ideal weight as determined by the formula proposed by Davidson (1976). Although the possibility cannot be conclusively ruled out that the age difference betweer, the subjects in the two studies contributed to the difference in elimination rates, it would appear to be highly unlikely. The rate of alcohol metabolism does not change in the aged (Kurzinger, 1963) nor has there been any reference. to the effects of age in reviews or in other investigations of the rate of alcohol metabolism in which subjects' ages varied moré widely (Coldiwe11 \& Smith, 1959; Bonnichsen, Dimberg \& Sjöberg, 1964; Lester, 1966; and Wallgren \& Barry, 1970). The fifetor most likely to account for this discrepancy would appear to be the drinking histories of the subjects in study 2 , since chronic excessive alcohol ingestion is known to result in an enhancement of ethanol metabolism (Mendelsón, Stein \& Me110, 1965). 
Although fluid int ake after alcohol in both studies correlated significantly with Previous measures of fluid balance and urine specific gravity, there were, in addition, significant positive correlations with peak BAL in Study 1 and with peak urine output in Study 2. While not significant in Study 1 , the correlation between peak urine output and fluid intake approached significance in this study during the first 30 minutes of ad $1 \mathrm{ib}$ drinking. The fact that it was significant only in study 2 is largely attributable to the higher correlation between peak urine output and fluid balance in the second study $(r=-.919, d f=14, p<.0001)$ than in the first $(r=-.817$, $d f=12, p<.0006)$

The correlations between cumulative fluid intake and peak BAL, however, are very different in the two studies. While there was a significant positive correlation between these variables in Study 1 , there was a nonsignificant negative correlation between them in study 2. The explanation for this difference, moreover, is unclear. None of the physiological effects' of alcohol differed between the studies, nor are there any significant differences between them in terms of the intercorrerations, among the physiological measures. The only effect of alcohol which distinguished between the studies and which could account for the different correftions is the latency of alcohol's maximal dipsogenic effect. The significant positive correlation between fluid intake and peak BAL in Study 1 occurred after 1.5 hours of ad lib drinking, during which the effects of alcohol on fluid intake were greatest. Although the two high negative correlations observed in study 2 occurred at approximately the same time during the , 
ad lib drinking period, in this study they preceded the maximal effect of alcohol on fluid intake. The different correlations between

: cumulative fluid intake and peak BAL in the two studies, therefore, may simply due to the difference in the latency of alcohol's. maximal dipsogenic effect?

77

$\phi$ 


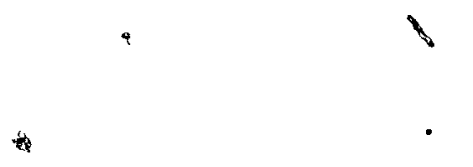

General Discussion

The results of the present studies confirm the first assumption proposed in the introduction and aprovide at least limited support for the second. Within relatively short period after consuming a moderate amount of beverage alcohol, both alcoholic and nonalcoholic subjects significantly increased their fluid intake. The finding that alcohol consumption significantly increased self-ratings of thirst in the first, but hot in the second study appears to reflect a difference between alcoholics and nonalcoholics in terms of their perception of internal states associated with thirst. This interpretation, furthermore, is consistent with the assumption that alcoholics in naturalistic drinking settings can misperceive alcohol-induced dehydration as craving. Moreover, the finding that craving was not affected in a laboratory setting, even by a moderate amount of alcohol, provides further empirical support for the critical role of cognitive and environmental factors in LOC.

In addition to ageneral investigation of the dose-response relationship between alcohol consumption and subsequent thirst and fluid intake, two related questions remain to be answered to dotermine the relevance of the prasent findings for the LOC phenomenon. The first is whether the alcohol administration procedur used in the present studies would increase ilcohollcs' craving and-subsequent alcohol consumption if the subjects wore at the sane time exposed to the stimuli typical of naturalistic drinking settings and were permitted ad lib access to beverage al cohol. The second question is whether 
such craving and ad lib al cohol consumption are related to the physiological indicies found in the present studies to be predictive of fluid intake after inftial alcohol ingestion.

In addition to the previous discussion of the likely contribution of alcohol availability to the enhancement of craving following initial alcohol consumption,"there is other evidence that the first question will eventually be answered in the affirmative. Two experimental studies have investigated the effect of external, alcohol. related stimuli on alcohol consumption in alcoholics. In one study, subjects had previously been adninistered a placebo or a beverage containing either $0.6 \mathrm{ml} / \mathrm{kg}$ or $1.2 \mathrm{ml} / \mathrm{kg}$ absolute ethanol (Ludwig et a1., 1974); in the other study subjects/had not been administered a preloading beverage (Miller, Hersen, Eisiler, Epstein \& Wooten, 1974).. Contrary to their prediction, Miller and his colleagues failed to observe any significant effect of alcohol-related stimuli amoñ their alcoholic subjects. As mentioned previpusly, however, Ludwig and his colleagúes, not only reported significant effects for preload beverage and stimulus condition, but they also reported an interaction between these factors such that measures of craving and alcohol. acquisition were greatest among those who received an alcohol preload in the presence of alcohol-related stimull. This latter finding would appear to account for therdifference between these two studies in the observed effect of alcohol-related stimuli. Since none of the subjects in the study by Miller's group had been adninistered an alcoholic beverage, the effeat of different environmental conditions was prabably minimized. This interpretation, furthermore, is not oniy. 
consistent with the assumptions of the proposed model of LOC, it is also in agreement with the findings of Pliner \& Cappel1 (1974) who have suggested that alcohol "induces a state of plasticity in which the organism responds more strongly than usual to the prevailing cognitive and social environment" ( $p .418)$.

In addtition to the experimental findings, there is support of a more, elinical nature for, the influential role of environmental factors in the LOC phenomenon. In a survey of alcoholics' craving experiences, .. + for example, Ludwig \& Stark (1974) found that environmentalsstimuli relevant to drinking situations substantially increased the craving for alchol in 20\% of their subjects. In addition, Glatt (1967), in discussing moderate drinking among former alcoholics, indicated that such environmental factors as the drinking setting and drinking 'companions appeared to be related to the alcoholic's inability to control his alcohol consumption once he had begun to drink.

Even' if it can be assumed that the preloading procedure employed in the present study would, under different stimulus conditions, result in increased craving and alcohol consumption, verification of the proposed model of LOC would also require that these effects be 'correlated with alcohol-induced changes in fluid and electrolyte balance. There is, unfortunately, no previous research that relates directly to this question.' In fact, there have been no previous invertigations of the relationship between the drinking behavior of alcoholics and any antecedent physiological measure other than BAL.

The only evidence which supports this hypothesis consists of two studies in which mẹasures of fluid and electrolyte balance were 
related in the first case to alcohol consumption in animals and, in the second, to craving in alcoholics. Baisset and Montastruc (1962) found in dogs that when the increases in urine output and fluid intake caused by chronic alcohol administration were prevented by concurrent administration of vasopressin, subsequent ad lib alcohol consumption was also much reduced. Although this study suffers from several methodological shortcomings, these findings are at least suggestive that chronic alcohol consumption, by virtue of its effect on fluid and electrolyte balance, can increase subsequent alcohol self-administration in dogs. To the extent that these findings can be generalized to the acute administration of alcahat to alcoholics, they support the untested assumption that alcohol-induced changes in fluid and electrolyte balance càn result in a subsequent increase in alcohol lconsumption.

As indicated previously, Silkworth and Texon (1950) found that alcoholics who complain of craving on admission to hospital have significantly lower blood chloride levels than alcoholics who do not. Since the reduced serum chloripe levels were attributed to the subjects' previous excessive alcohol consumption, these findings support the hypothesis that craving is related to an alcohol-induced imbalance in fluid and electrolyte levels. Although it is recognized that decreased electroplyte concentration produced be chronic alcohol -ingestion is the physiological converse of.electrolyte retention, the apparent result of acute alcohol administration in the present studies, these imbalances are comparable to the extent that both are ordinarily associated wi th the subjective state of thirst (Wolf, 
(1958). Thus, Silkworth and Texon's findings not only suggest a relationship between craving and the effects of alcohol on fluid and exectrolyte metabolism, they also indicate that a physiological state typically associated with thirst can be perceived by alcoholics as a craving for alcohol.

A comprehensive model of $L P C$ must also account for the fact's that the phenomenon occurs oniy among those who have chronically abused alcohol and that it is characterized as leading inevitably to gross intoxication. Although́ psychological factors undoubtedly play an important role in these as in all features of LOC, it appears likely that alcohol-induced changes in fluid and electrolyte metabolism may also be relevant. Acute alcohol administration has been shown to result in a significantly greater diuresis anong alcoholics than among| nonalcoholics of comparable age (Ogata, 1963; Kissin, Schenker "E Schenker, 1964). This difference, moreover, has peen attributed to the groups' different drinking histories. Thus, to the lextent that chronic excessive alcohol consumption enhance) those physiological effects which are produced by acute alcohol consumption and which . have been shown in the present studies to be predictive of subsequent fluid intake, the drinking behavior of alcoholics will be more greatly affected by moderate amount of alcohol than the drinking behavior of nonalcoholics.

Whether alcoholics are more inclined than nonalcoholics to mis label al cohol-induced changes in fluid and electrolyte balance remains to be demonstrated. There is, however, some data to suggest that these groups differ significantly in their perception of both 
internal and external events. Consistent with the previous discussion of the importance for alcoholics of external, alcohol-related stimuli in the perception of craving for alcohol, there are several studies which indicate that alcoholics are more'field-dependent than nonal coholics (Chess, Neuringer \& Goldstein, 1971; Jacobson, 1968; Witkin, Karp \& Goodenough, 1959). Moreover, it has been suggested that those who are highly field-dependent may be characterized by an excessive reliance upon external cues for the definition and identification of internal feelings and sensations (Witkin, 1965). More recent research, furthermore, has shown that alcoholics, in contrast to nonalcoholics, fail to show any improvement in their BAL estimation accuracy as a function of discrimination training techniques which focus upon internal affective and physiological concomitants of moderate degrees of alcohol intoxication (Lansky, Nathan $\&$ Lawson, Note 1). To the extent that these findings indicate that alcoholics are relatively unable to recognize the internal physiological events which are assocjated with moderate intoxication and that they are excessively dependent upon external environmental stimuli for the identification of internal states, they support/the notion that alcoholics are more, likely to perceive a physiological imbalance resulting from acute alcohol ingeftion in terms of prevailing environmental stimuli.

Alcohol-induced changes in fluid and electrolyte balance may also account for the fact that LOC is typiçlly characterized as leading to gross intoxication. Although it has been demonstrated that the diuresis propduced by initial alcohol consumption is not sustained, by repeated ingestion (Eggleton, 1942; Ogata, Mendel'spn \& Mello, 1968), 
serum osmolality and serum sodium concentration in alcoholics with ad lib access to alcohol show a progressive increase with increasing BAls (Ogata et al., 1968). It is reasonable to suppose, furthermore, that these alterations in turn result in an osmotic shift of body fluid from the intracellular to the extracellular fluid compartments. If this is indeed the case, and if Flynn (1958) and Lolli and his colleagues (1944) are correct in concluding that alcohol increases thirst and fluid intake by dehydring the intracellular fluid compartment, then continued alcohol self-administration would increase further the physiological imbalance produced by initial, alcohol consumption. Thus, to the extent that the alcoholic's continued alcohol consumption is a function of the same physiological processes which apparently controlled fluid intake in the present studies, its. rate would accelerate and presumably result in gross intoxication." :

Although the effect of increased serum osmalality and serum sodium concentration on continued alcohol consumption remains to be explored, there is some exidence to suggest that increased BALs contribute to $L O C$. It is widely recognized among clinicians, for example, that alcoholics typically resort to beverages containing à lower, concentration of alcohol when attempting to moderate their drinking (Glatt, 1967). This strategy would not only result in lower BALs during a drinking epispde; but would al so serve to minimize thirst stimuli presumably associated wi th increased serum osmolality. From an epideniological viewpoint, it has been noted that the prevalence of LOC is lower:among the alcoholics of predominantly wine- and beer-drinking countries than it is mong thosp living in 
countries where distilled spirits are the most preferred alcoholic bevérages (Jellinek, 1960). This observation, clearly, is also suggestive of a positive relationship between $B A L$ and continued alcohol self-administration.

It is clear from the preceding discussion that many assumptions aremain to be tested before the contribution of alcohol's dipsogenic properties to LOC can be adequately evaluated. The findings of Studies 1 and 2, while provocative, confirm only one of two basic 1 assumptions proposed at the outset--that alcohol has a dipsogenic effect wi thin a short period after it is consumed. In relating this finding to the LOC phenomenon, a theoretical model was developed which attempts to integrate the diverse findings of clinical/social psychology and physiology. Although it remains to be demonstrated that alcoholics mislabel as craving the physiological state of dehydration produced by moderate alcohol consumption, the model emphasizes the possibility that both fluid and electrolyte metabolism and cognitive labelling processes contribute to the craving and alcohol consumption which often follow initial alcohol self-administration in alcoholics. Because of the paucity of research relating these areas of investigation, however, the proposed model is only very loosely integrated and its primary value, therefore, will be heuristic. However, to the extent that it identifies the potential relevance of physiological states associated with thirst for the behavioral problems of alcohol abuse, it points the way to new and promising avenues for clinical research. 
1

c

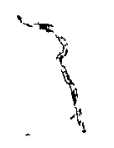

$\therefore$

86

1. Lanky, D., Nathan, P. E., \& Lawson, D. M. Blood alcohol level

- discrimination by alcoholics: the role of internal and external cues. Manuscript submitted for publication, 1977.

$=$

II

4

Note 


\section{References}

Adolph, E. F. Regulation of body water content, through water ingestion. In M. J. Wayner (Ed.), Thirst. New York: Macmil1an, 1964.

Alcoholics Anonymous. Alcoholics Anonymous. New York: Works Publishing, 1944 .

Allman, L. R., Taylor, H. A. E Nathan, P. E. Group drinking during a stress: Effects on drinking behavior, affect and psychopathology. American Journal of Psychiatry, 1972, $129(6), 669-678$.

Baisset, A. \& Montastruc, P. Inhibition par la vasopressine de la soif provoquée par ingestion d'alcool. Comptes Rendus des Seances de la Société de Biologie et des Ses Filiales, 1961, 155, 1128-1132.

Baisset, A. E Montastruc, P. Effet de l'hormone antidiurétique sur la soif consécutive à l'ingestion d'alcool. Annales d'. Endocrinologie, $1962, \underline{23}(4), 425-429$.

Baisset, A. E Montastruc, P. Effet altérant de diverses boissons alcoolisées. Comptes Rendus Hebdomadaires des Séances de 11 Academie des Sciences, 1963, 256, 2704-2705.

Baisset, A., Montastruc, P. E Garrigues, M. Recherches sur les Tinteractions de l'alcool et de la sécrétion antidiurétique neurohypophysaire. Influence des préparations post-hypophysaires sur la soif provequée par $l^{\prime}$ ingestion d' alcool. Pathologie et Biologie, $1965,13,241-251$.

Baldie, A. Alcoholic craving. Lancet, 1931, 221, 434-436. 
Beard, J. D., Barlow, G. \& Overman, R. R. Body fluids and blood electrolytes in dogs subject to chronic ethanol administration. Journal of Pharmacological and Experiment'al Therapeutics, 1965 , $148,348-355$.

Beard, J. D. E Knott, D. H. Fluid and electnolyte balance during acute withdrawal in chronic alcoholic patients. Journal of American Medical Association, 1968, 204 (2), 135-139.

Beard, J. D. \& Knott, D. H. The effect of alcohol on fluid and electrolyte metabolism. In B. Kissin \& H. Begleiter (Eds.), The Biology of Alcoholism, Vol. 1: Biochemistry. New York: Plenum Press, 1971.

Bigelow, E., Griffiths, R. E Liebson, I. Pharmacological influences upon human ethanol self-administration. In M. M. Gross (Ed.), Alcohol intoxication and withdrawal: experimental studies (Vol. 3). New York: Plenum Press, 1977.

Bigelow, G. E. E Liebson, I. Cost factors controlling drinking. Psychological Record, 1972, 22, 305-314.

Bland, J. H. Clinical metabolism of body water and electrolytes. Philadelphia: W. B. Saunders, 1963.

Bonnichsen, R., Dimberg, R. \& Sjöberg, L. Alkoholens förbränning (oxidation of alcohol). Stockholm: Institutet för Maltdrycksforskning, 1964.

Breen, M. H., Siler, K. F, Pearce, D. S. A comparison between the gas chromatograph intoximeter and a direct blood fnalysis. In $s$. Ísraelstam \& S. Lambert (Eds.), Alcohol, Drugs, E Traffic Safety. Toronto: Addiction Research Foundation of Ontario, 1975. 
Briddell, D.W. E Wilson, G. T. The effects of alcohol and expectancy set on male sexual arousal. Journal of Abnormal Psychology, 1976. $85,225-23 \dot{4}$.

Brown, R. A. \& Williams, R. J. Internal and external cues relating to fluid intake in obese and alcoholic subjects: Journal of Abnormal Psychology, 1975, 84, 660-665.

Charlin, A., Gardien, P. \& Marty, P. Dipsomanies-données pathogéniques. Annuals Médicine-psychologie, $1946,104,38-47$.

Chess, S. B., Neuringer, C. \& Goldstein, G. Arousal and field dependency in alcoholics. Journal of General Psychology, 1971, 85, 93-102.

Cohen, M., Liebson, I. A. \& Faillace, L. A. The role of reinforcement contingencies in chronic alcoholism: An experimental analysis of one case. Behavior Research and Therapy, 1971, 9, 375-379.

Cohen, M., Liebson, I. A., Faillace, L. A. \& Speers, W. Alcoholism: Controlled drinking and incentives for abstinence. Psychological Reports, 1971, 28, 575-580.

Coldwe11, 8. B. E Smith, H. W. Alcohol levels in body fluids after ingestion of distilled spirits. Canadian Journal of Biochemistry and Physiology, 1959, 37, 43-52.

Cutter, H. S. G., Schwaab, E. L. E Nathan, P. E. Effects of alcohol on its utility for alcoholics and nonalcoholics. Quarterly Journal of Studies on Alcohol, 1970, 21 (2), 369-378.

Davidson, J. K. Controlling diabetes mellitus with diet therapy. Postgraduate Medicine, 1976, 59, $114-122$.

Eggleton, M. G. The diuretic action of alcohol in man. Journal of. Physiology, 1942, 101, 172-191. 
Elhardt, W. E. Effect of ethyl alcohol on the growth of chicks: American Journal of Physiology, 1930, 92, 450-452.

Engle, K. B. \& Williams, T.K. Effect of an ounce of vodka on alcoholics' desire for alcohol. Quarterly Journal of Studies on Al cohol, 1972, 33, 1099-1105.

Fitzsimons, J."T. Thirst. Physiological Reviews, 1972, 52 (2), 468-561. Flynn, P. A. Water and electrolyte balance after a,lcohol ingestion. Unpublished doctoral dissertation, Yale University School of Medicine, 1958.

Funderburk, F. R. E Allèn, R. P. Alcoholics' disposition to drink; effects of abstinence and heavy drinking. Journal of studies on Alcoho1, $1977,410-425$.

Glatt, M. M. The question of moderate drinking despite "loss of contro1." British Journal of Addiction, 1967, 62, 267-274. Got thei 1, E., Corbett, L. O., Grasberger, J. C. E Cornelison, F. S. Treating the alcoholic in the presence of alcohol. American Journal of Psychiatry, 1971,128 (4), 475-480.

Gwinup, G., Chelvam, R., Jabola, R. \& Meister, L. Beer drinker's hyponatremia--Inappropriate concentration of the urine during ingestion of beer. California Medicine, 1972, 116, 78-81. Haggard, H. W., Greenberg, L. A. \& Carro11, R. P. Studies on the absorption, distribution, and elimination of alcohol. VIII. The diuresis from alcohol and its influence on the elimination of alcohol in the urine. Journal of Pharmacological and Experimental Therapeutics, $1941,21,349-357$. 
Hore, B. D. Craving for alcohol. British Journal of Addiction, $1974,69,137-140$.

Jacobson, G. R. Reduction of fijeld dependence in chronic alcoholic subjects: Journal of Abnormal Psychology, 1968, 23, 547-549.

Jellinek, E. M. Phases in the drinking history of alcoholics.

Quarterly Journal of Studies on Alcohol, 1946, Z, 1-88.

Jellinek, E. M. Phases of alcohol addiction. Quarterly Journal of Studies on Alcohol, 1952, 13, 673-684.

Jellinek, E. M. The disease concept of alcoholism. Highland Park, N.J.: Hilfhouse Press, 1960.

Keller, $M$. On the loss-of-control phenomenon in alcoholism. British Journal of Addiction, $1972,67,153-166$.

Keller; M. \& McCormick, M. A dictionary of words ábout alcohol. New Brunswick, N.J.: Rutgers Center of Alcohol Studiés, 1968. - Kissin̈, B., Schenker, V. J. E Schenker, A. C. Hyperdiures is after ethanol in chronic alcoholics. The American Journal of the Medical Sciences, $248,660-669,1964$. Knott, D. H. \& Beard, J. D. A diuretic approach to acute withdrawal a from alcohol. Southern Medical Journal, 1969, 62, 485-489. Kurzinger, R. (Metabolism of alcohotin old persons) Der Alkoholabbau bei alten Menschen. Deutsche Gesundheitsw, 1963, 18, 1224-1230.t.

Lemere, F. What causes alcoholism. Journal of clinical and Experimental Psychopathology, 1956, 17, 202-206. 
L

Lester, $D$. Factors influencing the metabolism and disappearance of

alcohol. In Alcohol and Traffic Safety Proceedings of the Fourth International Conference on Alcohol and Traffic Safety. Indiana University, 8 loomington, Indiana, 1966.

Lloyd, R. W. E Salzberg, H. C. Controlled social drinking: An alternative to abstinence as a treatment goal for some alcohol abusers. Psychological Bulletin, 1975, 82, 815-842.

Lolli, G., Rubin, M. \& Greenberg, L. A. The effect of ethyl alcohol on the volume of extracellular water. Quarterly Journal of Studies on Alcohol, 1944, $5,1-4$.

Ludwig, A. M. E Wikler, A. "Craving" and relapse to drink. Quarterly Journal of Studies on Alcohol, 1974, 35, 108-130.

Ludwig, A. M., Wikler, A. \& Stark, L. H. The first drink, psychobiological aspects of craving. Archives of General Psychiatry, 1974, 30, $539-547$.

Ludwig, A. M. \& Stark, L. H. Alcohol craving: Subjective and situational aspects. Quarterly Journal of Studies on Alcohol, 1974, 35, $889-905$.

Maisto, S. A., Lauerman, R. \& Adesso, V. J. A comparjison of two experimental studies of the role of cognitive factors in alcoholics' drinking. Journal of Studies on Alcohol, 1977, 145-149.

Manson; $M$. P. The Alcadd Test manual of directions and norms. Beverly Hills: Western Psychological Services, 1965. Marconj, J. T. The concept of alcoholism. Quarterly Journal of Studies on Alcohol, $1959,20,216-235$. 
Marconi, J., Poblete, M., Palestini, M., Moya, L. E Bahamondes, A. Role of the dorsomedial thalamic nucleus in "loss of control" and "inability to abstain" during ethanol ingestion. In R. E. Popham (Ed.), Alcohol and Alcoholism. Toronto: University of Toronto Press, 1970.

Marlatt, G. A., Derming, B. E Reid, J. B.' Loss of control drinking in alcoholics: An experimental analogue. Journal of Abnormal Psychology, 1973, 81, 233-241.

Mello, N. K. Behavioral studies of alcoholism. In B. Kissin \& H. Begleiter (Eds.), The Biology of Alcoholism, Vol. 2: Physiology and Behavior. New York: Plenum Press, 1971.

Mendelson,' J. H., Stein, S. E Mello, N. K. Effects of experimentally induced intoxtcation on metabolism of ethanol-1-c 14 in alcoholic subjects. Metabolism, 1965, 14, 1255-1266.

Merry, J. The "loss of control" myth. Lancet, 1966, 1, 1257-1258. Miles, W. R. The comparative concentrations olf alcohol in human blood and urine at intervals after ingestion. Journal of Pharmacological and Experimental Therapeutics, 1922, 20, 265-3.19.

Miller, P. M., Hersen, M., Eisler, R. M., Epstein, L. H. E Wooten, L. S. Relationship of alcohol cues to the drinking behavior of alcoholics and social drinkers: An analogue study. Psychological Record, 1974 , 24, $61-66$.

Murray, M. M. The diuretic action of alcohol and its relation to pituitrin. Journal of Physiology, 1932, 76, 379-386. Nathan, P.E. E O'Brien, J.S. An experimental analysis of the behavior of alcoholics and nonalcoholics during prolonged experimental $\therefore$ 
drinking: A necessary precursor of behavior therapy? Behavior Therapy, $1971,2,454-476$.

Nathan, P. E., Titler, N. A., Lowenstein, L. M., Soloman, P. E Rossi,

A. M. Behavioral analysis of chronic alcoholism. Archives of General Psychiatry, 1970, 22, $419-430$.

Ogata, M. Clinical and experimental studies on water metabolism in alcoholism. Quarterly Journal of Studies on Alcoholism, 1963, 24, $398-411$.

Ogata, M., Mendelson, J.H.E.Mello, N. K. Electrolytes and osmolality in alcoholics during experimentally induced intoxication. Psychosomatic Medicine, 1968, 30, 463-488.

Pliner, P.-E Cappeli, H. Modification of affective consequences of alcohol: A comparison of social and solitary drinking. Journal of Abnorma1 Psychology, 1974, 83, 418-425.

Ritchie, J. M. The aliphatic alcohols. In L. S. Goodman \& A. Gilman (Eds.), The pharmacological basis of therapeutics, 4th Edition. New York: Macmillan, 1970.

Roberts, K. E. Mechanism of dehydration following alcohol ingestion. Archives of Internal Medicine, 1963, 112, 154-157;

Rubini, M. E., Kleeman, C. R. E Lamdin, E. Studies on alcohol diuresis. I. The effect of ethyl alcohol ingestion on water, electrolyte and acid-base metabolism. Journal of Clinical Investigation, 1955, 34, $439-447$.

Sansweet, S. J. The punishment cure. New York: Mason/Chartier, 1975 . 
Schachter, S. The interaction of cognitive and physiological determinants of emotional state. In L. Berkowitz (Ed.)!, Advances in Experimental Social Psychology. New York: Academic Press, 1964. Schaefer, H. H., Sobe11, M. B. \& Mills, K. C. Baseline drinking behaviors in alcoholics and social drinkers. Behavior Research and Therapy, $1971,9,23-27$.

Silkworth, W. D. E Texon, M. Chloride levels in the blood of alcoholic patients in 'relation to the phenomenon of craving. Quarterly Journal of Studies on Alcohol, 1950, 11, 381-384.

Soulairac, A., Aymard, N., E Dalle, B. Étude de la diurèse chez l'alcoolique mental. La Semaine des Hopitaux de Paris, 1972, 48, $689-695$.

Strauss, M. B., Rosenbaum, J. D. E Ne1son, W. P., III. The effect of alcohol on the renal excretion of water and electrolyte. Journal of Clinical Investigation, 1955, 29, 1053-1058.

Wallgren, H. E Barry, H., III. Actions of Alcohol (Vol. 1). Amsterdam: Elsevier, 1970.

- Wallgren, H., Ahlquist, J., Ahman, K. E Suomalainen, H. Repeated alcoholic intoxication compared with continued consumption of dilute ethanol in experiments with rats on marginal diet. British Journal of Nutrition, $1967,21,643-660$. .

Wayner, M. J. Effects of ethyl alcohol on lateral hypothalmic neúrons. Annals of The New York Academy of Sciences, 1973, 215, 13-37.

Williams, R. J. The genetotrophic concept -. nutwitional deficiencies and al coholism. Annals of The New York Academy of Sciences, 1954 , 57, $794-811$. 
Williams, R. J. Biochemical individuality and cellular nutrition: Prime factors in alcoholism. Quarterly Journal of Studies on Alcohol, $1959,20,452-463$.

Williams, T.K. The ethanol-induced loss of control conçept in alcoholism (Doctoral dissertation, Western Michigan University, 1970). Dissertation Abstracts International, 1971, 31, 60738-60748. (University Microfilms No. $71-10,804$ )

Witkin, H. A. Psychological differentiation and forms of pathology. Journal of Abnormal Psychology, 1965, 20, 317-336.

Witkin, H. A., Karp, S. A. and Goodenough, D. R. Dependence in alcoholics. Quarterly Journal of Studies on Alcohol, 1959, 20, 493-504. $\rightarrow$

Wolf, A. V. Thirst--Physiology of the urge to drink and problems of water lack. Springfield, Illinois: Charles C. Thomas, 1958. World Health Organization. Alcohol and alcoholism. World Health Organization Technical Report Series, 1955, 94. 


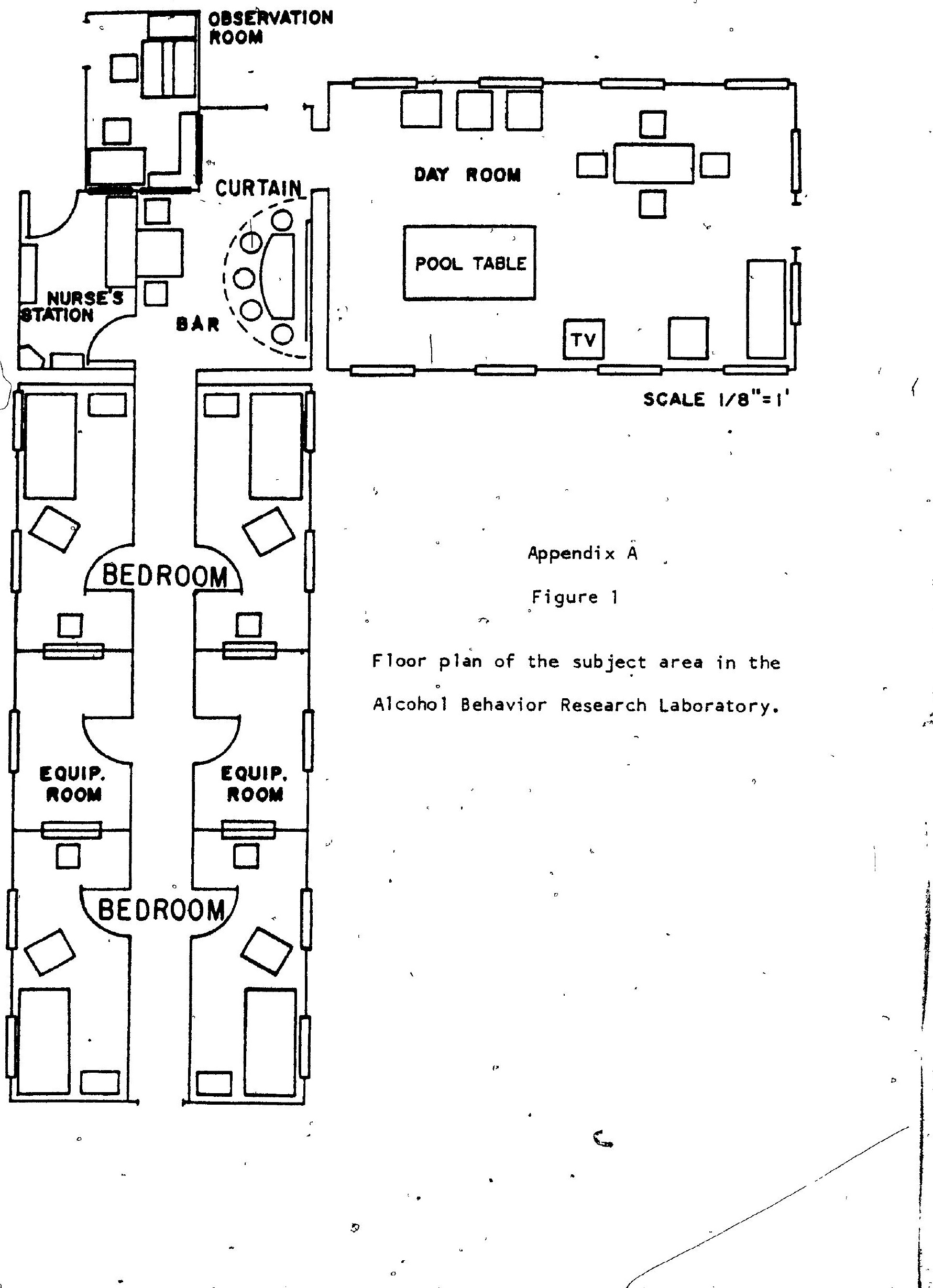




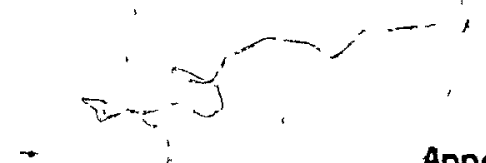

Appendix A

Table 1

Individual Subject Characteristics: ' Study 1

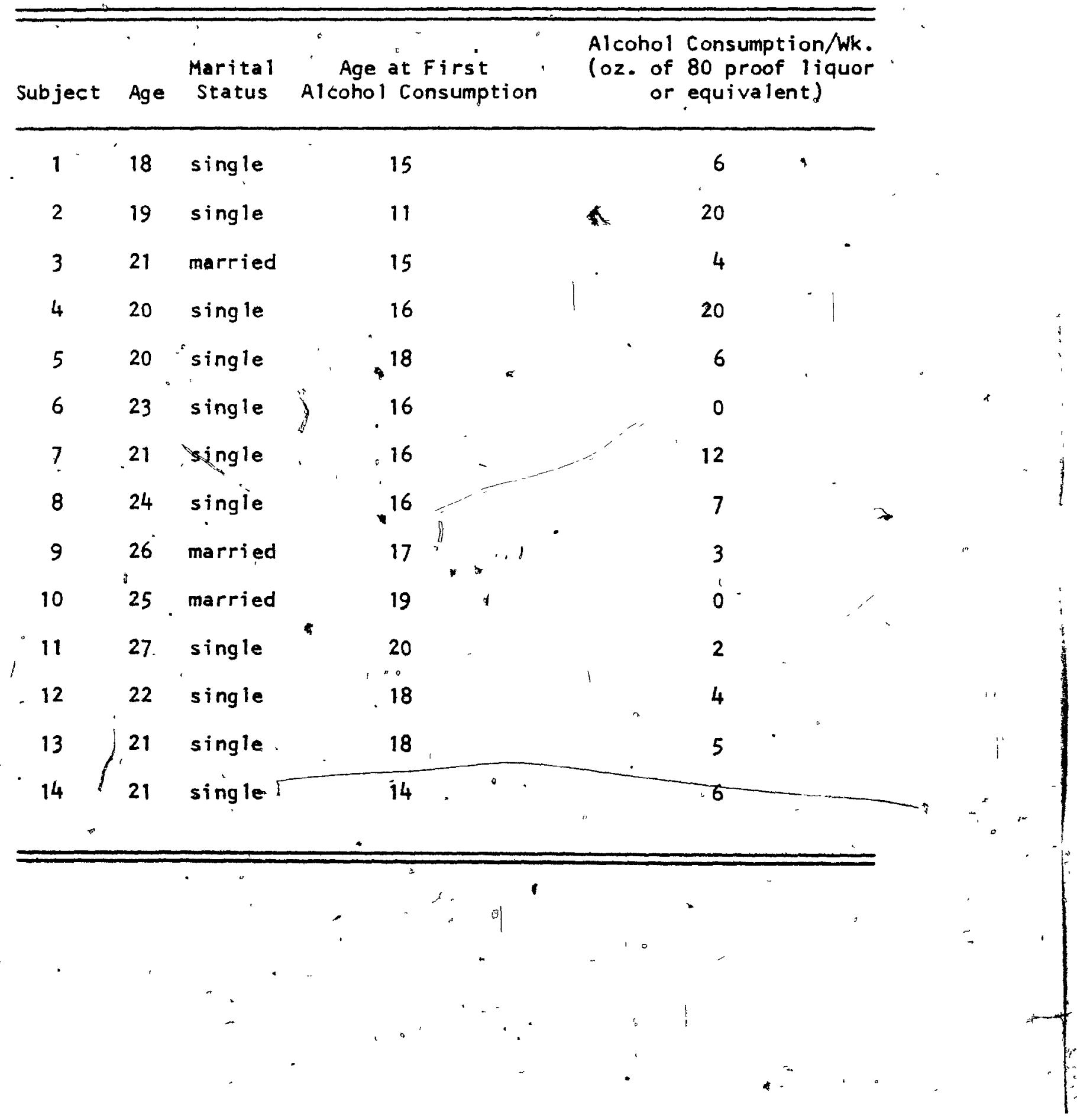




\section{ALCOHOL BEHAVIOR RESEARCH LABORATORY}

\section{$=\quad$ CONSENT FORM}

- I understand that I will be participating in a sesearch project. I have answered honestly and to the best of my knowledge all questions pertaining to my medical and drinking history. Data obtained from interviews, tests, and physiological measurements may be recorded and employed for research purposes. I understand that the information obtained will remain entirely confidential. No names or descriptions of individuals shall be made, in reporting results of research, in a manner that would permit a reader to identify anyone concerned.

I understand that I will be requested to drink an alcoholic beverage during the study and to give urine and breath samples at half-hour intervals during two day-long ( 8 am - $5 \mathrm{pm}$ ) experimental sessions. I will also be asked to indicate how I feel at various points during each session by completing a self-rating questionnaire.

I understand that my participation is entirely voluntary. I may terminate my participation at any time during the experiment although I realize, that I must remain in the laboratory until it has. been determined that I am no longer under the influence of alcohol.

For participating in the-experiment I will be paid at the rate of $\$ 2.00$ hour. If I withdraw from the study before its completion, I will be pofid at the same rate for the time I have participated in the study.

Al1 my questions about the study have been answered to my satisfaction.

Signature 
Appendix C

SELF -EVALUATION QUESTIONNAIRE

NAME

DATE

SESSION 1

SESSION 2

TIME

DIRECTIONS: A number of statements which people have used to describe themselves are given below. Read each statement and then circle the appropriate number to the right of the statement to indicate how you feel right now, that is, at this moment. There are no right or wrong answers. Do not spend too much time on any one statement but give the answer which seems to describe your present feelings best.

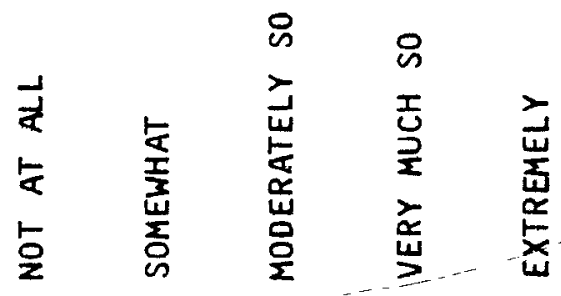

1. I feel dizzy

2. I feel sleepy

3. I feel shaky -

4. I have a headache -................ 1

5. I feel hungry ..... 1 , 2345

6: I feel warm ................... 1 2

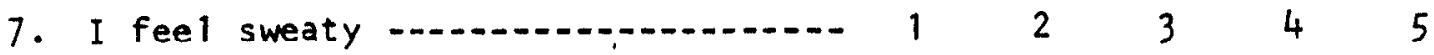

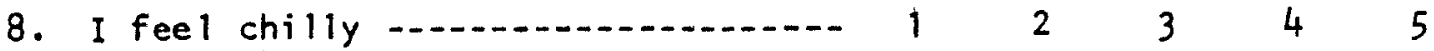

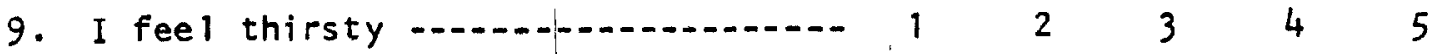

10. I feel restless ................... 1 2 3

11. I feel light-headed -.......... 1 2 344

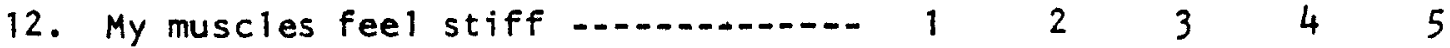

13. I feel uncoordinated -.......... 1 2 345

14. I feel flushed -...- 1242,3

15. I feel nauseous -.... 12425

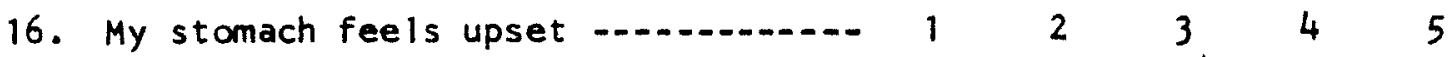

17. My mouth feels dry

18. I feel confused -............... 1245

19. I feel lethargic -

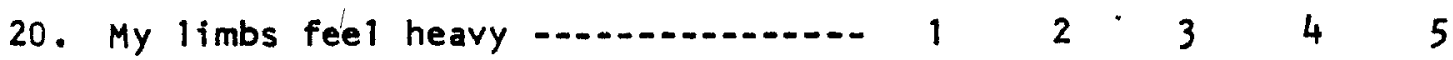


NAME

\section{Post-Experimental Questionnaire}

The following questions have been prepared to determine whether you clearly understood the purpose of the study and the instructions you were given and to get your reaction to the experiment. Please read each question carefully and answer by checking one or more of the alternatives listed.

1) I was instructed not to eat

$$
\begin{aligned}
& \text { ( ) high calorie foods } \\
& \text { ( ) antarches } \\
& \text { () dairy products }
\end{aligned}
$$

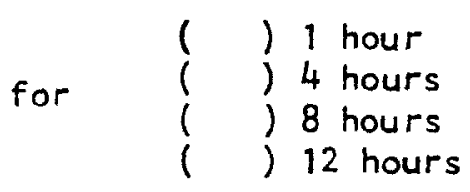

lprior to each session.

2) I was instructed not to drink

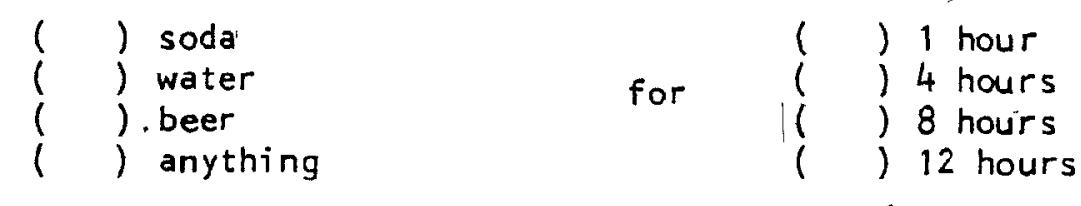

prior to each session.

3) I was instructed not to ingest

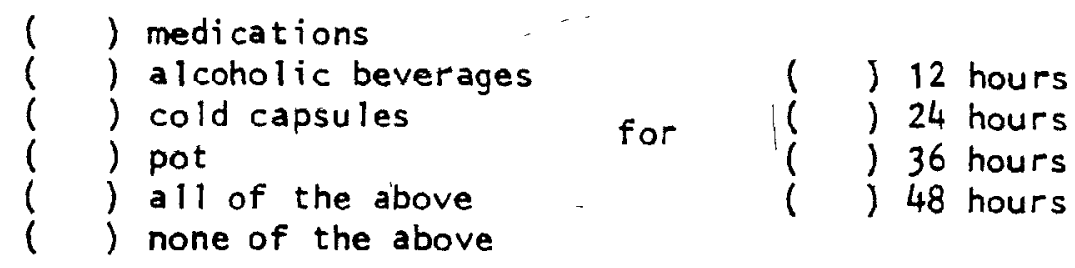

prior to each session.

4) At lunch I was instructed:

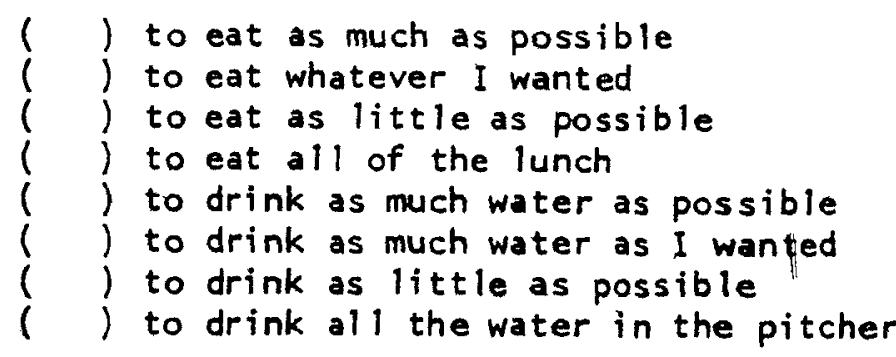


Post-Experimental Questionaaire, continued

5) Smoking is not permitted during any part of the experiment because:

( ) alcohol is highly flamable

) nohsmokers might object

) nicotine has a drug effect of its own

) it is prohibited in the laboratory by university fire regulations

( ) smoking while drinking increases the likelihood of a hangover

6) Drinking watet was available during the latter portion of the study because

) I might want something to drink

( ) I had to drink water to produce a measurable urine sample

( ) the room was so hot I needed it to cool off

- () drinking water was really what the study was all about

7) During most of the study I was asked to remain alone in a room because

( ) it made it easier to organize and conduct the experiment

( ) it provided controlled conditions for all subjects during the experiment

( ) social isolation is really what the study was all about

() subjects could be more easily observed in the bledrooms than in the dayroom

8) From my viewpoint as a subject, the worst part of the study was

) giving frequent urine samples

) having to drink so much alcohol.

) having to stay so long alone in a small room

) going without eating for so long

) not being able to smoke

)) other (please specify)

9) I volunteered for the study because

) a friend recormended the study

) I needed the money

) I like to drink

) I'm interested in laboratory research

) other (please specify) 


\section{Post-Experimental Questionnaire, continued}

10) Laboratory staff members were generally

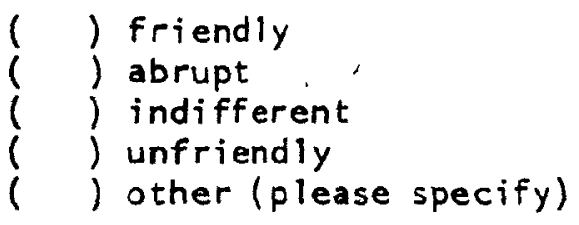

11) The information I was given about the study over the telephome and on first arriving at the lab-

$$
\begin{aligned}
& \text { ( ) gave me no idea } \\
& \text { ( ) gave me a rough, idea } \\
& \text { gave me a good idea }
\end{aligned}
$$

of what it would be like to participate in this study.

12) Additional, comments about the study: on reverse side 


\section{Appendix $E$ \\ Table 1}

ANOVA of Post-ingestion Urine Output: Study 1

Source

Between Subjects

$\begin{array}{llll}\text { Order }(0) & 1 & 5.186 & 0.099\end{array}$

$\begin{array}{lll}\text { Subjects } w . \text { groups } & 11 & 52.209\end{array}$

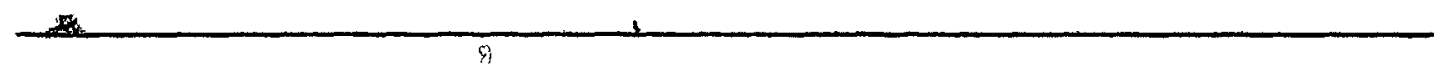

Within Subjects

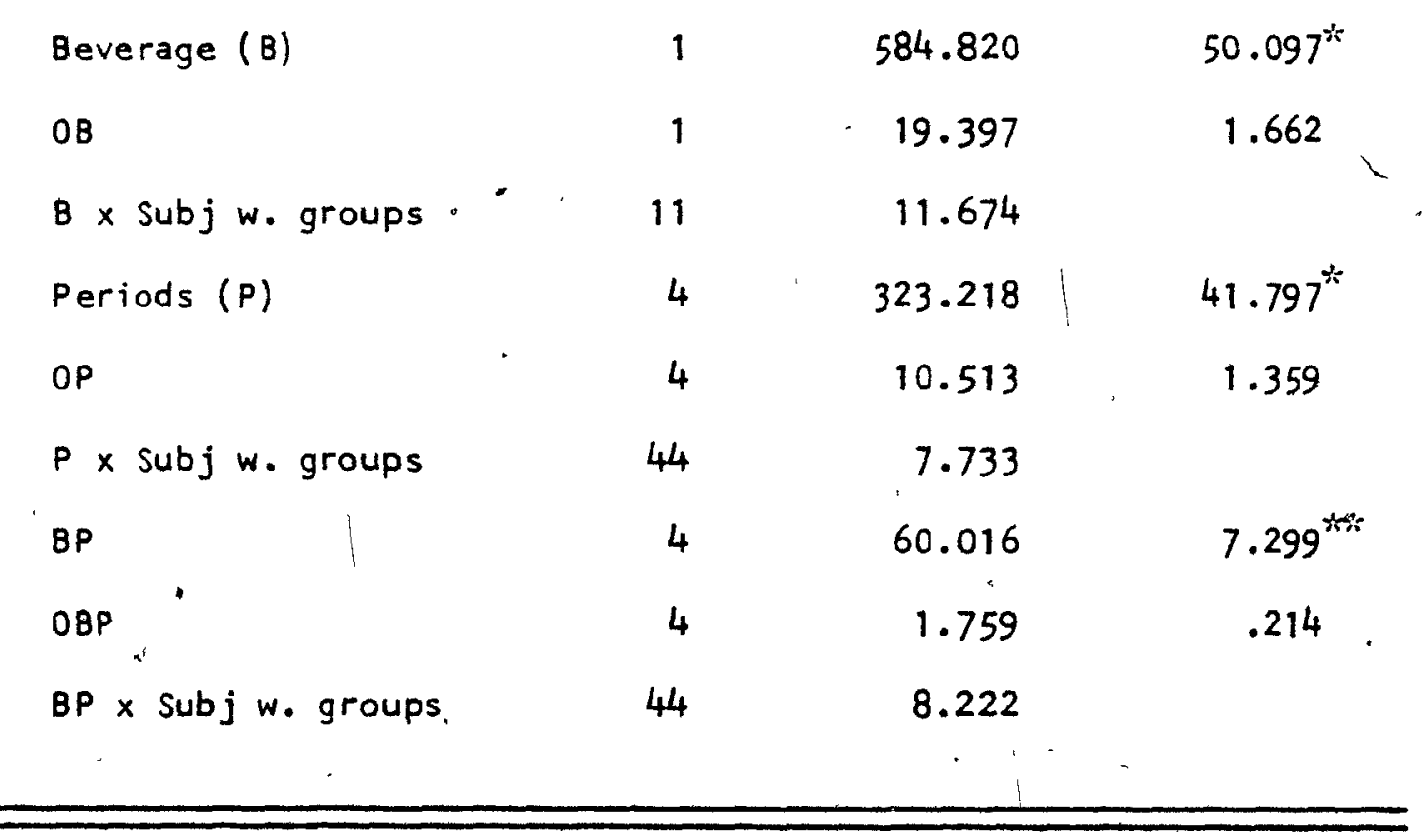

$x_{p}<.0001$

$p<0003$ 


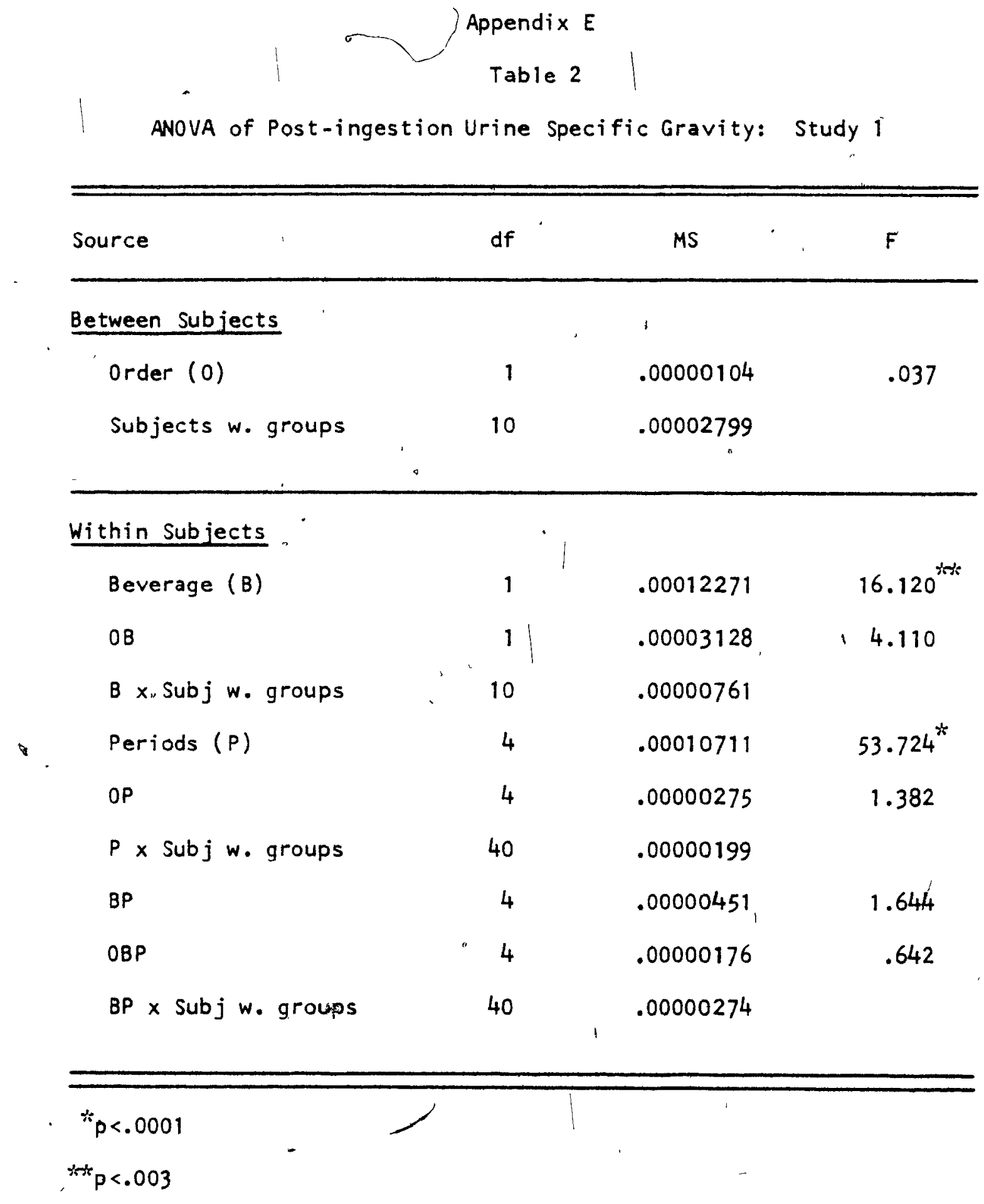





$$
\begin{gathered}
\text { Appendix } E \\
\text { Table } 5
\end{gathered}
$$

ANOVA of Fluid Intake (last $4 \mathrm{hr}$.$) : "Study 1$

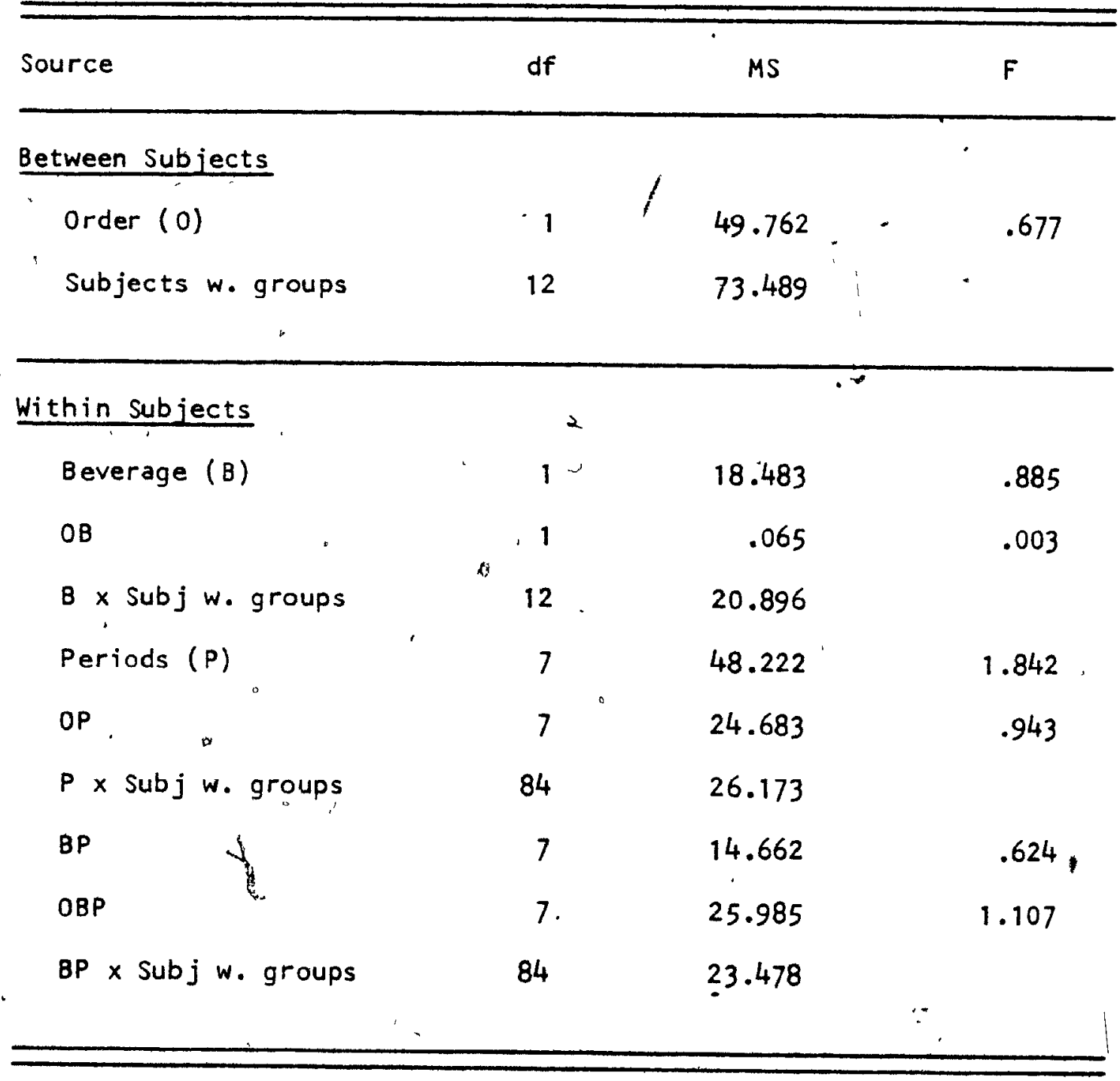




\section{Appendix E}

Table 6

Inter-Correlations $\left(r_{\mathrm{pbi}}\right)$ among Self-Ratings and Cumulative Fluid Intake in Study 1

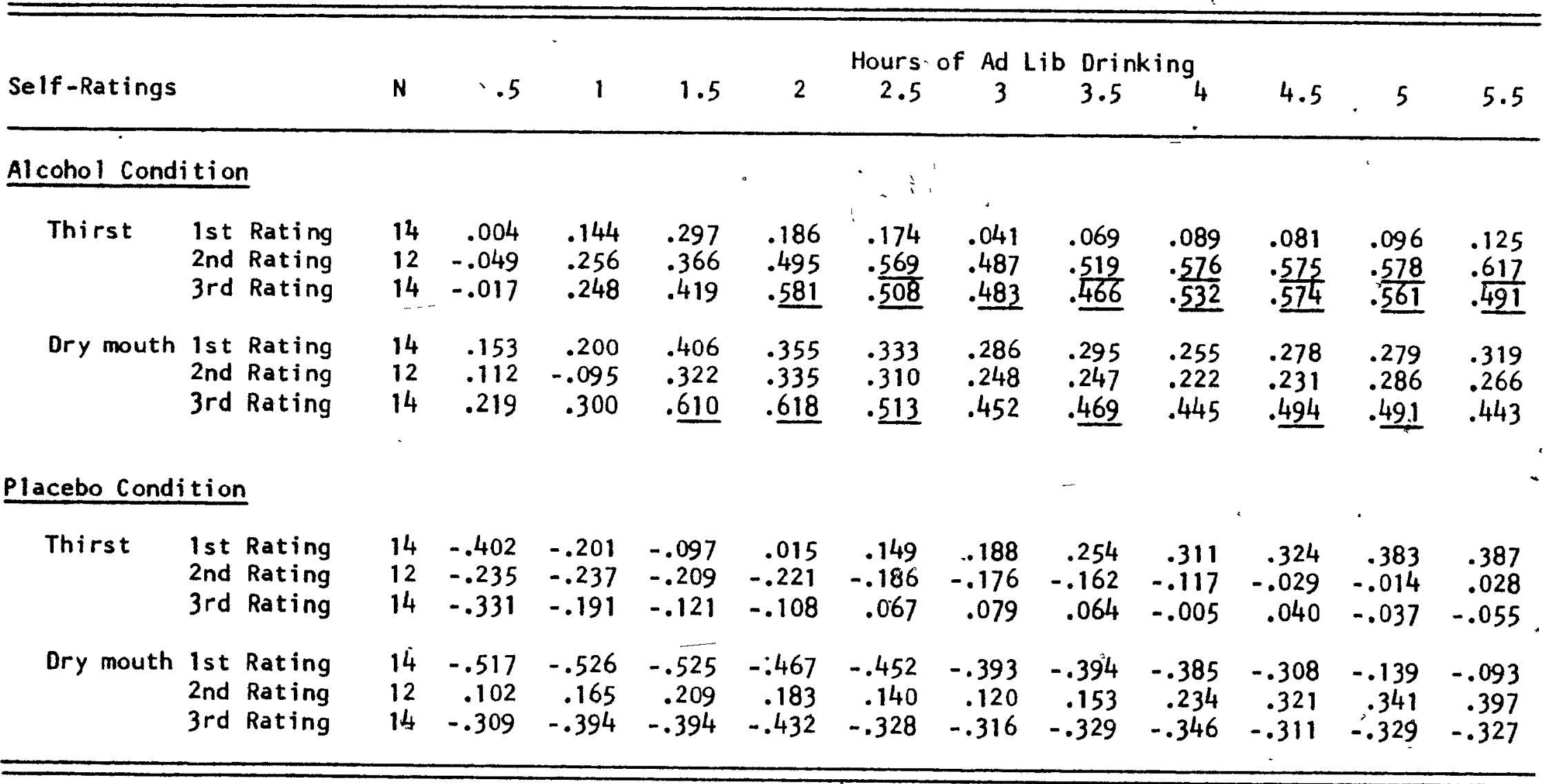

Underlined: $p<.05$ (one-tailed test) 


\section{Appendix E}

Table 7

Inter-Correlations ( $r$ ) Among Cumulative Fluid Intake and Physiological Effects

of Prior Beverage Administration in Study 1 .

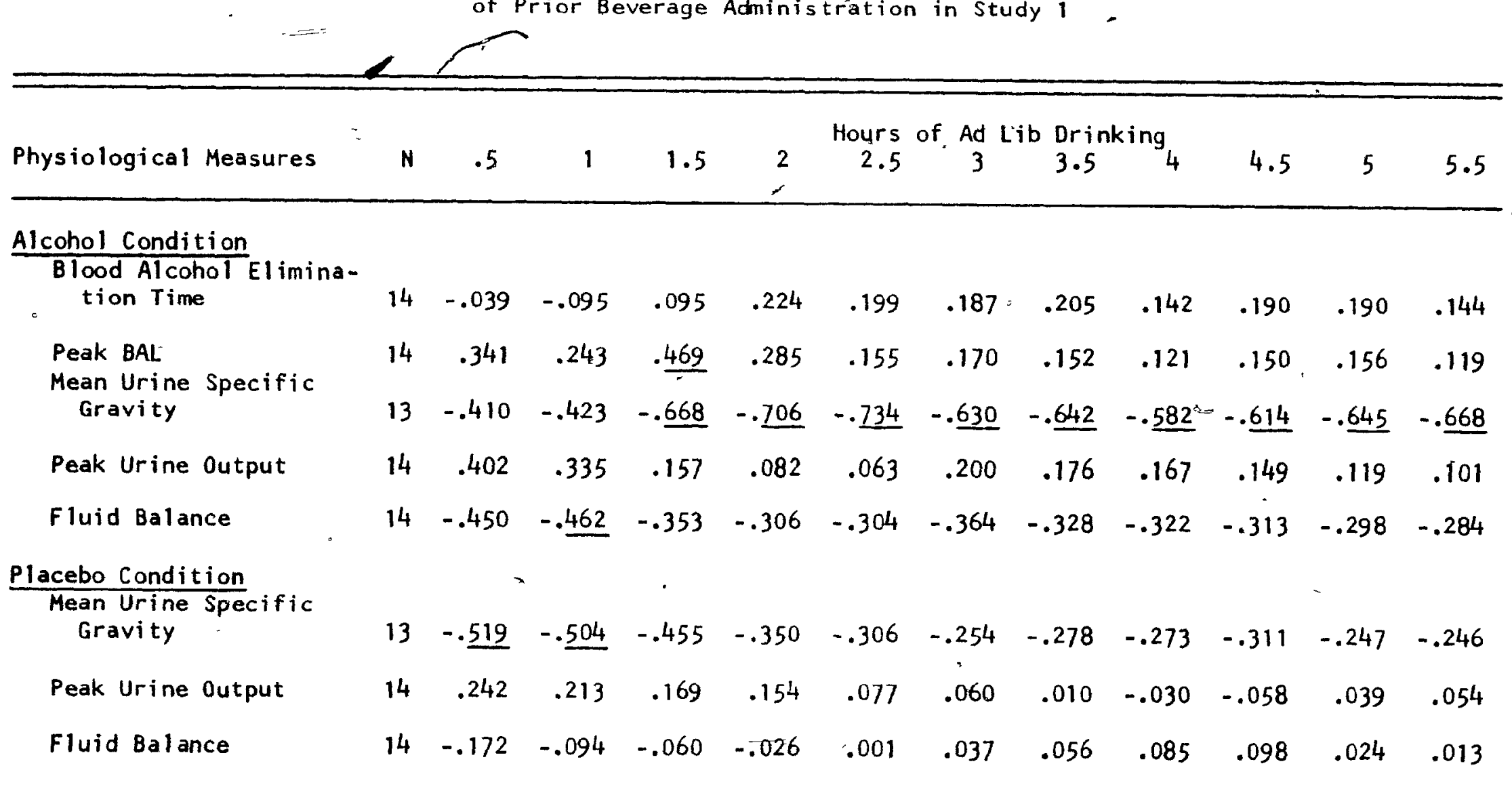

Underlined: $p<.05$ (one-tailed test) 


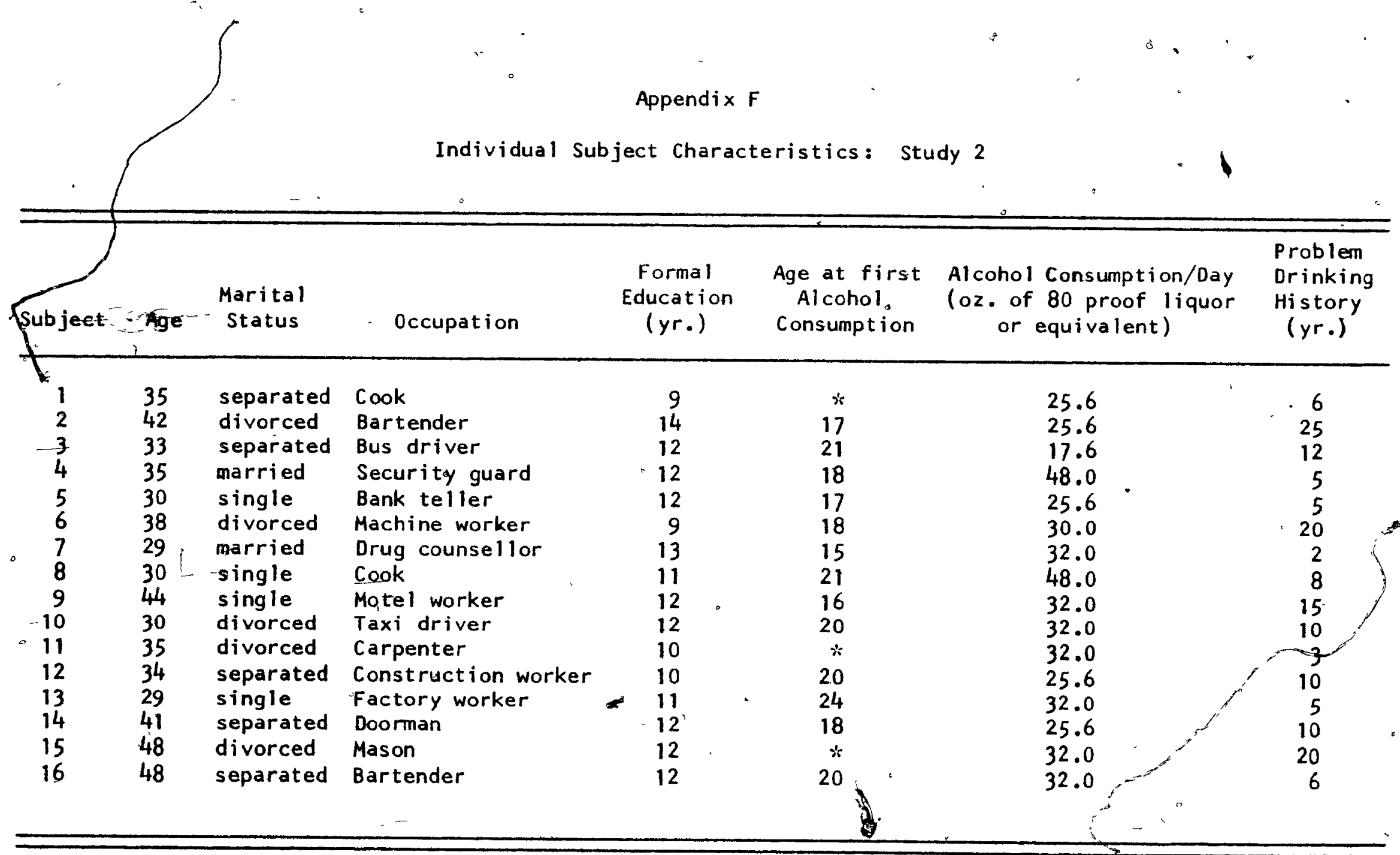

${ }^{*}$ Subjects misunderstood this questionnaire $i$ tem and answered inappropriately. 


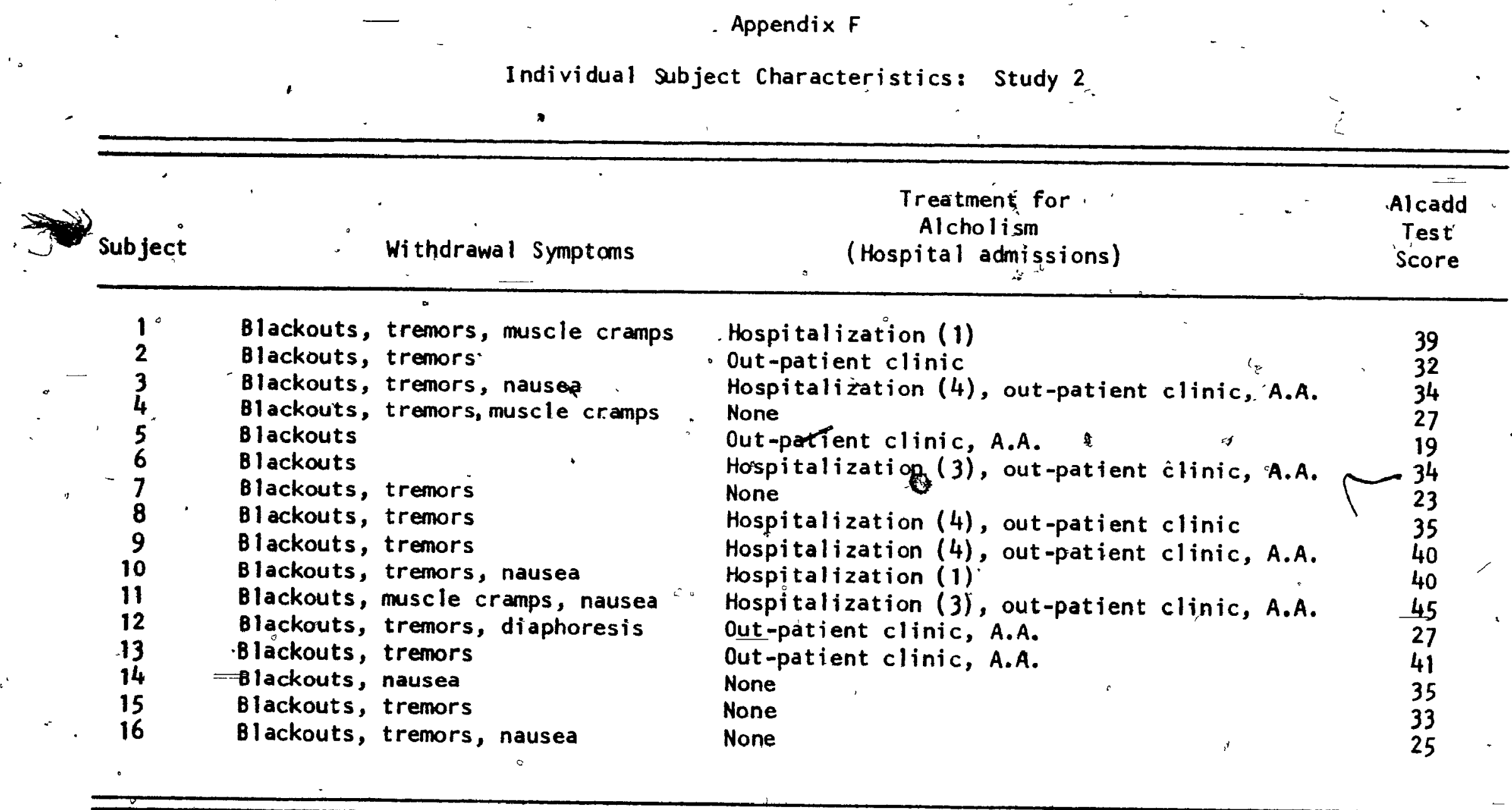


Appendix G

Craving Scale

Most people feel from time to time like having an' alcoholic beverage to drink - be' it beer, wine, whiskey or any other preferred beverage. It is also true that people sometimes feel more in the mood for a drink than at other times.

Please put a mark anywhere across's the line below to indicate how much you feel like a drink right now.

Not at al 1
Extreme craving for a drink 
Appendix $\mathrm{H}$

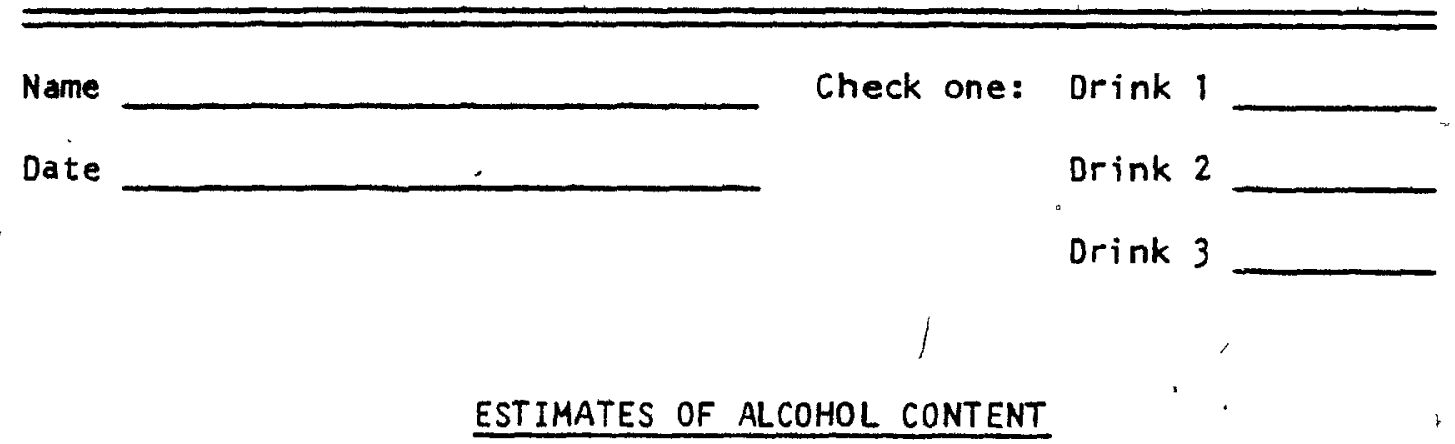

Please circle a number below to indicate your estimate of the amount

of 80 proof whiskey in the drink you have just finished:

OUNCES OF 80 PROOF WHI SKEY

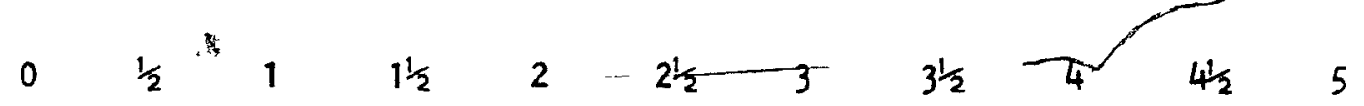

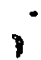




\section{Appendix I}

Table 1.

ANOVA of Post-ingestion Urine Output: Study 2

\begin{tabular}{llll}
\hline Source & df & MS & F \\
\hline
\end{tabular}

Between Subjects

Order (0)

Subjects, w. groups

178.165

1.871

Within Subjects

Beverage ( $B$ )

$O B$

B $\times$ Subjw. groups

Periods ( $P$ )

$Q P$

$P \times$ Subj $w$. groups

$B P$

OBP

$B P \times$ Subjw. groups
41.780<smiles>CCCC</smiles>

14
1.871

$35.739 \%$

.292

$14 \quad 9.529$

4

506.453

$30.555^{*}$

4

7.980

.481

56

16.575

4

43.934

$5.301^{* k}$

4

4.584

.553

\subsection{8}




\section{Appendix I}

Table 2

ANOVA of Post-ingestion Urine Specific Gravity: Study 2

\begin{tabular}{l}
\hline Source \\
\end{tabular}

- Between Subjects

$\begin{array}{lrrr}\operatorname{Order}^{-}(0) & 1 & .00000192 & .122 \\ \text { Subjects w. groups } & 13 & .00001568 & \end{array}$

Within Subjects

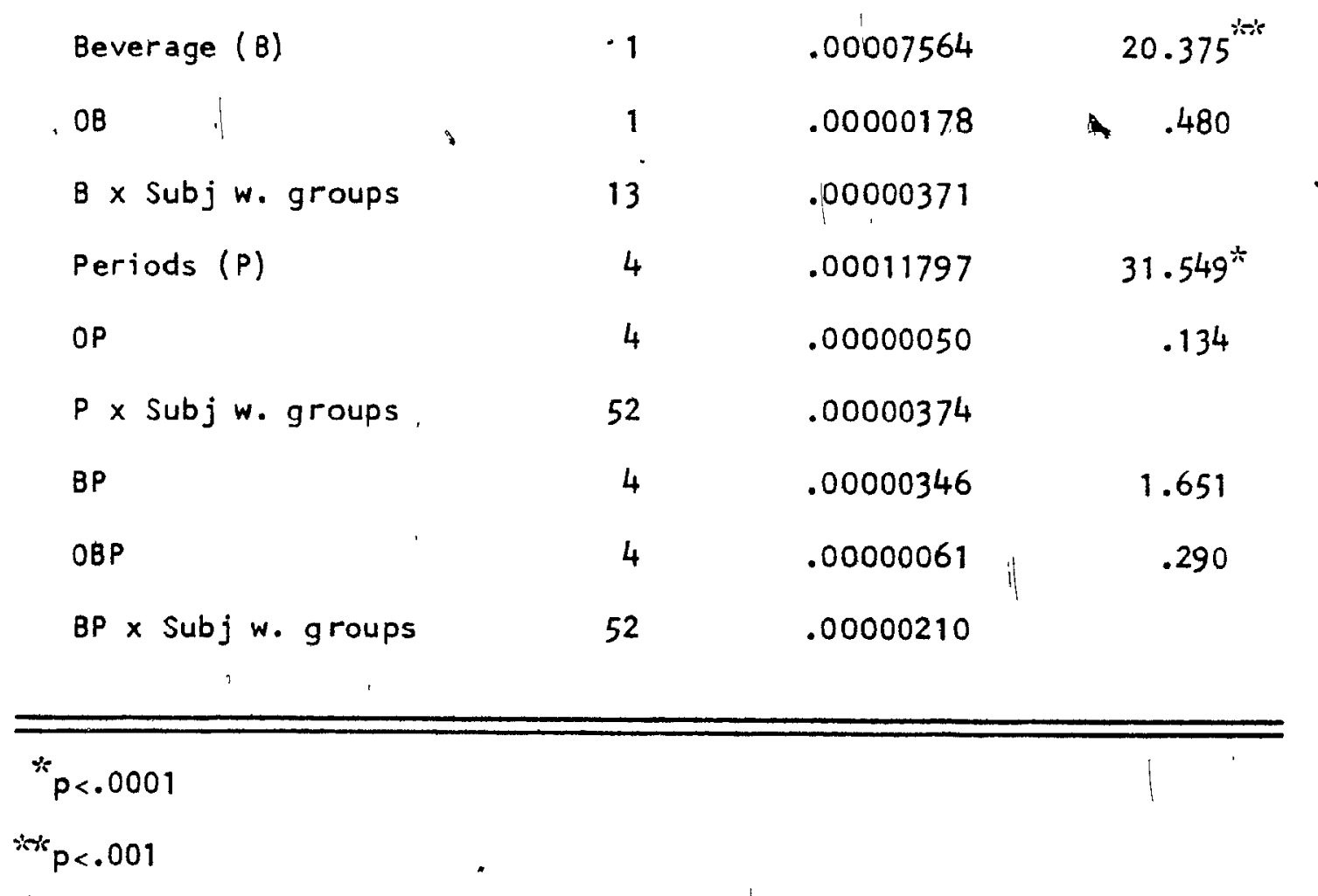


Appendix I

Table 3

ANOVA of Fluid Intake: Study 2

\begin{tabular}{lccc}
\hline Source & df & MS & $F$ \\
\hline Between Subjects & & & \\
\hline Order $(0)$ & 1 & 645.627 & 1.909 \\
Subjects iw. groups & 14 & 338.272 & \\
\hline
\end{tabular}

Within Subjects

$\begin{array}{lrrr}\text { Beverage (B) } & 1 & 158.176 & 7.614^{*} \\ \text { OB } & 1 & .037 & .002 \\ B \times \text { Subj } w \text {. groups } & 14 & 20.773 & \\ \text { Periods (P) } & 10 & 329.897 & 15.407^{\%} \\ \text { OP } & 10 & 17.797 & .831 \\ P \times \text { Subj } w . \text { groups } & 140 & 21.413 & 1.476 \\ B P & 10 & 37.741 & 1.615 \\ \text { OBP } & 10 & 41.311 & \\ \text { BP } \times \text { Subj w. groups } & 140 & 25.575 & \end{array}$

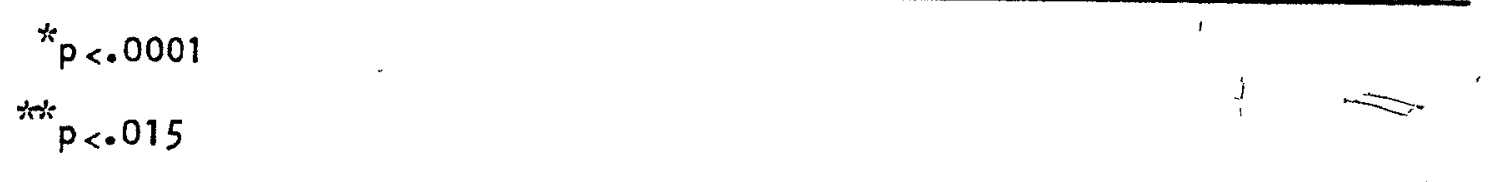




$$
\begin{gathered}
\text { Appendix I } \\
\text { Table } 4 \\
\text { Intercorrelations Among Self-Ratings: Study } 2
\end{gathered}
$$

Self-Ratings $\quad$ Dry Mouth $(\phi), \quad$ Cravimg $\left(r_{p b i}\right)$

\section{Alcohol Condition}

Thirst: 1st Rating 2nd Rating

3rd Rating

Dry Mouth: 1st Rating.

2nd Rating

3rd Rating
.378

$.733 \%$

$.545^{\circ}$
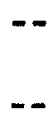

$--$
.035

.207

.009

.038

.278

.383

\section{Placebo Condition}

Thirst: 1st Rating

$.775^{*}$

.032

2nd Rating

$.832^{*}$

$-.181$

3rd Rating

.429

.090

Ory Mouth: 1st Rating

2nd Rating

$-.099$

3rd Rating

-.099
--
-
-309

" $p<.01$

$x * x<.05$ 


\section{Appendix I}

Table 5

Inter-Correlations Among Self-Ratings and Cumulative Fluid Intake in Study 2

\begin{tabular}{|c|c|c|c|c|c|c|c|c|c|c|}
\hline Self-Ratings & $\mathbf{N}$ & .5 & 1 & 1.5 & 2 & $\begin{array}{l}\text { Hours of Ad } \\
2.5\end{array}$ & $\begin{array}{l}\text { Lib Drinking } \\
3.5\end{array}$ & 4.5 & 5 & 5.5 \\
\hline
\end{tabular}

$<$

\section{Alcohol Condition}

\begin{tabular}{|c|c|c|c|c|c|c|c|c|c|c|c|c|c|c|}
\hline \multirow{3}{*}{$\begin{array}{l}\text { Thirst } \\
\left(r_{\text {pbi }}\right)\end{array}$} & $1 s t$ & Rating & 16 & .107 & -.063 & .145 & .223 & .185 & .195 & .194 & .166 & .214 & .232 & .231 \\
\hline & 2nd & Rating & 16 & .073 & .166 & .043 & .102 & .139 & .050 & .116 & .1 .16 &. .117 & .148 & .130 \\
\hline & $3 r d$ & Rating & 16 & .040 & .189 & .004 & $.000^{\circ}$ & .046 & -.066 & -.040 & -.034 & -.041 & $=-034$ & -.069 \\
\hline \multirow{3}{*}{$\begin{array}{l}\text { Dry Mouth } \\
\left(r_{\mathrm{pbi}}\right)\end{array}$} & $1 \mathrm{st}$ & Rating & 16 & .470 & .478 & .511 & .553 & .542 & .428 & .456 & .439 & .452 & .471 & .458 \\
\hline & 2nd & Rating & 16 & -.014 & .084 & -.001 & .066 & .109 & .036 & .100 & .111 & .122 & .155 & .138 \\
\hline & $3 r d$ & Rating & 16 & -.092 & -.033 & -.084 & -.053 & -.072 & -.059 & -.069 & -.081 & -.072 & -.072 & -.103 \\
\hline \multirow{3}{*}{$\begin{array}{l}\text { Craving } \\
(r)\end{array}$} & $1 \mathrm{st}$ & Rating & 16 & -.191 & .062 & .024 & -.040 & .000 & .086 & .089 & .101 & .065 & .056 & .063 \\
\hline & 2nd & Rating & 16 & $.460^{x}$ & .376 & .329 & .331 & .418 & .403 & .400 & .401 & .381 & .386 & .379 \\
\hline & 3 rd & Rating & 16 & .207 & .127 & .048 & .040 & .118 & .189 & .178 & .190 & .159 & .162 & .158 \\
\hline
\end{tabular}

Underlined: $\mathrm{p}<.05$ (one-tailed test)

${ }^{*} p=.07$ (two-tailed test) 


\section{Appendix I}

Table

Inter-Correlations Among Self-Ratings and Cumulative Fluid Intake in Study 2

\begin{tabular}{|c|c|c|c|c|c|c|c|c|c|c|}
\hline Self-Ratings & $\mathbf{N}$ & .5 & 1 & 1.5 & 2 & $\begin{array}{ccc}\text { Hours of } & \mathrm{Ad} \\
2.5 & 3\end{array}$ & $\begin{array}{c}\text { Lib Orinking } \\
3.5\end{array}$ & 4.5 & 5 & 5.5 \\
\hline
\end{tabular}

\section{Placebó Condition}

\begin{tabular}{|c|c|c|c|c|c|c|c|c|c|c|c|c|c|c|}
\hline \multirow[t]{2}{*}{$\begin{array}{l}\text { Thirst } \\
\left(r_{\mathrm{pbi}}\right)\end{array}$} & $\begin{array}{l}1 \mathrm{st} \\
\text { 2nd }\end{array}$ & $\begin{array}{l}\text { Rating } \\
\text { Rating }\end{array}$ & 16 & $\begin{array}{l}.011 \\
.365\end{array}$ & $\begin{array}{l}.165 \\
.303\end{array}$ & $\begin{array}{l}.152 \\
.248\end{array}$ & $\begin{array}{l}.246 \\
.241\end{array}$ & $\begin{array}{l}.315 \\
.303\end{array}$ & $\begin{array}{l}.274 \\
.240\end{array}$ & $\begin{array}{l}.309 \\
.235^{\circ}\end{array}$ & $\begin{array}{r}.342 \\
.248\end{array}$ & $\begin{array}{l}.331 \\
.237\end{array}$ & .306 & $\begin{array}{l}.308 \\
.244\end{array}$ \\
\hline & $3 r d$ & Rating & 16 & .072 & -.029 & -.078 & -.142 & -.145 & -.182 & -.134 & -.129 & -.138 & -.165 & -.172 \\
\hline \multirow{3}{*}{$\begin{array}{l}\text { Dry Mouth } \\
\left(r_{p b i}\right)\end{array}$} & $1 \mathrm{st}$ & Rating & 16 & .215 & .379 & .374 & .448 & .477 & .457 &.$\underline{486}$ & .525 & .517 & .492 & .492 \\
\hline & 2nd & Rating & 16 & .500 & .463 & .414 & .372 & .383 & .301 & .324 & .318 & .308 & .302 & .308 \\
\hline & $3 r d$ & Rating & 16 & .087 & .113 & .051 & .002 & -.081 & -.100 & -.109 & -106 & -.119 & -.141 & -.146 \\
\hline \multirow{3}{*}{$\begin{array}{l}\text { Craving } \\
(r)\end{array}$} & Ist & Rating & 16 & .091 & .276 & .242 & .221 & .150 & .118 & .191 & .173 & .175 & .142 & .132 \\
\hline & 2nd & Rating & 16 & -.055 & .102 & .088 & .096 & .034 & .014 & .100 & .106 & .110 & .060 & .045 \\
\hline & $3 r d$ & Rating & 16 & -.103 & .003 & .001 & -.019 & -.081 & -.093 & .020 & .034 & .040 & -.016 & -.036 \\
\hline
\end{tabular}

Underlined: $p<.05$ (one-tailed test) 


\section{Appendix I}

Table 6

Inter-Correlations, $(r)$ Among CumuTative Fluid Intake and Physiological Effects

of Prior Beverage Administration in Study 2

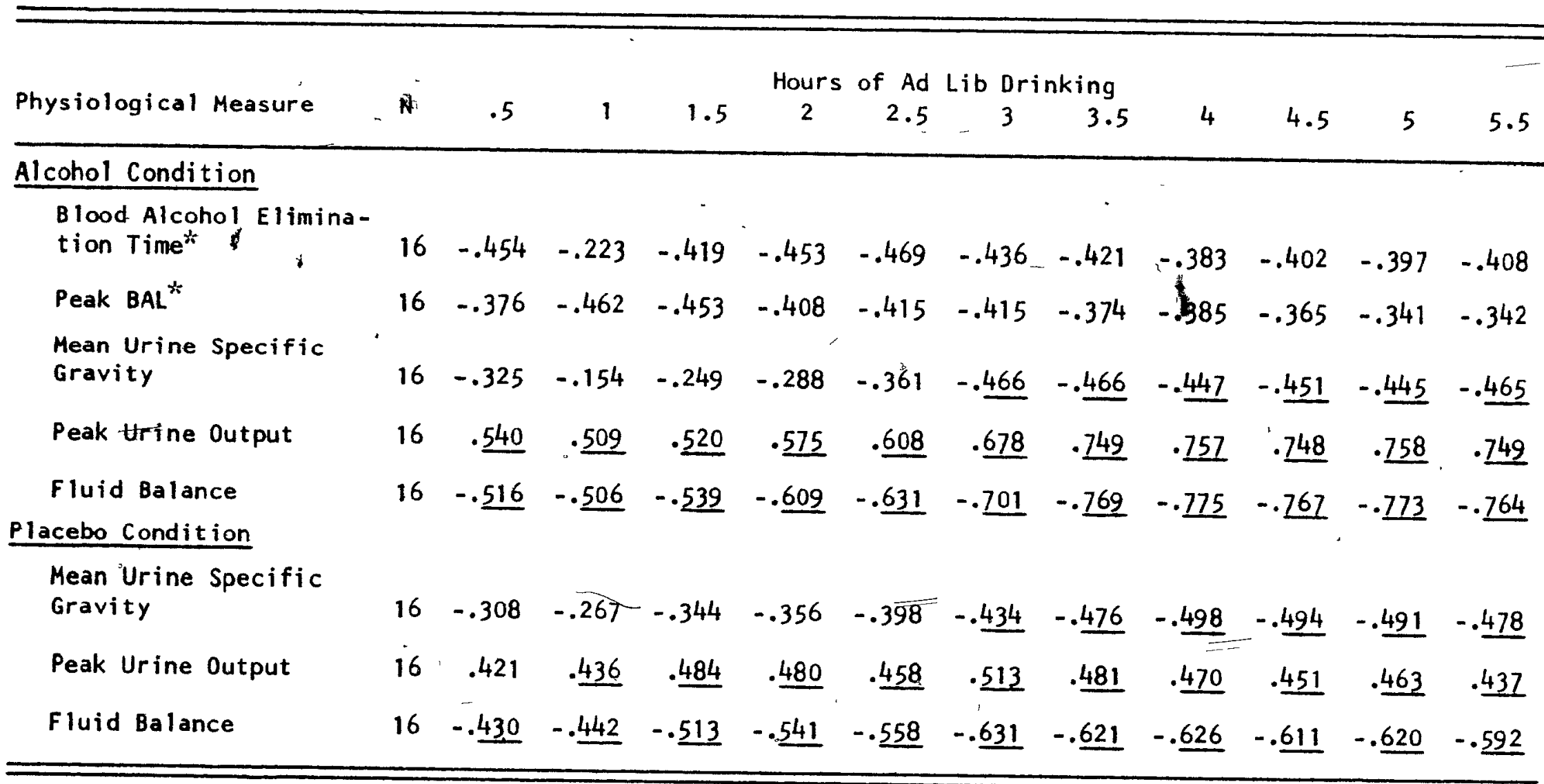

Underlined: $p<.05$ (one-tailed test)

'Two-tailed tests of significance applied to correlations with these measures. 


\section{Appendix J}

Table 1

ANOVA of Fluid Intake after Alcohol:

Study 1 vs Study 2

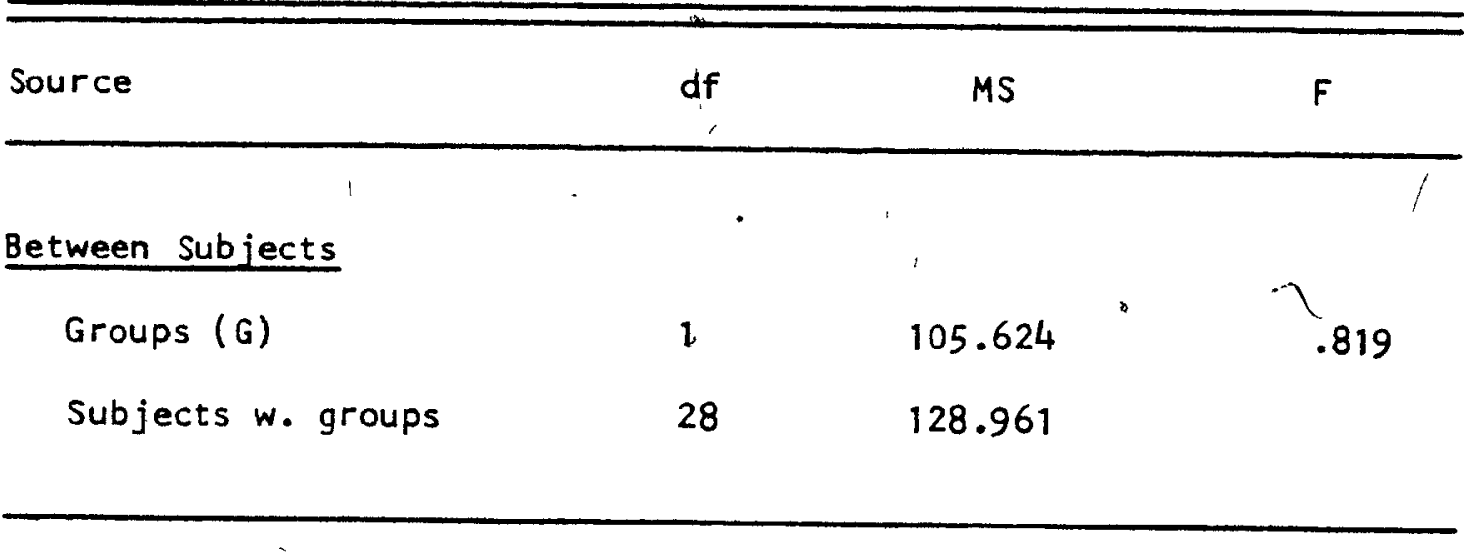

Within Subjects

Periods $\left(P_{0}\right)$

$G \times P$

$P \times$ Subj $w \cdot$ groups
10

10

280
508.446

$17.583^{*}$

89.478

$3.094^{x+k}$

$$
\begin{aligned}
& { }^{*} p<0001 \\
& * * x<.0015
\end{aligned}
$$


Appendix J

Tabie 2

ANOVA of Fluid Intake after Placebo:

Study 1 vs Study 2

Source

Between subjects

$\begin{array}{lccc}\text { Groups }(G) & 1 & 20.410 & .154 \\ \text { Subjects } w . \text { groups } & 28 & 1.32 .718\end{array}$

Within subjects

$\begin{array}{cccc}\text { Periads }(P) & 10 & 436.528 & 19.517^{*} \\ G \times P & 10 & 21.533 & .963\end{array}$

$P \times$ Subj $w$. groups $\quad 280$

22.367

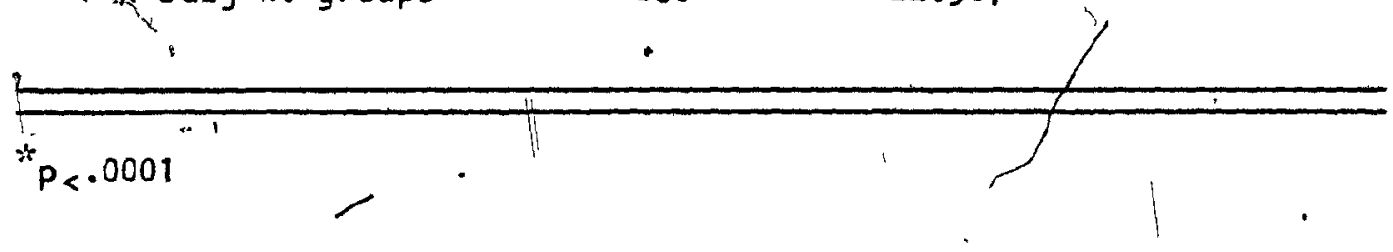

( ) 


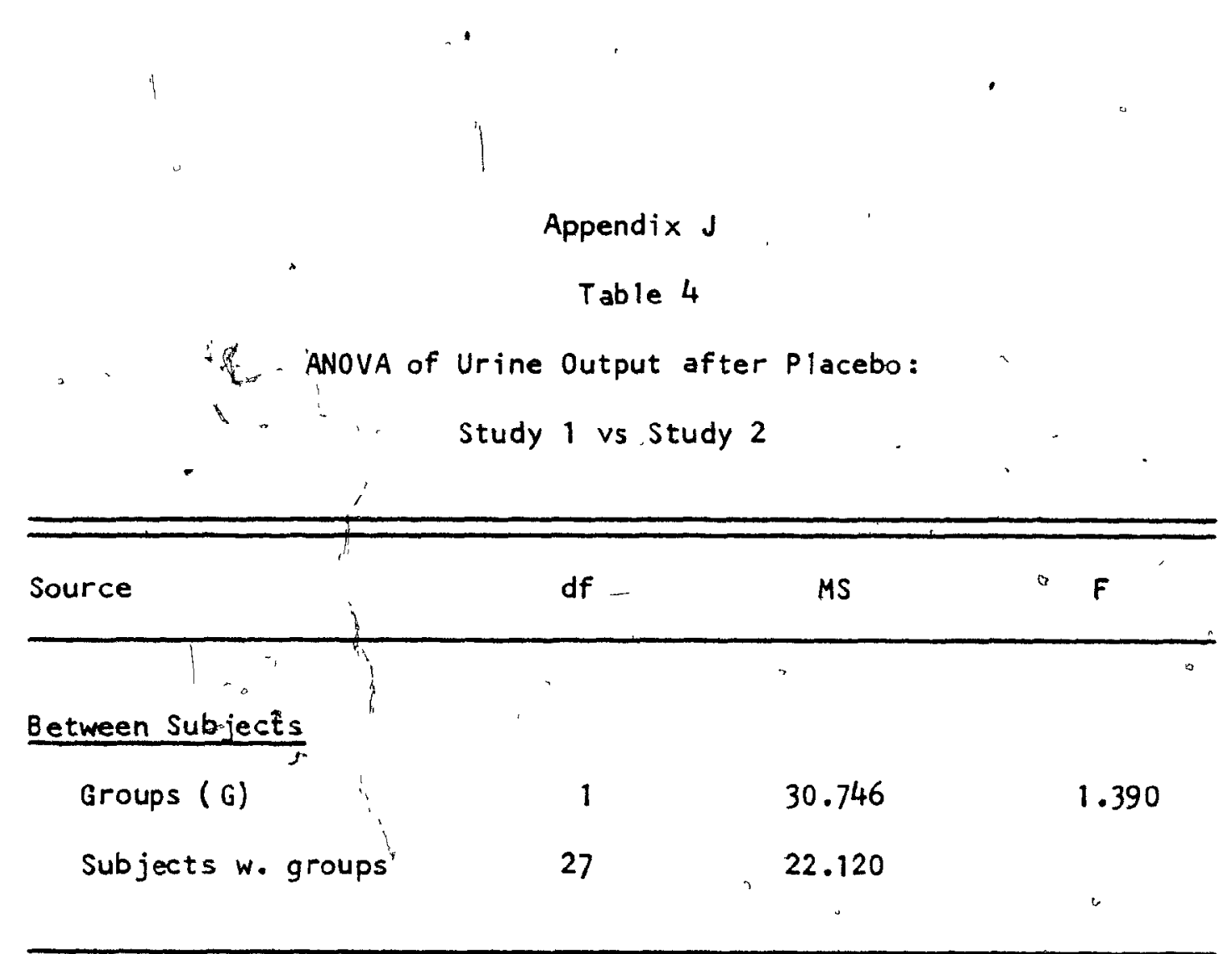

Within Subjects

$\begin{array}{lrrr}\text { Periods }(P)^{\circ} & 4 & 183.067 & 31.211^{*} \\ G \times P & 4 & 6.980 & 1.190 \\ P \times \text { Subj w. groups } & 108 & 5.865 & \end{array}$

${ }^{*} \mathrm{p}<.0001$ 


\section{Appendix J \\ , 1 \\ Table 5}

ANOVA of Urine Specific Gravity after Alcohol:

$1^{\circ}$

Study $1^{\circ}$ vs Study 2

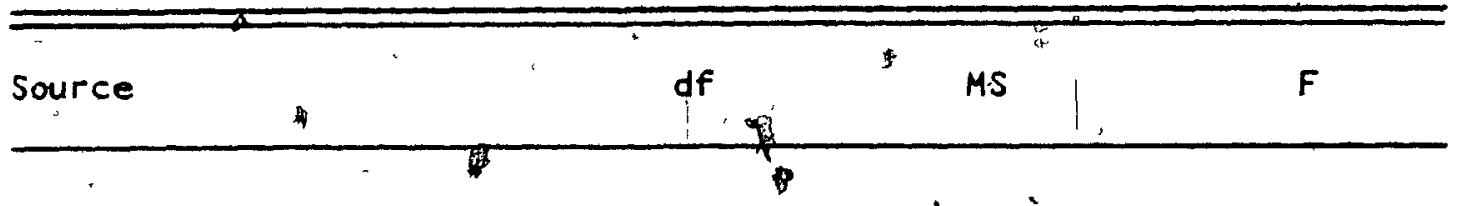

Between Subjects

Groups (G)

Sub jects ${ }^{\prime}$. groups.

1.00000006

.007

$25 \quad .00000884$

Within Subjects

$\begin{array}{lrrr}\text { Periods (P) } & 4 & .00014270 & 56.51]^{*} \\ G \times P & 4 & .00000191 & .756 \\ P x_{r,} \text { Subj w. groups } & 100 & .00000253 & \end{array}$
(

$\pi$

* $\mathrm{P}<0001$ 
Appendix J'

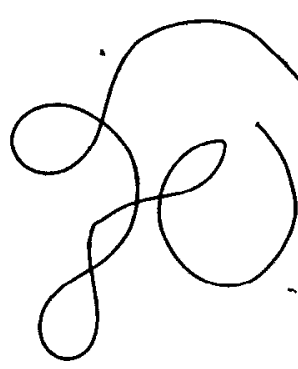

Table 7

ANOVA of Fluid Balanke:

Study 1 vs Study 2

\begin{tabular}{llll}
\hline Source & df & MS & $F$ \\
\hline
\end{tabular}

Between Subjects

Groups (G)

1

6648.172

.075

Subjects w. groups

28

89181.157

Within Subjects

\begin{tabular}{lrrr} 
Beverage (B) & 1 & \multicolumn{1}{|c}{2983747.700} & $74.576^{*}$ \\
$G \times B$ & 1 & 2500.000 & .062 \\
$B \times$ Subj w. groups & 28 & 40009.614 \\
\hline$P<.0001$
\end{tabular}

,

1

0 


\section{Appendix J \\ Table 8}

ANOVA of BAL: Study 1 vs Study 2

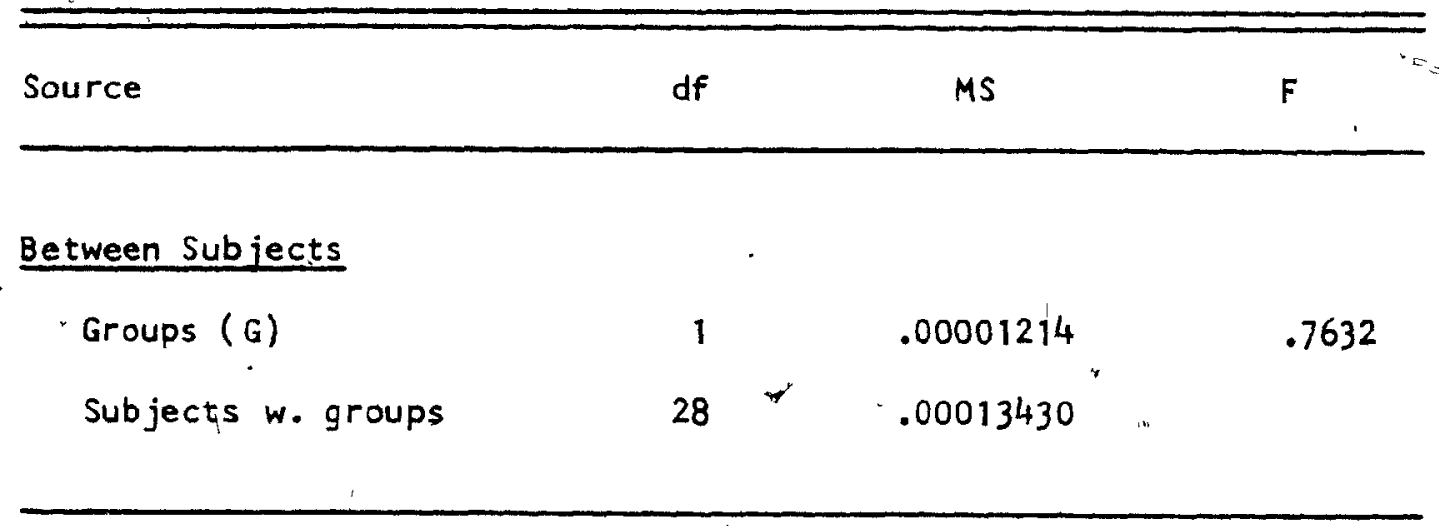

Within Subjects

$\begin{array}{lrrr}\text { Periods }(P) & 10 & .00478374 & 851.413^{*} \\ G \times P & 10 & .00002929 & 5.213^{*} \\ P \times \text { Subjw. groups } & 280 & .00000562 & \end{array}$

${ }^{*} p<0001$.

0 